BNL 50784

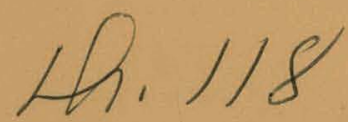

58 BROOKHAVEN NATIONAL LABORATORY DEVELOPING COUNTRIES ENERGY PROGRAM $6,-1-78$

\title{
ENERGY NEEDS, USES AND RESOURCES IN DEVELOPING COUNTRIES
}

MARCH 1978

\section{POLICY ANALYSIS DIVISION}

NATIONAL CENTER FOR ANALYSIS OF ENERGY SYSTEMS BROOKHAVEN NATIONAL LABORATORY

With contributions from

Cornell University

Donovan, Hamester and Rattien, Inc.

Gordian Associates

Institute for Energy Research, State University of New York at Stony Brook Meta Systems Inc.

Overseas Development Council University of California at Berkeley Thomas Vietorisz

prepared for

UNITED STATES AGENCY FOR INTERNATIONAL DEVELOPMENT

Under PASA No. ERDA/TAB-995-18-76 with the

U.S. Department of Energy 


\section{DISCLAIMER}

This report was prepared as an account of work sponsored by an agency of the United States Government. Neither the United States Government nor any agency Thereof, nor any of their employees, makes any warranty, express or implied, or assumes any legal liability or responsibility for the accuracy, completeness, or usefulness of any information, apparatus, product, or process disclosed, or represents that its use would not infringe privately owned rights. Reference herein to any specific commercial product, process, or service by trade name, trademark, manufacturer, or otherwise does not necessarily constitute or imply its endorsement, recommendation, or favoring by the United States Government or any agency thereof. The views and opinions of authors expressed herein do not necessarily state or reflect those of the United States Government or any agency thereof. 


\section{DISCLAIMER}

Portions of this document may be illegible in electronic image products. Images are produced from the best available original document. 
BNL 50784

UC-13

General, Misc., \& Progress Report

(Nonnuclear) TID-4500

\title{
ENERGY NEEDS, USES AND RESOURCES IN DEVELOPING COUNTRIES
}

\author{
Philip F. Palmedo, Robert Nathans, \\ Edward Beardsworth and Samuel Hale, Jr.* \\ with major contributions from \\ Jack Allentuck, Brookhaven National Laboratory \\ Russell J. delucia, Meta Systems, Inc. \\ Lawrence Ervin, Donovan, Hamester and Rattien, Inc. \\ William Knowland, Overseas Development Council \\ Vinod Mubayi, Brookhaven National Laboratory \\ Thomas Vietorisz, New School for Social Research
}

*Gordian Associates

MARCH 1978

This report was prepared as an account of work sponsored by the United States Government. Neither the United States nor the United States Department of Energy, nos any of their employees, nor any of their contractors, subcontractors, or the ir employees, makes any warranty, express of implied, of assulnes any legal liability or responsibility for the accuracy, completeness or usefulness of any information, apparatus, product of process disclosed, or represents that its use would not infringe privately owned rights.

\author{
POLICY ANALYSIS DIVISION \\ NATIONAL CENTER FOR ANALYSIS OF ENERGY SYSTEMS \\ BROOKHAVEN NATIONAL LABORATORY \\ ASSOCIATED UNIVERSITIES, INC. \\ UPTON, NEW YORK 11973 \\ prepared for \\ UNITED STATES AGENCY FOR INTERNATIONAL DEVELOPMENT \\ Under PASA No. ERDA/TAB-995-18-76 with the \\ U.S. Department of Energy
}


NOTIRF

This report was prepared as an account of work sponsored by the United States Government. Neither the United States nor the Agency for International Developmeni nur ilue Departuent uf Euergy, inir any of their employecs, nor any of their contractors, subcontractors, or their employees, makes any warranty, express or implied, or assumes any legal liability or responsibility for the accuracy, completeness or. usefulness of any information, apparatus, product or process disclosed, or represents that its use would not infringe privately owned rights.

Printed in the United States of America Available from

National Technical Information Service

U.S. Department of Commerce

5285 Port Royal Road

Springfield, VA 22161

Price: Printed Copy $\$ 9.00 ;$ Microfiche $\$ 3.00$

March 1978

2100 copies 
Prepared for the Agency for International Development in response to a request by Congress, the report identifies the energy needs, uses, and resources in the developing countries of the world and examines the energy options available to them for their continued social and economic growth. If traditional patterns of development are to continue, oil consumption in the non-OPEC LDCs will grow steadily to become comparable with current U.S. consumption between 2000 and 2020. Attempts to exploit indigenous hydrocarbon resources even in those IDCs with untapped reserves will be limited by shortages of capital and technical manpower. In the absence of major actions to replace noncommercial fuels or to increase the effectiveness with which they are used, a large fraction of the 3-4 billion IDC rural population in the year 2000 will not be able to raise their energy usage above subsistence levels.

There is a wide variety of solutions to these problems, many of them emerging directly from the changed economics of energy. For example, most LDCs have not adequately explored and developed. their own indigenous resources; in virtually all energy conversion and utilization processes there are opportunities for improvements in efficiency and substitution of renewable energy forms. In virtually all these areas there are opportunities for. effective assistance activities. 
This report represents the combined efforts of a great many people. The project was initiated and supported by the office of Science and Technology in AID and profited from the guidance of Jerome Bosken in that office throughout. Many members of the staff of the National Center for Analysis of Energy Systems at Brookhaven contributed their wisdom to the development of the ideas in the report, particularly Kenneth Hoffman, Head of the Center, Steve Carhart, James Keyser, and David Behling. Comments on an early draft of the report by Robert Ichord, Department of Energy, were particularly helpful. Warren Donnelly, Congressional Research Service, Library of Congress, provided valuable guidance in planning the report.

The preparation, editing, and production of the report through many drafts under severe time constraints was accomplished only through the combined efforts of many members of the staff of the Energy Policy Analysis Division. We are particularly grateful to Gale Munson, Georgia Irving, and Elizabeth Seubert, for their dedicated and expert work during this period. The efforts of Robert Stern and the staff of the BNL Graphic Arts Division made possible the production of the reports in the required time.

People who participated in the study through the preparation of draft material for this report, the organization of workshops, and the preparation of issue papers are listed below. 
Brookhaven National Laboratory

Jack Allentuck

Edward Beardsworth

M. Virginia Davis*

Vinod Mubayi

Robert Nathans

Philip F. Palmedo

Thomas Vietorisz*

Cornell University

David Pimentel

Donald M. Nafus

Donovan, Hamester, and Rattien

Lawrence Ervin
Robert Gordon
Stephen Rattien
Eric Forman
Larry Beck
Gary Kah

Gordian Associates

Samuel Hale, Jr. Sidney Leveson

Assif Shaikh

Institute for Energy Research

State Univ. of N.Y. at Stony Brook

Romir Chatterji

Manuel Taylor

Debra Stabile

Arundhati Raychandhueri
Meta Systems, Inc.

Russell J. delucia

Peter Rogers

Overseas Development Council

William knowland

James Howe

James Tarrant

James Bever

R. R. Nathan Associates

John Beyer

University of California at Berkeley and Lawrence Berkeley

Laboratory

Richard L. Meier

Samuel Berman

* Consultant 


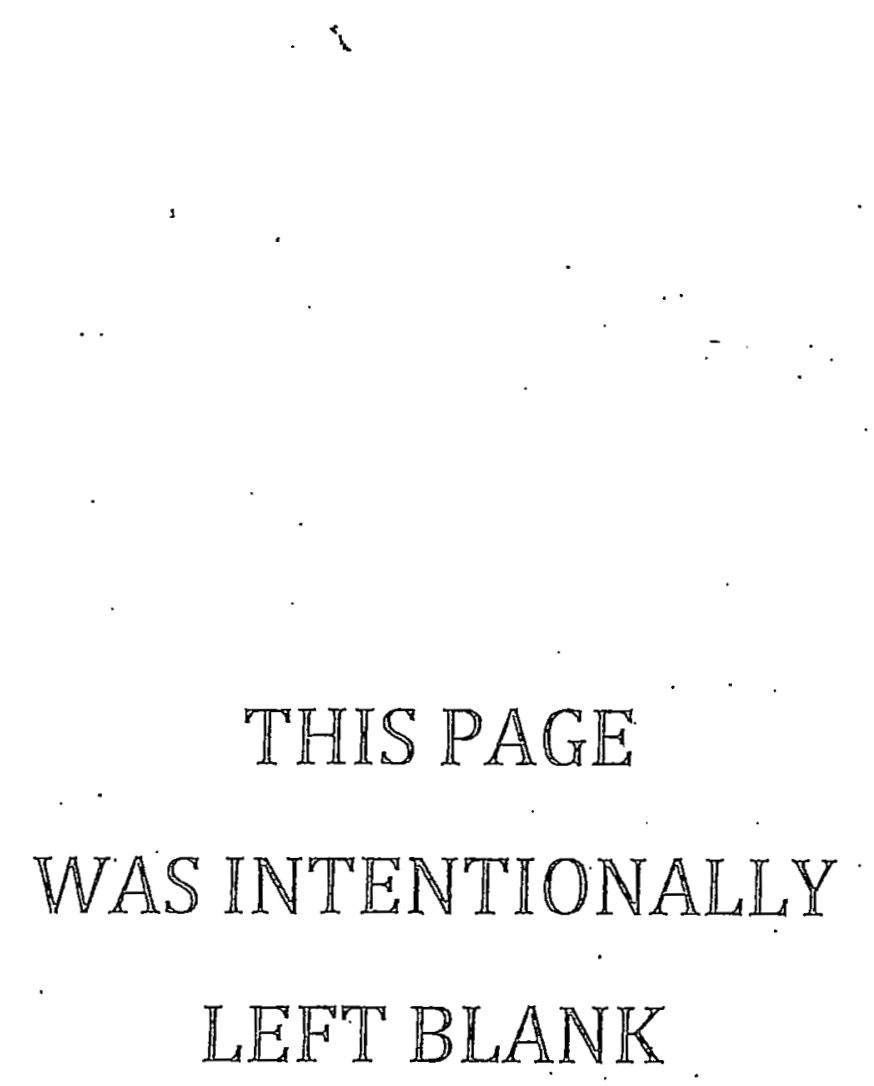


A. INTRODUCTION

1. The Energy Problems of the Developing Countries . 1

2. The U.S. Interest " 2

3. Energy and Traditional Development Assistance 5

4. Towards Solutions for Energy Development 7

5. This Report 8

B. ENERGY SUPPLY AND DEMAND IN THE NON-OPEC DEVELOPING COUNTRIES

1. Introduction

1.1 The Analytical Approach 11

1.2 The Outlook 12

1.3 Characteristics of Non-OPEC Developing Countries 13

1.4 Country Groups - Contrasts and Similarities 15

1.5 The Current Energy Situation 21

2. Projections of LDC Energy Demand

2.1 Introduction . 27

2.2 Basis for Projecting Commercial Energy Demand 27

2.3 Basis for Projcoting Noncommercial Fnergy Demand 29

2.4 Total Projected Energy Demand 31

3. World and LDC Energy Supply

3.1 Future World oil Supply 35

3.2 Future Commercial Energy Supplies to the LDCs 36

3.3 Oil Reserves and Future Production 39

3.4 Natural Gas : : 43

3.5 Coal : 44

3.6 Electricity Supply $\quad 49$

3.7 Noncommercial Energy Supply 52 


\subsection{Financing and Other Constraints on IDC Energy} Resource Development

C. ENERGY FOR BASIC HUMAN NEEDS

1. Introduction $67^{\circ}$

$\begin{array}{ll}1.1 \text { The Outlook } & 67\end{array}$

2. Rural Life and Energy 69

3. Food Production and Preparation 75

3.1 Enaxigy in Fuud rroduction 76

4. The Problem of Data and Means of Analysis 77

5. Lovelo of Energy and Subsistence. 79

5.1 Subsistence $\quad 79$

5.2 "Basic Human Needs"

5.3 "Improved Living Standard" 81

6. Conclusions 81

D. CHARACTERIZING SOLUTIONS TO THE ENERGY PROBLEMS OF THE DEVELOPING COUNTRIES .

1. Introduction 83

2. The Essential Role of Energy in Development 84

3. Energy System Solutions ' 87

3.1 Energy Resource Solutions $\quad 87$

3.2 Energy Conversion Solutions 90

3.3 Demand sectors $\quad 92$

4. Developmental Solutions 107

4.1 Stabilization of the Rural and Handicraft Sector 107

4.2 Urban Redesign 108

4.3 An "Alternative" Development Strategy. 109

5. The Acceptability and Time Scale of Solutions 110

6. Some Final Considerations 111 
TABLE OF CONTENTS (Cont'd)

NOTES AND REFERENCES

Chapter A

115

Chapter B

116

Chapter $\mathrm{C}$

121

Chapter D

123

APPENDIX A

Basic Social and Economic Indicators 127

Key to Data $\quad 135$

Table, Current Non-OPEC LDC Oil Reserves and Production 136

\section{APPENDIX B}

$\begin{array}{lr}\text { I. Workshops } & 137\end{array}$

II. Issue Papers $\quad 143$ 
B-1 Country Groups $\quad 14$

B-2 Basic Social and Economic Indicators-Mean Figures is

B-3 Standard Energy Conversions $\quad 24$

B-4 IDC Commercial Energy Consumption Assumptions 26

B-5 Aissumptions Used in Other LDC Commercial Energy $\begin{array}{ll}\text { Projections } & 28\end{array}$

B-6 Population Growth 30

B-7 Projected LDC Energy Consumption Current Trends 3.2

B-8 Total Commercial Energy Demand Projections for

B-9 Indigenous Production of Commercial Energy, Million

B-10 World Share Estimated Proved Crude Oil Reserves as 40

B-11 World Shares of Additions to Estimated Crude oil Reserves Between $1 / 1 / 77$ and $1 / 1 / 78 \quad 40$

B-12 Drilling Density in Oil-Exporting LDCs 41

B-13 Gas Production 1977 (Jan. - Oct.) 41

B-14 World Shares of Additions to Estimated Gas Reserves Between $1 / 1 / 77$ and $1 / 1 / 78 \quad 4.5$

B-15 1976 world Coal Production 46

B-16 Electricity Growth in LDCs 48

B-17 IDC Nuclear Production - $1975 \quad 50$

B-18 World Forest Resources . 54

B-19 Estimated Investment Costs for Non-OPEC LDC Energy. 57

B-20 Projected.non-OPEC LDC Energy Financing Requirements, 1975-2.nnก $\quad 58$

$\begin{array}{ll}\text { B-21 } & \text { Distribution of Reserves by Availability of Financial } \\ \text { Resources } & 61\end{array}$

B-22 Some Recent LDC Agreements with Foreign Companies 63.

C-1 Energy Sources and Applications in Seven Villages 72

C-2 Comparison of Energy Use in LDC Rural Villages

$\begin{array}{ll}\text { D-1 Population Projection for the World's Largest } \\ \text { Metropolitan Growth Areas } & 100\end{array}$ 


\section{LIST OF FIGURES}

Figure Number

Title

Page

B-1 Relationship of Per Capita Energy Consumption to Per Capita GNP

B-2 Distribution of World Commercial Energy Consumption

B-3 Total Annual Energy Consumption Projections by LDC Country Groups

B-4 Annual Per Capita Energy Consumption vs. Total Population

C-1 Noncommercial Energy Use as a Percentage of Total

Energy Use, vs. Population, By Country

C-2 Relationship Between Physical quality of Life

Index and Energy Consumption per Capita 


\section{THIS PAGE}

\section{WAS INTENTIONALLY LEFT BLANK}




\section{EXECUTIVE SUMMARY}

\section{A. BACKGROUND AND CONCLUSIONS OF THE REPORT}

This report examines the future energy requirements of the non-OPEC developing countries.* It was commissioned by the U.S. Agency for International Development in response to the International Development and Food Assistance Act of 1977 which authorizes the President to carry out "studies to identify the energy needs, uses and resources which exist in developing countries." The report assesses the energy supply-demand situation in the non-OPEC developing countries through the year 2000; reviews energy requirements to satisfy basic human needs; identifies the major energy problems to be overcome; and finally, describes a taxonomy of solutions to those problems upon which energy assistance programs can be based.

The general picture that emerges from the analysis, although uncertain in many respects, raises serious concerns about the development prospects of the many energy-poor countries of the world. If traditional patterns of development are to continue, oil consumption in the non-OPEC LDCs will grow steadily (even if energy is used more efficiently in response to increased cost) to become comparable with current U.S. consumption between 2000 and 2020. It is likely, however, that world petroleum production will peak and prices will increase substantially well before that time. Attempts to exploit indigenous hydrocarbon resources even in those LDCs with untapped reserves will be limited by shortages of capital and technical manpower. In the absence of major actions to increase the effectiveness with which noncommercial ${ }^{* *}$ fuels are used or to replace these fuels, a large fraction of the 3-4 billion LDC rural population in the year 2000 will not be able to raise their energy usage above subsistence levels.

There is a wide variety of solutions to these problems, many of them emerging directly from the changed economics of energy. For example, most

* In this summary we use the terms "developing country" or "less developed country" (IDC) interchangeably to refer to the 88 poorest countries of the world. They are listed in Table B-1, page 14.

$\star \star$

Public Law 95-88, August 3, 1977, Section 114 (b) 1.

*** "Noncommercial" or "traditional" fuels are ones not generally bought and sold (though they are in some instances) and in widespread use in rural pre-industrial economies. They include wood, dung, and agricultural waste. 
IDCs have not explored and developed their own indigenous resources adequately; in virtually all energy conversion and utilization processes there are opportunities for improvements in efficiency. More difficult to implement, but necessary in the long term, is the conversion to dependence on renewable energy sources and movement toward national strategies which can accomplish economic and social development with lower energy requirements. In virtually all of these areas there are opportunities for effective assistance activities.

\section{B. THE LDC ENERGY CRISIS}

As a group the non-OPEC developing countries have seen delays and even reversals of their economic and social progress as they have sought to adapt to the higher prices of petroleum. Some have had little choice but to reduce imports at the cost of economic growth. Others have had to decrease food production because of the lack of petroleum-based fertilizers and fuels to operate irrigation systems. Those able to borrow for payments for imported energy are incurring unmanageable debts.

Less widely acknowledged is the second "energy crisis" coming from diminishing supplies of traditional fuels--wood, dung, and straw. In the face of increased deforestation, the increasing diversion of fuelwood and charcoal to urban areas (where it is replacing more expensive kerosene), and the increased pressures of population growth, the ecosystem which supported village life is breaking down.

These two crises are closely linked because in the modern development process the shift from noncomercial fuels to oil has been the key to emergence from subsistence to modern means of production.

The U.S. Interest

These LDC energy "crises" have a bearing on a number of U.S. interests.

- The succege of forcign asoiotancc cfforts to inerenge the staniarils of living of the rural and urban poor will depend on the availability of an adequate supply of affordable fuels. 
- Increased competition for world oil supplies between the advanced industrial countries, OPEC and the non-OPEC LDCs, carries with it the potential for increased global political and economic instability.

- Worldwide concern for the effects of the increasing concentration of carbon dioxide in the atmosphere is related to the rapid growth of total energy consumption in the LDCs and the almost total dependence of this growth on carbon based fuels.

- The large capital requirements of energy resource development, production, and distribution will impose an increasing burden on the international monetary system.

\section{THE CURRENT ENERGY SITUATION}

Non-OPEC developing countries contain $41 \%$ of the world's population and consume 98 of the world's commercial energy. Prior to the 1973 increase in oil prices, their energy growth was rapid, up 2508 from 1970 to 1974 . Still, their per capita energy consumption in 1974 averaged less than 6\% of the U.S. level. This includes both commercial and noncommercial fuels. Per capita consumption varies from $16 \%$ of the U.S. value in the industrial and oil exporting developing countries (758 of which is commercial) to 58 in the remaining non-OPEC LDCs (only $10 \%$ of which is commercial). The per capita consumption levels for this latter group, who make up $75 \%$ of the non-OPEC LDC population, is sufficient only to satisfy basic requirements of subsistence.

Dependence on Oil and Balance of Payments

Petroleum based fuels accounted for at least 908 of commercial energy use in two-thirds of the oil importing LDCs. As a qroup these count.rips imported oil. in 1975 at an average daily rate of 2.7 million barrels at a cost of $\$ 12.5$ billion, which amounted to 78 of the total value of their annual exports. At the same time, outstanding disbursed debt increased from 128 of GNP in 1974 to 158 of GNP in 1976. Debt service requirements increased. from 8.5 to 108 of total annual export value. For Brazil, Mexico, Chile, Egypt, Pakistan, and Zaire this figure exceeds $30 \%$.

GNP growth rates have also slowed dramatically--down from an average of 7.68 to 3.08 between 1973 and 1975. According to the World Bank, the effects of these oil related dislocations will be felt most severely by the lowest income LDCS. It is projected that the per capita income of more than 
billion people in these countries will increase from its 1975 value of $\$ 150$ to only $\$ 180$ by 1985 , even under optimistic assumptions regarding development assistance and trade liberalization.

D. PROSPECTS FOR LDC ENERGY SUPPLY AND DEMAND Demand Projections *

The future demand for commercial fuel was estimated based on assumed GNP growth rates and correlations between energy demand, GNP growth and energy prices. Noncommercial energy consumption was based on crude estimates of current consumption levels, subsistence energy requirements and population growth projections. GNP growth rates are lower than past expectations but higher than the present rates which reflect post-1973 prices. The results are shown in Flgure 1 . The 2020 projections are intended only to tientify the major characteristics of the longer term energy demand situation.

\section{The Outlook}

With anticipated growth, even at high energy prices, some time between 2000 and 2020, IDC total oil demand will probably exceed the current rate of U.S. oil consumption (18 million barrels per day). In spite of a threefold increase in coal and natural gas, oil will still account for $55 \%$ of total energy demands in the LDCs in 2000. Noncommercial fuel use will also grow, and without a dramatic increase in the efficiency of use, shortages will become more severe, with accompanying environmental damage. The more industrialized developing countries together will continue to account for the same share of oil use in the year 2000 as they do now, about 458. Since oil availability at prices affordable by a large fraction of these countries in the year 2000 is problematic, 1t may be impossible to raise the standard of living in the lower income LDCs even to minimally acceptable levels.

For each of the country groups, projections were made of future demand for "primary commercial energy", usiny actual $19 \%$ consumption ao a etartiny point and assuming a continuation of current trends in the rate of GNP growth and the ratio of that rate to. the growth rate for energy. (The "income elasticity" was estimated for oil to be from 0.8 to 1.1 for different country groups in different time periods, for electricity, between 1.0 and 1.8, with comparable values for gas and coal. Assimied ONP growth range from 3.6 percent to 6.3 percent until 1990 , and from 2.8 percent to 5.4 percent thereafter. These are conservative assumptions, leading to lower projections of future demand than other recent analyses.) For noncommercial energy, population estimates were multiplied by a minimum subsistence per capita consumption level. 
FIGURE 1

TOTAL ANNUAL ENERGY CONSUMPTION PROJECTIONS

FOR ALL NON-OPEC LDCS

(CURRENT TRENDS CASE)

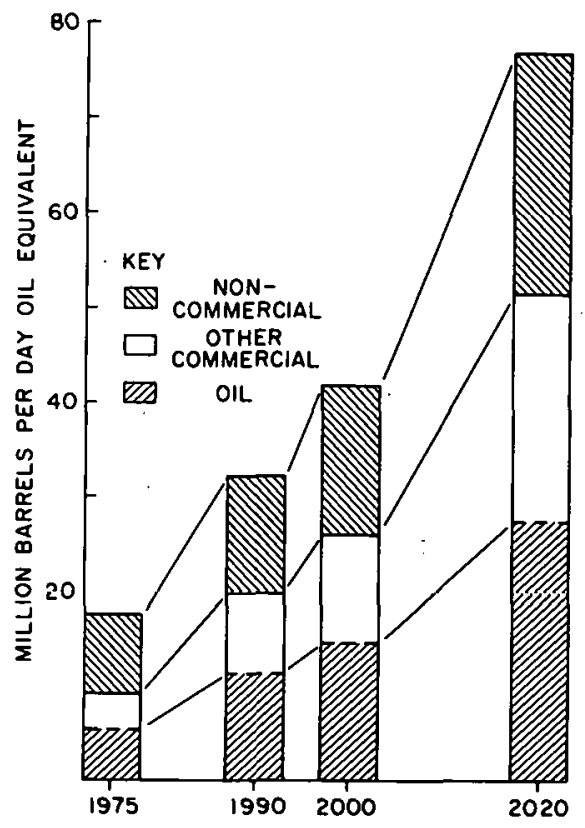

World Oil Supply and Non-OPEC LDC Oil Production

Virtually all estimates made under a variety of assumptions show worldwide oil production peaking before 2000 and by the year 2020 to be less than it is today. The WAES* study, for example, using a projected annual addition to non-Communist world reserves of 20 billion barrels (which would mean new discoveries by the year 2000 equal to the entire remaining reserves of OPEC in 1975) estimates annual production in the year 2000 of 70 million barrels per day. The oil demand by the non-OPEC LDCs noted above would call for their recelving one barrel out of every five of this non-Communist world supply.

* Workshop on Alternative Energy Strategies, Energy: Global Prospects 1985-2000, McGraw Hill, N.Y., 1977. 
Some $7 \%$ of the world's present crude oil reserves, or 44 bilition barrels, is located in the non-OPEC LDCs. It is concentrated, however, mainly in Mexico, Oman, Egypt and a few other countries. Past exploration has been very limited in most of the non-OPEC LDCs. Their drilling density has averaged only $1 \%$ of the U.S. in spite of the fact that they have approximately half of the world's total prospective area for petroleum. In 1977, the nonOPEC LDC additions to reserves was $16 \%$ of the world's total. Although virtually all of this came from new discoveries in Mexico, it reinforces the speculation that proven oil reserves in the non-OPEC LDCs is likely to undergo a dramatic increase with further exploration. Even so, many of the poorer LDCs are still likely to have to continue to rely on imported oill for the forsepahto future.

\section{Natural Gas}

In 1977, the LDCs produced 58 of the world production while accounting for 158 of the net world additions of natural gas. On a worldwide basis this more than made up for the declines in reserves in the developed countries. Like oil however, production and reserves of natural gas are concentrated in only a few developing countries. Huge quantities are flared for lack of investment capital for distribution systems--a situation likely to limit the use of natural gas in the IDCs in the near future.

Coal

Although exploration for coal in most of the LDCs has been essentially nonexistent, geologists speculate that supplies of coal and liqnite may be widespread throughout the world. Eighty percent of current coal production in non-OPEC LDCs is confined to three countries--India, Korea and Yugoslavia-amounting to 58 of total world production. If they can obtain the financing and other infrastructure support, many more LDCs will be able to use their coal resources more extensively.

\section{Electricity Supply}

Electrlclty growth rates in virtually all the LDCs exceeded the average U.S. value of 78 for the period 1970-1975. For all but a few countries the bulk of the increase in production relied on hydropower and oil sources. Hydropower now accounts for 508 of electririty supply in these countries. Nuolcar and geothermal account for less than 38 and are confined to five of the countries 
in this group (Argentina, Spain, India, Pakistan and Mexico). Coal is used to supply electricity only in India and a few other developing countries. Increasing future electric generating capacity will be limited by a lack of capital and remaining easily accessible hydropower sites. In this connection "mini-hydro" may have considerable potential in serving local needs.

Financing and Other Constraints on LDC Energy Resource Development

Annual investments in energy resources in the non-OPEC LDCs will have to increase 508 in real terms over current rates by the year 2000 for energy supplies to come near meeting IDC commercial energy demands. The total capital required for the LDCs as a group to attain this "self-sufficiency" is about $\$ 125$ billion. Should the current policies controlling the allocation of capital funds to energy projects be continued, over 338 of this amount would be required for hydropower based electricity development even though this source will account for only $5 \%$ of the additional energy supplies that will be required. Oil will account for 408 , natural gas $20 \%$, and coal 3\%, of the investment. At present, only a few countries have substantial access to private international investment--77\% of Eurocurrency, for example, goes to six countries. Thus a continuation of present public and private lending policies will make it difficult for the most severely impacted countries to improve their overall situations. The effective utilization of new capital inputs may be seriously constrained by limited knowledge of indigenous resources, inappropriate energy pricing, and organizational and institutional constraints. opportunities to expand investment by international companies in oil, gas, and coal explorations and development will depend on the ability of the companies to obtain secure and profitable agreements from LDC governments.

E. NONCOMMERCIAL ENERGY SUPPLY

Energy for Basic Human Needs

Two and a half billion of the population in the LDCs continue to rely on wood, dung, straw and human and animal power to meet their basic energy needs. The useful work derived from these energy inputs, which goes almost exclusively to food production, processing and preparation, is less than one quarter of that which could be obtained were commercial energy sources used for similar tasks. Continuing supplies of these fuels are critically dependent on a supporting 
ecosystem which is being rapidly disrupted due to increased population pressures. Further, wood is being increasingly diverted into the urban market as kerosene prices rise.

Levels of Energy and Subsistence

From a number of studies an approximate figure of 300-400 kilograms of coal equivalent per capita per year has emerged as the minimum energy input needed to provide a subsistence level of food and shelter in a rural agrarian setting. This represents $3 \%$ of the per capita energy consumption in the U.S. Increasing health and well-being as reflected in reduced infant mortality rates, increased life expectancies and literacy levels, correlate with increased energy use. Preliminary efforts to analyze this relationship by the Overseas Development Council suggest that a doubling or tripling of energy use will be required to bring the lowest income LDCs up to the level necessary for an adequate life with some opportunity for emergence to improved health and well-being.

Traditional Energy Resources

Although on a worldwide basis we are consuming only a fraction of total annual growth of forest resources, demand is expected to grow rapidly. In some regions wood resources are already being overused, while in other, forests, if managed properly; can provide an increased amount of energy. The longterm trend for forest resources is no more encouraging than that for oil. Nearly a third of the original tropical forest area has been destroyed within recorded history, and it has been predicted that by the year 2000 or shortly thereafter virtually all humid tropical forests will have been transformed into desert or unproductive wasteland.

Dung is increasingly used as a fuel instead of being returned to the soil as a fertilizer, while commercial fertilizers, which have increased rapidly in price since 1973, are less available. Shifts to higher producing cereal strains which produce less straw reduces the amount of agricultural waste for use as fuel or in maintaining soil quality.

Given the increasing demand for fuels in the rural areas of the LDCs and the reduced supply, traditional fuel use will have to be made more efficient, natural resources better managed, and alternatives substituted. on a widespread basis before the end of the century. 
F. CHARACTERIZING SOLUTIONS TO THE ENERGY PROBLEMS OF THE LDCS

Alternative courses of action for the LDCs can take two forms: they can entail changes in the energy support system for greater use of indigenous or plentiful energy resources and for alternative energy conversion and enduse technologies, or they can involve modifications in social, regional and economic development. The former are primarily technical and are expected to be easier to implement.

Energy System Solutions

The benefits of even a modest oil discovery would be so great that oil resource surveys would be attractive to all the oil importing LDCs, except for those with the bleakest of geological prospects. Development of indigenous coal would permit its substitution for oil in electricity production, process heat and trains. Reforestation and biomass generation could provide increased rural energy supplies. Small or low grade deposits of oil and coal, not formerly deemed commercially exploitable, may now become so in the light of increased energy prices.

Accelerated use of electricity produced from non-oil energy resources using large scale systems can play a significant role particularly in the more industrialized developing countries. For the other LDCs on-site electric systems such as mini-hydro, and small to medium scale plants using low grade coal, agricultural waste, wind and solar may be more appropriate, less costly, and involve less delay. Solar energy devices have a considerable potential for widely dispersed settlement patterns provided high capital costs can be reduced, reliability of systems improved, and institutional difficulties overcome.

Numerous opportunities for reducing energy demand through increasing energy end-use efficiencies exist in the industrial sector. This sector consumes at least 30-40z of total energy in all but a few LDCs. Possibilities include modernizing inefficient facilities, switching from direct use of oil to non-oil based electricity, and developing on-site solar systems.

Alternatives to oil in the transport of goods and people presents one of the difficult problems for all countries. Solutions that do exist are long-term, involve mode shifts and changes in urban settlement patterns. 
The near-term potential for transportation energy saving in all but the most advanced LDCs will be small: Alcohol or electrically powered vehicles must also be considered as longer term solutions. Increasing food production/ hectare through greater use of small tractors, irrigation systems, fertilizers and pesticides entails not only greater use of energy, but use of scarce oil resources. Substitutes such as methanol use in tractors and wind powered pumps, although they have not yet gained wide acceptance, are promising if oil prices continue to rise.

Urban systems using less energy intensive materials and requiring lower energy operating cost may offer significant energy savinys over the next decade or two, due to the rapid urbanization in many LDCs. Clustering of structures, design for natural heating and cooling, and greater use of renewable materials pose no serious technical problem but are likely to meet social resistance. Similarly, the difficulties in implementing "appropriate technologies" such as biogas systems in rural areas are not primarily technical, but revolve around the lack of institutions to integrate and manage their use.

Developmental Solutions

Urban migration, import substitution, improved health and educational delivery, income redistribution--almost all the manifestations of progress in the LDCs--have been historically associated with sharply increased energy demands. More difficult to implement than the solutions discussed above are approaches that would change the structural path of develonment in order to meet national economic and social development goals with less energy use. Examples of these solutions would be stabilization of the rural and handicraft sector, development of energy efficient decentralized communities and adjustment of the industrial $\mathrm{mix}$ to decrease dependence on imported energy. Long-term benefits may accrue to altered development strategies, but such strategies can be implemented only over long time periods.

\section{SOME FINAL CONSIDERATIONS}

The United States has a direct interest in assisting the developing countries in addressing their energy problems. In virtually all of the solution areas discussed above there are opportunities for such assistance. 
A paramount concern in arriving at assistance programs must be the perceptions of the LDCs. For example, most developing countries attach higher priority to programs of increased resource production than to programs of increased end-use efficiency. On the other hand, the potential of small and medium scale energy technologies, and the role of energy conservation, are generally not adequately appreciated.

The large technical component of the problems we have addressed presents an opportunity and a challenge for U.S. foreign assistance. There is an opportunity to bring the scientific and technical expertise of the Western world to bear on a fundamental set of problems of the developing world. But in approaching these problems we must not prejudge solutions. Those solutions must derive from a careful analysis of country needs and goals. We must also bear in mind that energy is important only as it satisfies social and economic needs. It drives the machinery of a nation in all its vast human, cultural and economic complexity. Programs of energy assistance will succeed only if they are conceived and implemented with due respect for that complexity. 
CHAPTER A

INTRODUCTION

1. THE ENERGY PROBLEMS OF THE DEVELOPING COUNTRIES

The consequences of the 1973 increases in the price of petroleum have raised energy to a priority issue around the world. Within a short period the costs of energy, and even the possibility of an eventual worldwide energy shortage, have become an immediate and pressing concern. Nowhere has the situation had a greater impact than in the developing countries. ${ }^{*}$ While the industrial countries have endured inflation and relatively high unemployment over the past five years, with few exceptions their economies have continued to grow albeit at a reduced rate. Most developing countries, however, have experienced pressing problems in accomodating their economies to this new situation. Taken together with their rapidly growing populations, growing urbanization, high unemployment rates, and recurring food shortages, they are incurring increasing difficulties resulting from increased payments for imported energy. 2 Moreover, the economic and social progress most have struggled for has been delayed, and in some cases reversed. Higher priced fuels needed for industrial development have been purchased at the expense of economic growth, and food production has decreased because of the lack of energy intensive fertilizers and fuels to operate irrigation systems.

The energy situation of many of these nations is such that the continuation of this "crisis" will leave them with a series of difficult challenges:

- The combination of increased costs for oil imports and debt service payments will leave many of these countries with a rapidly declining ability to finance needed investment to stimulate economic growth or to provide for even the minimum basic human needs of a large segment of their populations.

- Many of these countries have seen serious depletion of their noncommercial energy sources, ${ }^{3}$ causing major environmental. damage and social harm, which can only increase with higher prices of kerosene.

* Notes and References appear at the end of the report, beginning on page 115. 
- The current pattern of economic development in all the LDCs is increasing their dependence on petroleum at a time when the world is beginning to reach limits of petroleum production. Thus, if, as many studies have indicated, increased competition for world oil supplies in the post-1985 period leads to further rapid increases in oil prices, the current unfavorable economic position of these countries will be further aggravated.

Seen in this light the energy crisis of the developing world has three basic components. 1) For the immediate future LDCs must maintain oil imports--a problem measured in barrels of oil and dollars. 2) The classiral problem of providing the basic needs for survival to the rural and urban poor will be exacerbated--a problem measured. in calories and dollars. 3) In the long term alternative energy supplies must be provided to support national economic and social development in an era of increasing competition for capital resources--a problem measured in energy units, dollars and strategic terms. 2. THE U.S: INTEREST

The energy situation in the LDCs directly concerns the United states and other advanced industrial countries. Foremost is a humanitarian concern for the living conditions of the very poor. Both the urban and rural poor have been directly and indirectly affected by the reduction in economic output of many of the poorest developed.countries which resulted from forced reductions in imports of vitally needer petroloum and pntrnleum based fertilizer. Assistance projects which were intended to bring higher living standards instead brought higher energy requirements.

The energy based difficulties of the more advanced developing countries will have an increased bearing on the economic, social, political and security interdependence between these countries and the advanced industrial countries. This interdependence is manifest in international security alliances, trade agreeminls fur food, manufactured goods and minerai supplies and the interlacing private sector arrangements involving growing financial obligations. Already the potential instabilities brought about the the inability of many of these developing countries to compete either for oil in the international. market 
or for the capital to finance energy alternatives have entered into the. North-South dialogues and the discussions surrounding the nonproliferation. of nuclear weapons.

Finally, it is clear that energy consumption in the developing countries must inevitably grow substantially in the face of their rapidly growing populations. To an overwhelming extent this will involve the burning of carbon-based fuels, directly relating worldwide concerns for increasing levels of carbon dioxide in the atmosphere to energy development in the LDCs.

Beyond these general concerns there are a number of specific U.S. concerns and interests tied to the energy situation in the LDCs as it is now developing.

- With the emergence of OPEC as a political force, the dependence of many IDCs on imported oil has subjected them to a new set of potential pressures and constraints. These new forces may be directed counter to U.S. interests.

- The U.S. has a strongly stated interest in reducing the proliferation of technology which can facilitate the acquisition of nuclear weapons. The success of the U.S. in convincing the advanced developing countries to seek nonnuclear alternatives to generate electricity will depend on the rate of growth of electric supplydemand gaps and on the availability of alternative technologies and resources.

- World trade patterns in energy technologles and resources that may develop over the next several decades will affect the political development of LDCs and their relationship to the U.S. For example, coal exports from the U.S. would have a direct bearing. on our relations with these countries. Likewise, the U.S. may find itself increasingly dependent on oil and gas imports from some LDCs where it is estimated that there are large untapped reserves of these fuels. 
- The U.S. has a direct interest in the ability of a number of these countries to service their increasing debts to international agencies and private banks. This ability is directly tied to the continued growth of their economies which in turn depends on their ability to acquire the necessary energy.

- Opportunities for U.S. exports to the LDCs, and U.S. industrial involvement generally, will be strongly affected by the economic health of developing countries and the energy solutions they choose.

Formal recognition by the U.S. of the relationship between these basic o.s. interests and the energy needs of the LDCs is beginning to take place. The International Development and Food Assistance Act of 1977 provides AID with $\$ 18$ million for "cooperative programs with the developing countries in energy production and conservation, with particular emphasis on programs in research, development, and use of small scale decentralized renewable energy sources for rural areas". The act ${ }^{4}$ also authorizes the President to carry out "studies to identify the energy needs, uses and resources which exist in developing countries". This report was prepared in fulfillment of that mandate. The Department of Energy in collaboration with AID and the State Department has also initiated a program at the request of the president to identify programs to assist developing countries to implement nonnuclear energy technologies.

Energy has also played a role in the so-called North-South dialogue between the developed and developing countries. The conference on International Economic Cooperation (CIEC) ${ }^{5}$ included an Energy Commission which agreed on a set of guidelines that called for "intensified national and international coperative efforts to expand energy conservation, and accelerate the development of conventional and nonconventional energy supplies...". 6 However, an attempt to establish a continuing coordination of energy programs with the IDCs through an International Energy Institute failed, primarily through pressure by the OPEC countries represented. A similar initiative within the U.N. met the same fate. 


\section{ENERGY AND TRADITIONAL DEVELOPMENT ASSISTANCE}

Traditional development strategies and the assistance supporting these strategies have emphasized the adoption of economic and technological practices similar to those employed by the advanced industrial societies. We are now beginning to understand that such strategies implicitly assume the availability of cheap energy--a situation which characterized the recent economic history of most industrial countries. This development strategy led to an emphasis on capital and energy intensive heavy industry, and the high yield crop strains requiring heavy fertilization and energy intensive irrigation. It is not surprising that since the energy implications of development plans were not considered a significant element in the choice of alternatives they were also absent from the planning of developmental assistance.

Historically, development assistance concerned with energy has emphasized capital intensive electricity production facilities--large hydroelectric installations, coal, nuclear and oil fired electric generation stations and grid systems. Donor assistance has taken the form of loans and grants covering feasibility studies, construction, and manpower training. This strategy views electricity production and distribution as central to the. achievement of the developmental goal of import substitution in the organized sector of the economy. Rural electrification is viewed as instrumental in diversifying the base of rural economies. Up until recently, essentially all World Bank energy loans were restricted to electricity production and distribution systems, as were most AID capital projects until the early 1970's. There has recently been a broadening of policy at the Bank, and AID has substantially reduced its capital investment program in large energy systems over the past years. Nevertheless, the overwhelming fraction of donor total assistance in energy still goes to the electrical sector. During the period of 1970 to 1977 the World Bank invested $\$ 4.4$ billion in electrical systems in the LDCs (including OPEC countries). In 1973 the energy program represented 128 of the total Bank lending, a figure that increased to 168 in 1977, and is expected lo yo even higher in the future. Other international agencies active in energy directed development assistance include the U.N., the International Development Association, the Asia, Inter-American, and African Development Bank and the Arab Fund for Economic and Social Development. The 
recipient countries strongly support the continued focus of the Bank and other assistance agencies on the electrical sector.

Two important changes in energy directed foreign assistance have taken place within recent years. Partly in response to the post 1973 developments, the World Bank now entertains loan applications for development of oil and natural gas reserves. It is the intention of the Bank to leverage its own investments by using its commitments to encourage commercial banks and oil companies to commit their own funds to such efforts. This change in policy is likely to mean that an increasing fraction of World Bank funds is likely to shift from the electric sector to resource exploration and development. 'I'he other smaller development banks who have had similar restrictions on energy loans are also discussing similar changes in policy.

A second change has occurred in the attention given to noncunvunlivial, renewable, small scale energy systems for rural areas. Although a number of countries had received assistance for projects involving small scale energy technologies in connection with improvements in agricultural productive and village services, the role of small scale energy supply systems in furthering rural development was not viewed as requiring a separate focus until the increase in oil prices: Over the past few years, however, a number of such assistance programs have been initiated by the U.N., a number of European countries, and several private foundations. Because assistance in this area is relatively new, the projects so far have been mostly exploratory in nature. Some concern themselves with what specific technologies should be considered under what circumstances, in what countries and for what regions. The African Bureau: of AID has undertaken such an evaluation for several countries and is preparing to initiate a much larger effort for other AID countries in Africa. The International Development Research Center of Canada (IDRC), a semi-autonomous public corporation, is evaluating the potential for methane manufacturing ant application in. Thailand, Sri Lanka, the Philippines and.Korea. Others are assessing the technical factors in developing new technologies or versions of existing technologies suitable to the conditions under which they will be used. Appropriate Technology International is supporting such efforts dealing with non-oil based fertilizer production, and other such projects involving solar utilization are receiving support in the U.K., Netherlands, and Sweden. 
Another component of the small scale or appropriate energy technology is being emphasized in an attempt to bring training in the use of such technologies to the grass roots level; the UNEP, for example, has set up prototype Rural Energy Centers in Sri Lanka and Senegal.

It is difficult to estimate the combined size of all these efforts, not only because of the diversity of funding sources but because of the difficulty in separating "energy" projects from water, food and rural development projects (on a worldwide basis). An upper bound would be about $\$ 35$ million and a lower bound $\$ 20$ million. These numbers are significant in two ways: first, they represent only a small fraction of the investments in conventional electricity facilities, and second, none of the funds are coming from the international banks. The latter point is significant because of the role banks play in legitimizing, through financial support, certain energy development paths.

4. TOWARDS SOLUTIONS FUR ENERGY DEVELOPMENT

If it is clear that the energy situation as it will develop in the LDCs must inevitably be considered as an integral component of all development assistance policies, it is also evident that energy directed assistance must take into account the development priorities of both donors and recipients. Development assistance policies historically have sought to direct the benefits of such assistance to the lower income LDCs in the areas of agricultural production, regulation of population growth, industrial development, regional development, institution building, and more recently have been aimed at satisfaction of basic human needs of the rural and urban poor. Assistance efforts in each of these areas must now be re-examined in the light of their energy implications but without misdirecting the priorities of LDC governments towards too much emphasis on energy and other capital intensive activities and away from those fundamental goals. But because energy does play an essential role in development, and because large amounts of capital will be required for any alternative, the forms of the energy assistance efforts that are chosen will exert a pronounced influence on the poor who have been the avowed target groups of our development assistance. 
Even to begin to plan an energy assistance effort will require a much stronger and more diversified factual basis of the energy needs and requirements of the developing countries, individually and collectively, than is currently available. We have only very limited knowledge of how energy utilization is related to social welfare of the lowest socio-economic groups, or of how energy production and utilization interact with GNP growth in the less industrialized developing countries. Data on potential energy resources in almost all these countries is either missing or meagre at best. National and international agencies have only started to collect and assemble energy data within the past several years, and studies and analyses relating energy to development are just beqinning to appear. This arrnints in largo moanurr. for the sizeable uncertainties in the data on energy supply and demand in this report.

\section{THIS REPORT}

This report was commissioned by the Agency for International Development in response to a Congressional request for the President to undertake a review of developing country energy needs and resources. In line with the language used in the authorization of funds by Congress for AID for energy related assistance, the perspective adopted is that energy plays an essential but supporting role to development. This means not only that future energy demands in the LDCs must be seen in terms of the need of these countries to achieve economic and social development goals, but the technical means used to supply this energy must themselves be supportive of such goals. The study therefore begins with a review and analysis of the non-OFEC LDC energy supply/demand situation, including future availability and demand for noncommercial fuels. We next examine the traditional role of energy in development, and its role in meeting basic human needs. This is followed by a study of the types of solutions available to the LDCs. Finally we discuss briefly the present conclusions which emphasize the implications of these assessments for future assistanse artivities. 
This project was directed by the Brookhaven National Laboratory but was structured in such a way as to draw on a wide spectrum of the development community. A series of workshops was held to clarify key issues of energy in development assistance. Those workshops and their participants are listed in Appendix B. They provided material to this report. A series of reports and issue papers was also commissioned to clarify certain issues and analyze parts of the problem. These are also listed in Appendix $B$. 
THIS PAGE

\section{WAS INTENTIONALLY LEFT BLANK}




\section{CHAPTER B}

ENERGY SUPPLY AND DEMAND IN THE NON-OPEC DEVELOP ING COUNTRIES

\section{INTRODUCTION}

\subsection{The Analytical Approach}

This chapter ${ }^{1}$ assesses the energy situation of the non-OPEC developing countries through the year 2000. We have also extended our analysis to the year 2020 in order to identify the major characteristics of the longer term supplydemand situation. A basic difficulty which confronts any broad analysis of the energy problems of LDCs is the tremendous diversity of countries referred to as "developing." To structure our technical analysis in a way that facilitates subsequent policy analysis, we have grouped the LDCs into six relatively homogeneous groups in terms of their economic structure and resource position. These groups are then used to bridge the gap between global analysis of world supply and demand, and the situation of specific countries. No analysis of this scope can, of course, be construed to apply to any individual country. Individual country situations will be used, however, to develop the perspective for the country groups.

A large fraction of the population of the "third world" depends for its energy needs on so-called norfcommercial fuels. ${ }^{2}$ These include wood, which has been called the poor man's oil, agricultural wastes and animal dung. Growing shortages of these fuels, and severe ecological impacts of their increased use, has created a second "crisis" in the LDC energy situation. Thus, despite all almost complete lack of reliable information in this area, in sections 2 and 3 of this chapter we deal, in a necessarily very approximate way, with supply and demand for noncommercial fuels.

Throughout the analysis one must be aware of the very large uncertainties which result from two factors: the great paucity of reliable basic data and the large uncertainty of future developments and conditions. Nevertheless, there are important and firm conclusions that emerge from the analysis despite these uncertainties. This in itself is an indication of the seriousness of the energy problems of the LDCs. 


\section{2 The outlook}

In this chapter we take a conservative, or optimistic, view of the energy supply problems of the LDCs as a group. The major features of the future situation that will emerge from this analysis are as follows:

- At the heart of the commercial energy supply crisis is petroleum supply.

- Even with increased efficiency of energy use, LDC oil consumption will probably exceed $20 \mathrm{million}$ barrels per day some time during the perind 2000-2020. (current U.S. consumption is 18 million barrels per day.)

- Hydrocarbon resources are very unevenly distributed among the LDCs. 'l'hus, even with extreme success in discovering and exploiting new reserves, most of the LDCs will have to rely on imports for most or all of their oil. Even if worldwide supplies remain adequate (which appears unrealistically optimistic), in the latter years of this century the cost of oil imports will impose a serious financing burden on all but a few of the non-OPEC LDCs, and, in the absence of offsetting actions, will significantly retard their economic and social development.

- Even those countries with major untapped conventional energy sources may have serious supply problems. If they now depend significantly on imported oil, they may well not have sufficient rapital to develop those indigenous resources which lie untapped under their own soil.

- Unable to afford oil or electricity, the majority of the population in most LDCs will continue to use more and more noncommercial fuel. Without a dramatic increase in the management of these resources and in the efficiency of their use, there will be severe shortages. Serious depletion has alrcady ocourred in some LDC's; worsening life lui a llldjuz fraction of the world's population, destroying habitats, and causing serious ecological damage on a vast scale. Without cheap locally available energy to supplement their own human energy, much of the population will not be able to raise their standard of living even to minimally acceptable levels by 2020 . 


\subsection{Characteristics of Non-OPEC Developing Countries}

The non-OPEC LDCs are a highly disparate group of nations that span a wide range of per capita income levels, income distributions, economic and social structures, stages of development and political systems.

Gross National Product (or alternatively, Gross Domestic Product), the usual measure of wealth and progress, provides a rough indication of relative wealth, but if fails to reflect the true state of economic and social well-being among a large fraction of the lowest socio-economic groups in these countries because subsistence agriculture and bartered goods are not counted and because distributional patterns are not indicated. National aggregate figures on GDP also obscure the large differences in income, welfare and energy use that characterize most countries. For example, in Brazil, which has a relatively high GNP per capita (\$920) and high annual per capita commercial energy use ( $31 / 3$ barrels of oil equivalent per year in 1974), it is estimated that $30 \%$ of the population lived below the poverty line, in the "traditional" sector. ${ }^{3}$ In India, the lowest 308 of the population in terms of income accounted for only 13.58 of total private consumption in 1973/74. This same segment of the population had an average per capita consumption of Rs $25 /$ month, compared with the Rs $40.6 /$ month which the Indian government has designated as the poverty line. ${ }^{4}$ And, as the tables in Appendix A indicate, the populations within most of the countries have short life expectancies and high infant mortality rates (with even worse statistics for low income groups within the countries). In addition, access to some of the "luxuries" of life (e.g., electricity, medical care, transport, education) is severely restricted for the vast majority of the population due to the lack of adequate infrastructure. In the Philippines, for example, only 6.98 of the rural dwellings are electrified compared with 60.48 of the urban dwellings. ${ }^{5}$ According to World Bank definitions, one third of the total population of the IDCs and almost three fourths of the population in the Asian LDCs have incomes below $\$ 50 /$ year. Even after taking into account rural subsistence and other production not included in the national accounts, this places them below the poverty line as defined by the countries themselves. (Country-by-country social and economic data are given in Appendix A.)

Most developing countries do not have adequate physical and social infrastructure--transportation, power communication, sanitary services, medical services, etc.--to cope with their rapid population growth and high rates of 
TABLE B-1

COUNTRY GROUPS
I. Industrialized

Argentina

Brazil

Chile

South Korea

Singapore

Spain

Taiwan

Uruguay

Yogos lavia

II. Oil Exporters

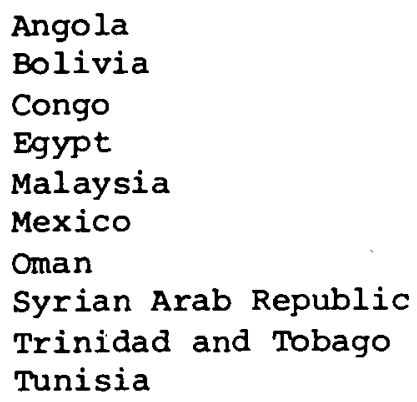

Angola

Bolivia

Congo

Egypt

Malaysia

Mexico

Oman

Syrian Arab Republic

Trinidad and Tobago

Tunisia

III. Balanced Growth Economies

Colombia

Greece

India

Pakistan

Panama

Peru

Philippines

Turkey

IV. Primary Exporters

Botswana

Guinea

Guyana

Jamaica

Liberia

Mauritania

Morocco

Sterra Leone

Surinam

Togo

gaire

Zambia
V-a. Agricultural Exporters

Costa Rica

Dominican Republic

Gambia

Guatemala

Honduras

Ivory Coast

Senegal

sri Lanka

v-b. Other Agricultural

Afghanistan

Bangladesh

Benin

Burma

Burundi

Cameroon

Central African Empire

Chad

Cyprus

El Salvador

Eq. Guinea

Ethiopia

Fiji

Ghana

Haiti

Jordan

Kenya

Lebanon

Lesotho

Madagascar

Malawi

Mali

Mauritius

Mozambique

Nepal

Nicaragua

Niger.

Papua N. Guinea

Paraguay

Rwanda

Somalia

Ewaziland

Sudan

Tanzania

Uganda

Upper Volta

Yemen A. Rep. 
urbanization. The absolute levels of LDC economic activity are low and not highly monetized. Domestic savings rates are below those in developed countries. The limited domestic purchasing power is concentrated in a small segment of the population. Even the most developed of the LDCs have been unable by themselves to support the levels of investment in infrastructure and productive assets necessary to generate self-sustaining development. For example, in 1976, the five most industrialized LDCs--Brazil, Mexico, the Philippines, Argentina and South Korea--accounted for over $70 \%$ of all Eurocurrency bank credits, and the first three accounted for just under $70 \%$ of publically financed bond issues. 6 Combined with the need to import basic consumer and capital goods, the inadequacy of indigenous investment has meant heavy IDC dependence on foreign currency flows (export earnings, private debt or equity capital, and/or official development assistance).. Unfortunately most LDC exports are mineral or agricultural commodities, which are subject to extreme price instability, and official develojment assistance has been declining in real terms. Most non - il exporting LDCs can therefore neither predict the amounts of external capital flows nor be reasonably assured of their adequacy.

\subsection{Country Groups - Contrasts and Similarities ${ }^{7}$}

We have separated the 88 nations analyzed in this report into five relatively homogeneous groups which are more consistent with their development and energy choices than the usual high, middle, and low income categories. These new groupings reflect the varying stages and patterns of development implied by per capita income, income distribution, industrialization, urbanization and such social indicators as infant mortality. But they are based primarily on characteristic economic and resource structures which determine the basic energy strategies which are available to them.

All the non-OPEC LDCs have been categorized as follows: (The members of each group are shown in Table B-1).

I. Industrialized Countries (Those for which the industrial sector is the largest sector in terms of percent of Gross Domestic Product)

In each of the nine countries categorized as "industrialized", industrial activity accounts for a higher contribution to Gross Domestic Product than agricultural activity. Also, compared to other LDCs, there is relatively less traditional handicraft production and relatively more "modern" industry. Howevex, their modern (and prcdominantly urban) industrial sector usually 
TABLE B-2

BASIC SOCIAL AND ECONDMIC INDICATOES - MEAN PIGURES (BY GROUP)

\begin{tabular}{|c|c|c|c|c|c|c|c|c|c|c|c|}
\hline oups & $\begin{array}{c}\text { GNP } \\
\text { Per Capita } \\
1979 \text { U.S.S } \\
\end{array}$ & $\begin{array}{l}\text { i U=ban- } \\
\text { 1zar=1on } \\
\text { (1975) }\end{array}$ & $\begin{array}{l}\text { Ccmmercial } \\
\text { Energy } \\
\text { Congumpti in } \\
\text { Per Capitg } \\
\text { (1975) } \\
\end{array}$ & $\begin{array}{l}\text { Crude } \\
\text { Death Rate } \\
\text { (per 1,000) } \\
\text { (1975) } \\
\end{array}$ & $\begin{array}{l}\text { Infant } \\
\text { Mortality } \\
\text { Rate } \\
\text { (per 1,000) } \\
(1970) \\
\end{array}$ & $\begin{array}{l}\text { Life } \\
\text { Expectancy } \\
(1975) \\
\end{array}$ & $\begin{array}{l}\text { Income } \\
\text { Received } \\
\text { by Lowest } \\
208 \text { (1975) }\end{array}$ & $\begin{array}{l}\text { Income } \\
\text { Receivea } \\
\text { by High } 2 s t \\
58(197 \jmath) \\
\end{array}$ & $\begin{array}{l}\text { Mnfg Value } \\
\text { Added (In } \\
\text { Producers } \\
\text { Values) to } \\
\text { GNP } \\
\end{array}$ & $\begin{array}{l}\text { Export \& } \\
\text { of GNP }\end{array}$ & $\begin{array}{l}\text { Arable Land } \\
\text { (sq.km 10-3) } \\
\text { Per Capita }\end{array}$ \\
\hline
\end{tabular}

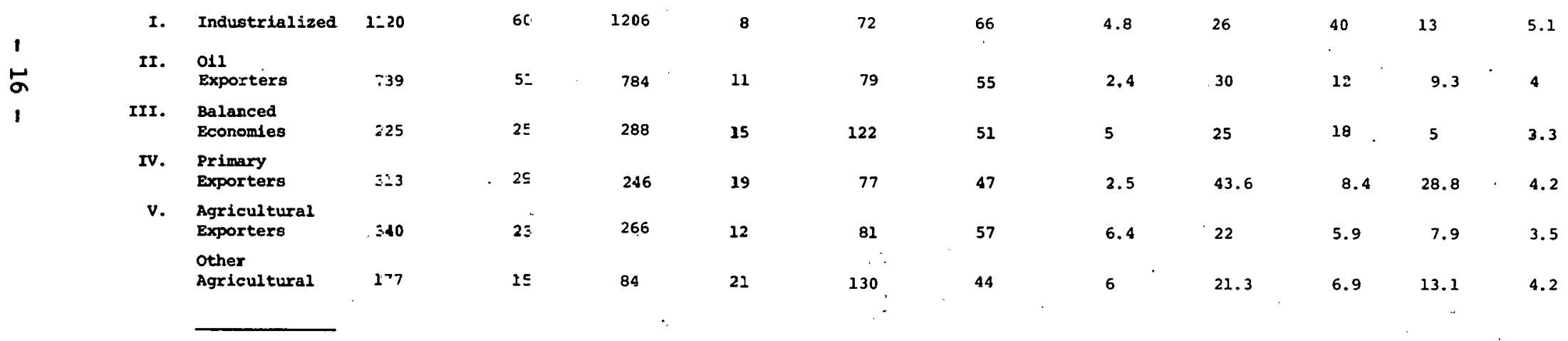

Source: Gordian Assoc. - Population veighted averages of country data. 
exist independently from the traditional urban and rural sectors and, as in other LDCs, the social infrastructure and corresponding services have not increased at a rate commensurate with their economic growth.

As shown in Table B-2 the industrialized LDCs have the highest median GNP per capita $(\$ 1120)$, the lowest crude death rate and infant mortality rate, the longest life expectancy and the most even income distribution of any group. They also have the highest percentage of their populations located in urban areas $(60 \%)$ and, not surprisingly, the highest commercial energy consumption per capita (1206) All, interestingly, are coastal nations with significant trade activities. As in the other oil importing groups, all of the industrialized LDCs consume more energy than they produce. ${ }^{8}$ However, relative dependence on imports and the nature of indigenous energy resources vary considerably.

\section{Current Oil Exporters}

The oil exporting non-OPEC LDCs will be only briefly addressed in this report. A few general points are relevant, however. First, because most of the present non-OPEC oil exporting countries (Oman being the notable exception) face sizable short-term debt service and/or domestic public spending needs, they are likely as a group to press for higher production and exports than does OPEC as a group. Longer-term, their interests are more likely to coincide with those of OPEC.

Second, the group of oil exporters is expected to broaden over the next few years as LDCs receive relatively more exploration emphasis. Potential short-run examples include Argentiná, Guatemala (presuming, as is expected, that the Reforma field extends southward into that country), and possibly coastal countries of French West Africa (e.g., Ivory Coast). Third, the two major (and related) decisions facing each country with potentially exportable oil resources are (1) the rate of development and use (domestic or export) of such resources and (2) the rate and pattern of use of the public (and, to the extent controllable, private) savings represented by the excess of government and company revenues over costs. 
III. "Balanced Growth" Economies (Those in which the industrial sector is relatively developed but not dominant in terms of contribution to GDP).

There are several LDCs which have diverse and relatively substantial resource bases but have not yet developed a specialized infrastructure which commits them to a particular development course. These countries are unique among LDCs in that they are typified by "balanced economies", and consequently have a considerable potential for flexibility in pursuing future development strategies. Most of the countries within the balanced economies category have already completed the primary and intermediate phases of import substitution, and are attemptinq, oreen unsuccessfuily, to embark upon the flnd slaye uf becoming self-sufficient in the heavy industrial sector.

All of the countries in the group are still essentially agrarian societies in that the agricultural sector is of primary importance in determining the economic and social well-being of the population. For example, agricultural production still absorbs well over half of the total work force in India, Turkey, and Pakistan. In addition to direct agricultural labor, the rural sector provides employment opportunities in the service and cottage industries sectors, so that by far the vast majority of the population resides in and is dependent upon the rural economy. Nevertheless, problems with unemployment are severe in the rural sector. This is due in part to the lack of multiple cropping in most LDCs and the resultant disparity between the peak labor requirements of the harvest and the limited need for labor during the remainder of the year. The Indian Bhagavati Unemployment Commission has estimated that among the totally unemployed in $1971,85 \%$ were located in the rural areas. In addition, $87 \%$ of those who worked less than 28 hours per week and $86 \%$ of those who worked less than 14 hours per week were located in the rural sector. 9

IV. Primary Exporters (Countries in which minerals account for the bulk of total exports and are a major contributor to GDP)

As a group, the Primary Exporters vary considerably from the industrialized LDCs and those with balanced economies. Their mean GNP per capita figure (\$313) is considerably lower than the industrialized and balanced economy countries, and they consume considerably less commercial energy. As would be expected, their export figure, as a percentage of GNP, is higher than the other LDCs. While their infant mortality rate is low (77 per 1,000 births), their mean life expectancy is low (47 years). These and other characteristics, however, vary considerably within the group. 
As might be expected, the percentage of GDP which can be attributed to mineral production is generally high and all of the countries export a large amount (60-80\%), if not the total amount, of the minerals produced. Zambia, for example, exported $60 \%$ of its cobalt, $95 \%$ of its copper, 758 of its lead and 608 of its zinc in 1974 .

Although these countries on the whole are not large energy consumers, they still consume more enexgy than they produce. In fact, few of the countries produce any substantial amounts of energy; Surinam, zaire and zambia are exceptions. Most of the energy produced is hydroelectric. Guinea, Jamaica, Liberia, Morocco and Surinam consume all the hydroelectric energy that they produce; zaire almost meets its needs; zambia produces more than it consumes.

v. Agriculturally oriented Economies (Countries in which agricultural output clearly dominates GDP).

This group can be divided into two subcategories: the agricultural exporters and the basic agricultural economies (Other Agricultural).

The agriculturally oriented LDCs run as a belt up the eastern coast of Afxica, across that continent to the tropical countries of Western Africa, comprise virtually all of the Central American nations, and are spotted throughout Asia and South America. Lying between the Tropic of Cancer and the Tropic of Capricorn, climatically they experience a full summer without winter. Mean temperatures of the warmest month are above $20^{\circ} \mathrm{C}$, and for the coldest month are over $13^{\circ} \mathrm{C}$. Rural land use and vegetation is a.mix between tropical woodland and grassland, grazing land including marginal farm land, equatorial forest, arable soils suited to intensive farming, and some areas with deciduous or coniferous forests. Most of the land, area is under shifting or marginal cultivation, and hunting, gathering and primitive cultivation are also prevalent. Nomadic herding is practiced within several of the more northern African nations, and plantation crops are cultivated in dispersed pockets usually located in coastal areas. They are uniformly without significant commercial quantities of mineral resources. 
F IGURE B-1

RELATIONSHIP OF PER CAPITA ENERGY CONSUMPTION TO PER CAPITA GNP

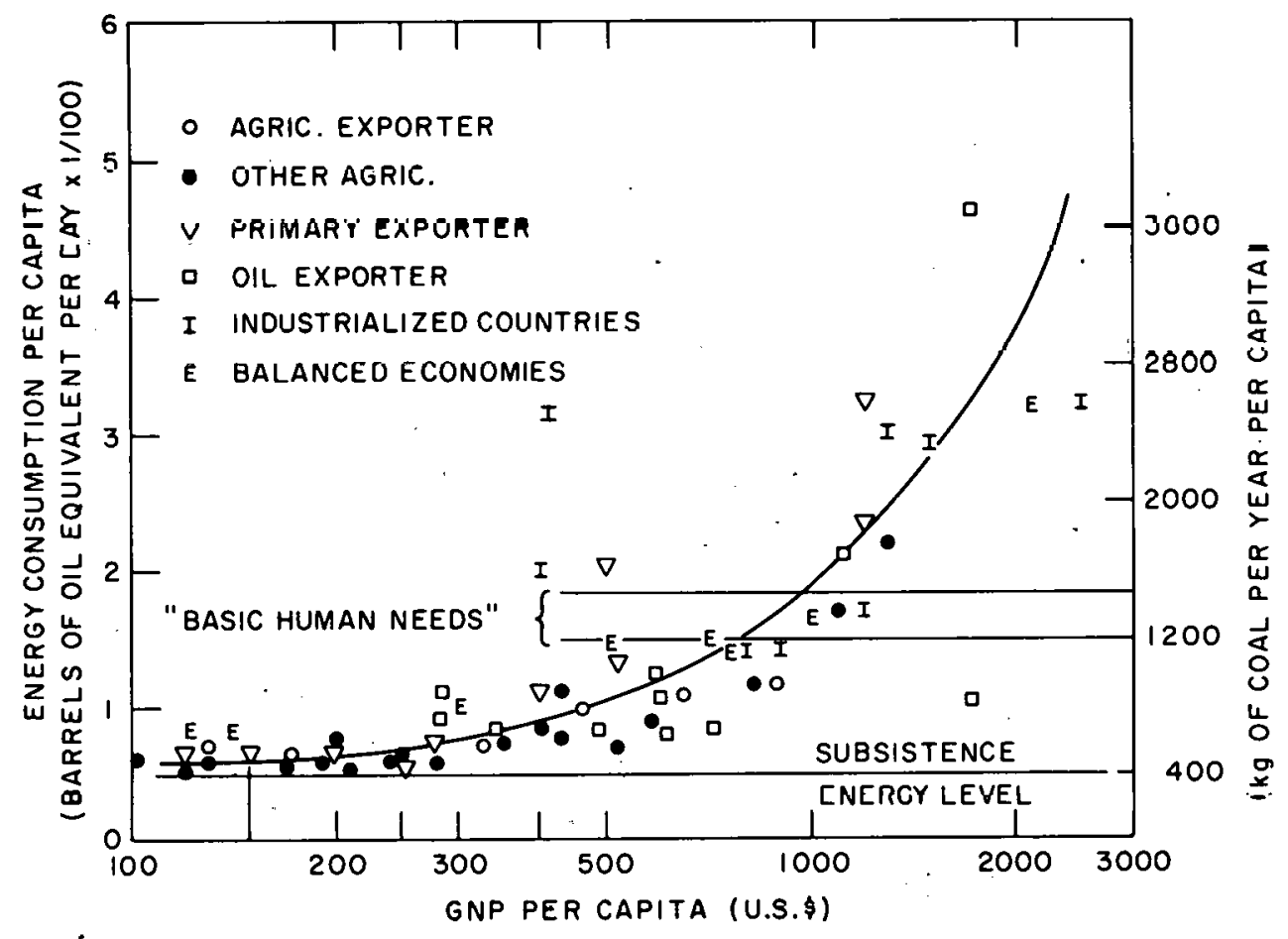

NOTE: An cotimatc of $100 \mathrm{~kg}$ : per year has been added to each country to account for noncommercial energy use. 
Demographically this group has a mean life expectation of 45 years and within these nations one finds the lowest life expectancy for the world. In the Central African nation of Chad the life expectancy for males is but 29 years. Five agrarian African economies have average life spans for both men and women of less than 40 years, seventeen stand with less than 45 years. Only with a few island nations and those in the Americas does this average climb substantially beyond fifty years and into the low sixties. Abysmal as these statistics are, life expectancy and infant mortality have been improving significantly with the attendant familiar result of rapid population growth: $2.4 \%$ per year for the group as a whole.

The bulk of energy consumption by these societies is of noncommercial fuels, primarily wood with some crop residues and animal wastes. The character of this consumption will be discussed in a subsequent section.

As a group, these agrarian economies can be divided into subgroups based on the character of their economies and the classification of some 20 percent of these nations as exporters of agricultural commodities. The structural economic characteristics of all of these nations reflect their limited level of development and a continuing tie to traditional subsistence levels of production. But capital inflows generated by agricultural exports provide their economies with some opportunity to mitigate the more severe impacts that result from the need to import the capital goods and make the investments required to support the growth of their economies. As with the primary (mineral) exporters, however, market price fluctuations have led to "boom or bust" cycles, with a pattern of inflation followed by economic decline.

\subsection{The Current Energy Situation}

Although the non-OPEC developing countries contain 418 of the world's population, they consume only 98 of its commercial energy. However, non-OPEC LDC commercial energy consumption is increasing rapidly, having risen $250 \%$ between 1970 and 1974. Per capita energy consumption for these countries increased 1758 over this period but in 1974 still averaged only 400 kilograms of coal equivalent ( $\mathrm{kgce}$ ) or less than 48 of the U.S. average per capita use. The range of per capita consumption between developing countries is substantially wider than the differences between the country groups, which range from 81 kgce for agricultural non-exporters to $1220 \mathrm{kgce}$ for the industrialized developiny countrics. Individual country per capita energy consumptions 
FIGURE B-2

DISTRIBUTION OF WORLD COMMERCIAL

ENERGY CONSUMPTION

ANNUAL 'PER CAPITA CONSUMPTION

VS. TOTAL POPULATION

(AREA GIVES TOTAL ENERGY)

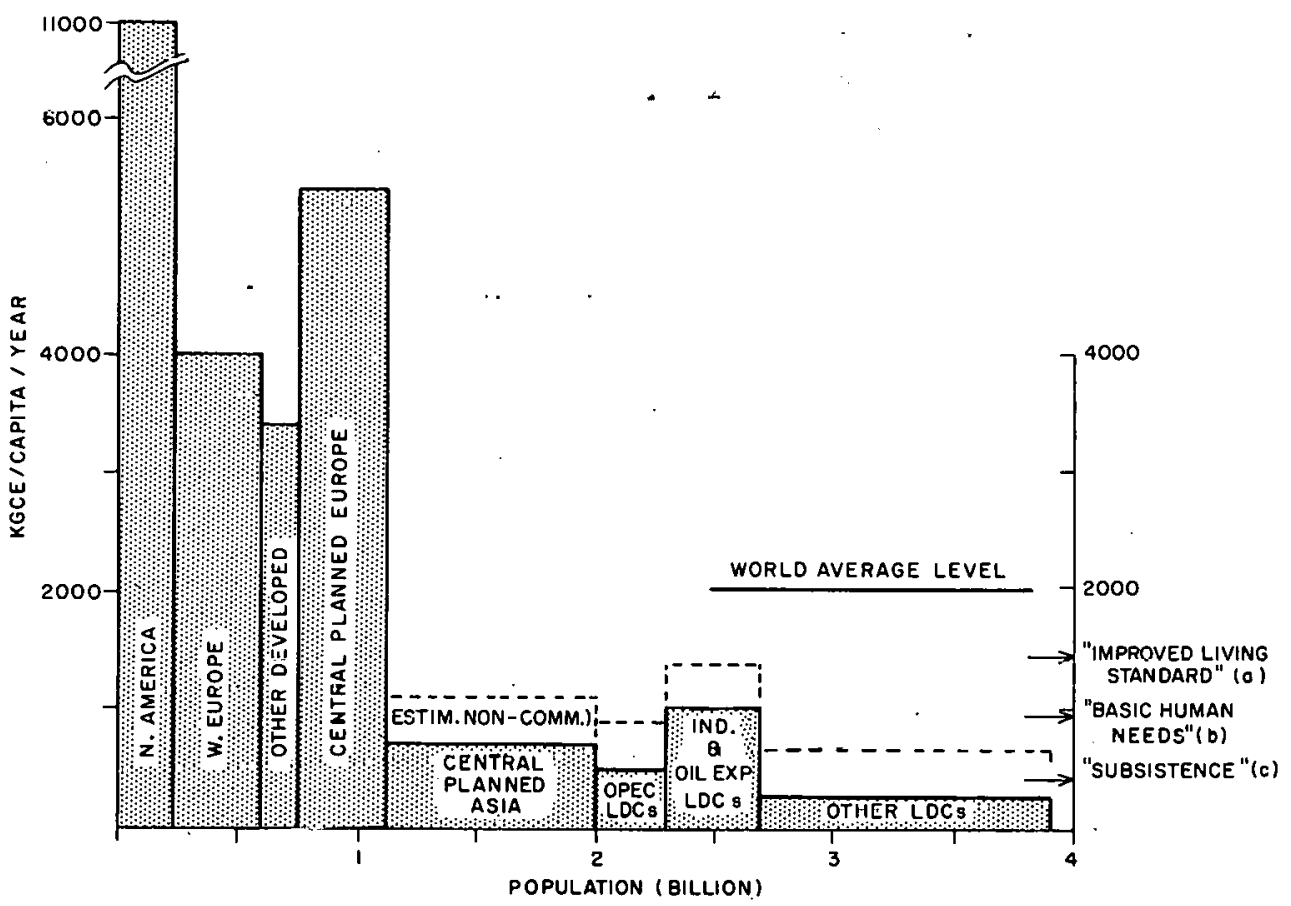

Note: Leviels '(a), (b) and (c) are discussed in Chapter C. 
are shown in Figure B-1. Five of the nine industrialized and one of the eight balanced growth countries had per capita averages above $1000 \mathrm{kgce}$ (three--Spain, Singapore, and Greece--being over $2000 \mathrm{kgce}$ ) while, at the other extreme, twenty of the thirty-eight agricultural economies, one agricultural exporter, and three of the twelve primary exporters had averages below 100 kgce per capita. Three countries--Rwanda, Burundi, and Nepal--had averages of $10 \mathrm{kgce}$ per capita, or less than one-tenth of 18 of the U.S. average. Inclusion of noncommercial primary energy, which accounts for over $90 \%$ of total energy in some low-income LDCs, lessens this gap somewhat: total per capita energy use then ranges from $480 \mathrm{kgce}$ for agricultural nonexporters to 160.5 kgce for industrialized developing countries. Figure B-2 shows energy distribution for the world, indicating the number of people living at various levels of energy consumption. Nearly $3 / 4$ of the world lives at or below a level which

provides "basic human needs" ${ }^{10}$, even when noncommercial energy is taken into account.

\section{Dependence on 0 il}

Besides the relatively low levels of per capita energy consumption and the greater importance of noncommercial energy, there is a third important characteristic of LDC energy use: the high degree of dependence on oil. For the LDCs as a whole in.1975, liquid fuels accounted for $61 \%$ and natural gas $15 \%$ of total commercial energy use; but this is largely because a few very large LDCs (primarily India) have achieved relatively balanced energy economies. Of the oil importing countries, 29 of the 40 African LDCs, 12 of the 20 Western Hemisphere LDCs, 2 of the 3 Mideast LDCs, and 5 of the 11 Asian LDCs depended upon liquid fuels for at least $90 \%$ of their commexcial energy. In only four countries do liquid tuels represent less than b0\% of total commercial energy consumption. India (23\% oil) and Korea ( $48 \%$ oil) have the bulk of LDC coal reserves and have developed coal-oriented energy economies (accounting for $73 \%$ and $51 \%$ respectively, of fuel use.) Pakistan ( $40 \%$ oil) has exploited its natural gas ( $48 \%$ of total commercial energy). while zambia ( $36 z$ oil) has invested heavily to develop both indigenous solid fuels and hydropower (36\% and 28\%, respectively, of total commerrial energy).

In 1975 the oil importing LDCs imported an average of 2.7 million barrels of oil per day or a total annual value, at $\$ 13$ per barrel, of $\$ 12,8$ billion (over 78 of their total export value). At the same time, non-OPEC LDCs have been investing heavily in the development of their energy resources and conversion 
TABLE B-3

STANDARD ENERGY CONVERSIONS

(Equivalent Values Lie in Vertical Colimns)

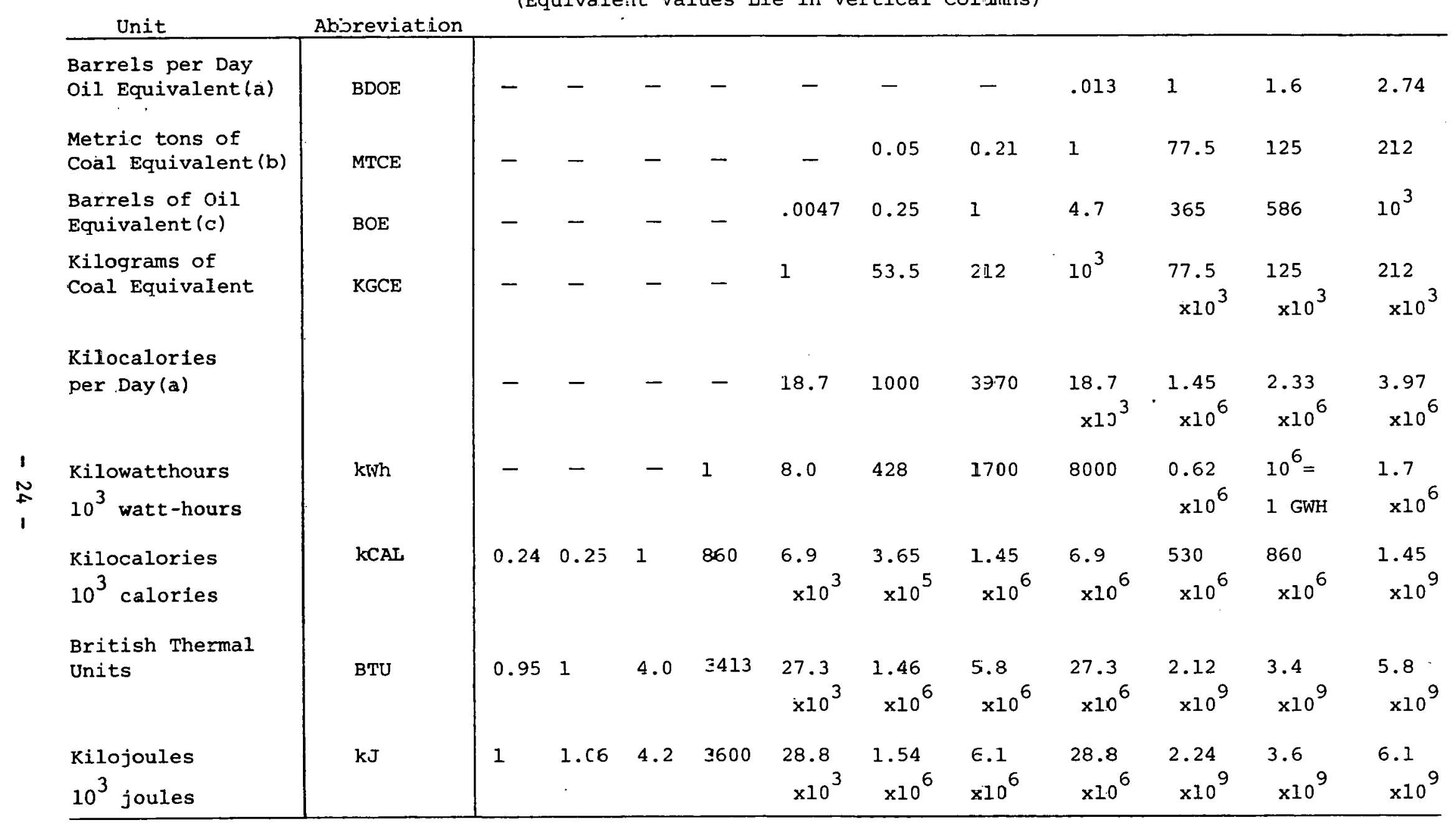

(a) Equivalerts in cther units are shown on a per annum basis. For example, one barrel per day of oil, maintained for a year, equals $2.24 \times 10^{9}$ kilojoules.

(b) One metric ton $=1000$ kilograms $=2202$ pounds $=1.1$ short tons.

(c). One barril of oil $=5.8$ million BTU.

Source: Adopted from Energy Convezsion Equivalents Table, Shell Iiternational Petroleum Co., Ltd. as given in WAES ( $\operatorname{Ref}, 14 \mathrm{I}$. 
capacity. This investment averaged $\$ 4.2$ billion per year (or 7-88 of LDC gross fixed capital investment) over the period 1960-1974, with the largest share devoted to expansion of electric power generation and distribution systems. $^{\text {II }}$

\section{Balance of Payments}

In short, the prospects of the developing nations, which were not bright before the quadrupling of oil prices, have substantially worsened as a result of recent energy trends. Partly as a result of the increased oil import burden, non-oil exporting LDCs have run large balance of payments (current account) deficits, have seen their terms of trade ${ }^{12}$ deteriorate (from an index of 100 in 1970 to 87 in 1976), and have incurred increasing amounts of debt to finance decreasing rates of economic growth. Thus for 76 non-OPEC LDCs, outstanding disbursed public debt increased from 11.98 of GNP in 1974 to 158 of GNP in 1976, while, as a result of this debt increase and the growing importance of private lending at higher interest rates, debt service requirements increased from 8.48 to 108 of total annual export values. $^{13}$ For nine countries, 1977 debt service is estimated to have represented over 208 of export value: Argentina (238), Brazil (538), Chile (378, Egypt (308), Mexico (438), Pakistan (348), Peru (288), Uruguay (318), and zaire (428).

Finally, partly as a direct result of the increased energy financing burden and partly due to lower growth rates in developed countries following the Arab oil embargo, LDC growth rates have slowed substantially. The World Bank estimates that IDC growth rates fell by more than $608-$ from 7.68 to 3.08 between 1973 and 1975, The World Bank also estimates that, for the decade 1975-85, the per capita income of the more than a billion people living in the low-income LDCs will increase by only 208 (from $\$ 150$ to $\$ 180$ ) even under very optimistic assumptions regarding increases in official development assistance to the U.N. target level, combined with trade liberalization; and other measures. 
LDC COMMERCIAL ENERGY CONSUMPTION ASSUMPTIONS CURRENT TRENDS CASE

Annual GNP Growth Rate: ${ }^{(a)}$

\section{Industrial and Balanced Economies}

1975-1990

1990-2020

\section{5}

4.4 .
Primary Exporters and Agricultura1 Countries

\section{6}

2.8
Oil

Exporters

6.3

5.4

Income Elasticities of Demand by Type of Commercial Energy:

\section{(b)}

Industrial and

Oil. Exporting
Balanced Economies and

Primary Exporters
Agricultural Countries

$\underline{\text { OIL }}$

1.975-77

1977-90

1990-2020

ELECTRICITY
.88

.85

.82
1.1

1.04

.98
.85

.90

.96

$\begin{array}{llll}1975-77 & 1.15 & 1.6 & 1.8 \\ 1977-90 & 1.09 & 1.52 & 1.7 \\ 1990-2020 & 1.03 & 1.43 & 1.6\end{array}$

NATURAL GAS.

1975-77

$1977-90$

1990-2020

COAL
1975-77

$1977-90$

1990-2020
1.0

.97

.94
1.2

$1.1 \%$

1.13
1.0

1.03

1.06

Price Elaoticity of Demand for Total Commercial Energy: ${ }^{(c)}$

$$
\text { All country groups }-.3
$$

(a) Source: WAES (Reference 14), based on average of WAES High and Low estimates extrapolated to 2020 .

(b) Gordian Assoclates Inc., based on World Bank (Reference 21) elasticity estimates for oil and gas and World Bank staff estimates for coal and primary electricity.

(c) Based on World Bank staff analyses to be published In mid-1978. 


\section{PROJECTIONS OF LDC ENERGY DEMAND}

\subsection{Introduction}

It is a risky time to make predictions of future energy demand--even for countries where economies are mature and understood and for which there are adequate data. For the LDCs neither of those conditions prevail and our estimates of future energy consumption should be treated as a means of adding some quantitative dimensions to a set of problems in order to understand them better rather than as predictions of the future.

We have proceeded to estimate future energy demand for both commercial and noncommercial fuels for each of the country groups. Commercial fuel demand was estimated based on assumed GNP growth rates and correlations between energy demand, GNP growth and energy prices. Noncommercial consumption was estimated on necessarily very crude estimates of minimum subsistence requirements.

\subsection{Basis for Projecting Commercial Energy Demand}

For each of the IDC country groups we have projected future demand for "commercial primary energy" : oil, natural gas, coal and primary electricity (hydropower, nuclear, geothermal and solar) ander the assumption that there is a continuation in current trends of economic growth and the relationship between that growth and energy consumption. The assumptions used for this "current trends" case are summarized in Table B-4. The primary sources of

data are the Workshop on Alternative Energy strategies ${ }^{14}$, Gordian Associates ${ }^{15}$, and The World Bank ${ }^{16}$

For each country group actual 1975 fuel consumption was used as the starting point. The income elasticities of energy demand shown in the table are the ratios of the assumed expected growth rates for specific fuels to the assumed GNP growth rates. 17 These income elasticities were derived on the basis of the historical development experience of individual countries (time series) and the relationship between countries at different levels of economic growth (cross-sectional). The trends in income elasticity over time take into consideration the fact that income elasticity of oil and gas consumption generally tends to rise as per capita income levels increase from "low" to "middle", then typically decline as income rises to higher levels. Income elasticity of demand for coal were derived from future year consumption estimates. 
TABLE: B-5

ASSUMFTIONS USED IN OTHER LDC COMMERCIAL ENERGY PROJECTIONS

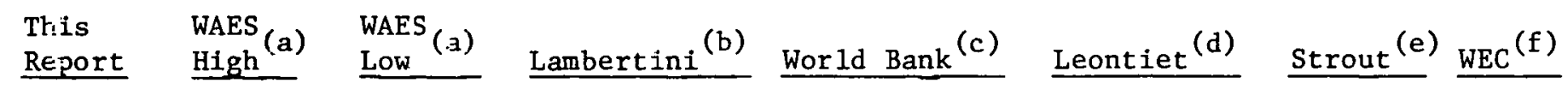

1. Annual GNT

growth rates

$1975-85 / 90$

$1985-2000$

3. $6 .-6.2 \%$

$2 . \varepsilon-5.4 \%$

$4.4-7.2 \%$

$2.8-5.5 \%$

$4.5-5.5 \%$

$2.1-6.5 \% \quad 2.5-4.2 \%$

$4.1-7.6 \%$

$\{5.4-7.1 \%\} 5.48$

2. Per Capita

GNP growth

$1975-85 / 90$

1985-200C.

$\begin{array}{lll}0.9-3.8 \% & 1.7-3.7 \% & 0.2-1.7 \% \\ 0.4-2.9 \% & 0.8-2.3 \% & 0.2-1.4 \%\end{array}$

$0.8-2.3 \% \quad 0.2-1.4 \%$

$1.7-4.6 \%$

$\{3.1-4.9 \% \quad\} 2.9 \%$

3. Income Elasticity

of Demand

of

$.8-1.1$

-Gas $.0-1.2$

-Coal .

-Primary Elec. 1-1.8

-Total Primary

Energy

$1.05-1.3 \quad 1.0-1.2$

$.85-1.1$

$$
1
$$

$1.15-1.8$

$1.3-1.7$

$0.8-1.2$

1.2

1.1

4. Price Elasticity

of Demand

$-0 i 1$

$-.3 \quad-.14$

$-.27$

$-.05-(-.11)$

-Total Primary

Energy

$-.3$

$-.01$

$-.1 .3$

$-.3$

1.26

1.44

0.89

- $\quad+---\ldots$

(a) WAES (Reference 20:

(b) World Bank, Lambertini (Reference -6)

(c) World Bank (Reference 2l)

(d) Leontief/U.N. (Reference 22)

(e) A. Strout/M-T (Reference 23)

(f) World Energy Conference 1977 (Reference 24) 
The assumption was then made that energy prices would increase in real terms by $50 \%$ by 2000 and $100 \%$ by 2020. A price elasticity of demand (ratio of the percentage change in energy demand to the percentage change in energy price) of -0.3 was used to reduce total commercial energy demand in the future reference years.

In a number of ways these assumptions are conservative, leading to a low estimate of future LDC energy demand. As shown in Table B- 5, our assumed GNP growth rates are on the low side of World Bank and other estimates. Furthermore the income elasticities that we have used are on the low side compared to the other values in the tables of Leontief and the World Bank and other recent estimates. Finally, we have applied a generous price elasticity of demand.

\subsection{Basis for Projecting Noncommercial Energy Demand}

Later in this report there is a detailed discussion of noncommercial energy, its role in subsistence and development, and the shortcomings of data and projections. Though a few studies have attempted to draw together the disjointed and thoroughly inadequate information available on noncommercial fuel use, they provide no real basis for an estimation of current noncommercial energy use. For the purposes of this report we have assumed that the per capita use of noncommercial energy is 400 kilograms coal equivalent per year. This corresponds to about a ton of wood a year, or the equivalent of a 3 inch lump of coal per person per day. ${ }^{18}$ other estimates in the literature range from slightly less to several times the value used here for per capita consumption. Since cooking is an absolute necessity and it is known to be provided by noncommercial fuels, this per capita consumption level is almost assuredly conservative. The assumed population growth rates used to project noncommercial demand into the future are given in Table B-6 for each country group. 19 


\begin{tabular}{|c|c|c|c|c|c|c|c|c|}
\hline & \multicolumn{8}{|c|}{ TABLE B-6 } \\
\hline & \multicolumn{8}{|c|}{$\begin{array}{l}\text { POPULATION GROWTH } \\
\text { (millions) }\end{array}$} \\
\hline & & 1975 & 8 & 1990 & $\frac{8}{8}$ & 2000 & $\frac{8}{1}$ & 2020 \\
\hline I. & Industrial & 262 & 2.5 & 380 & 2.4 & 480 & 2.3 & 760 \\
\hline II. & Oil Exporters & 134 & 2.5 & $194^{\circ}$ & 2.5 & $230^{\circ}$ & 2.4 & 4010 \\
\hline III. & Balanced & 784 & 2.5 & 1140 & 2.4 & 1445 & 2.3 & 2280 \\
\hline IV. & Primary Export & 61 & 2.5 & 88 & 2.4 & 110 & $2.3^{\circ}$ & 180 \\
\hline v. & Agriculture & 398 & 2.7 & 600 & 2.6 & 770 & 2.5 & 1260 \\
\hline & Total & 1640 & 2.6 & 2402 & 2.6 & 3055 & 2.5 & 4880 \\
\hline
\end{tabular}




\subsection{Total Projected Energy Demand}

The projected energy consumption for the various country groups is shown in Table B-7 and Figure B-3. Three groups of fuels are distinguished: oil, other commercial energy forms (natural gas, coal and primary electricity) and noncommercial fuels. Under the assumptions described above the total commercial energy demand of the non-OPEC LDCs increases from 9.1 million barrels per day of oil equivalent (MMBDOE) in 1975 to 26 MMBOE in 2000--a threefold increase over the period--corresponding to an annual rate of increase of $4.3 \%$ per year. Estimated LDC demand for oil in the year 2000 is 14.4 MMBDOE, which is near the total U.S. 1976 petroleum consumption of 17 MMBDOE.

In 2000, industrialized LDCs account for 438 and "bälanced growth" countries another 268 of total IDC oil demand. Their respective shares for 1975 were 458 and 248 . LDC oil use grows substantially despite a projected threefold increase in coal use, in primary electricity (which since it implies a much more dramatic rise in nuclear power, may be unrealistic), and in natural gas as well. Oil is projected to account for 558 of cammercial primary energy use in 2000--if that much is available. Thus, the rise in IDC demand for oil is not the result of lack of development of alternative conventional energy sources. Noncommercial energy still accounts for 388 of the total even though conservatiyely estimated.

Finally, it is important to note that, even given the above growth rates, non-OPEC LDCs still will account for only a fraction of projected worldwide energy consumption in 2000. "WAES" estimates to 2000 yield a range of total commercial energy consumption by the "World Outside Communist Areas" (WOCA) of from 160 to 207 MMBDOE. Projected non-OPEC LDC consumption thus would equal 20-268 of WOCA commercial energy consumption compared to a current share of 188 .

The distribution of future per capita energy consumption in the non-OPEC LDCs is shown for the "current trends" case for 2000 in Figure B-4 where it is compared with the current distribution. Under these assumptions, it is only the industrialized and oil exporter groups who make significant 
TABLE $B-7$

PROJECTED ILEC ENERGY CONSUMPTION CURRENT TRENDS CASE.

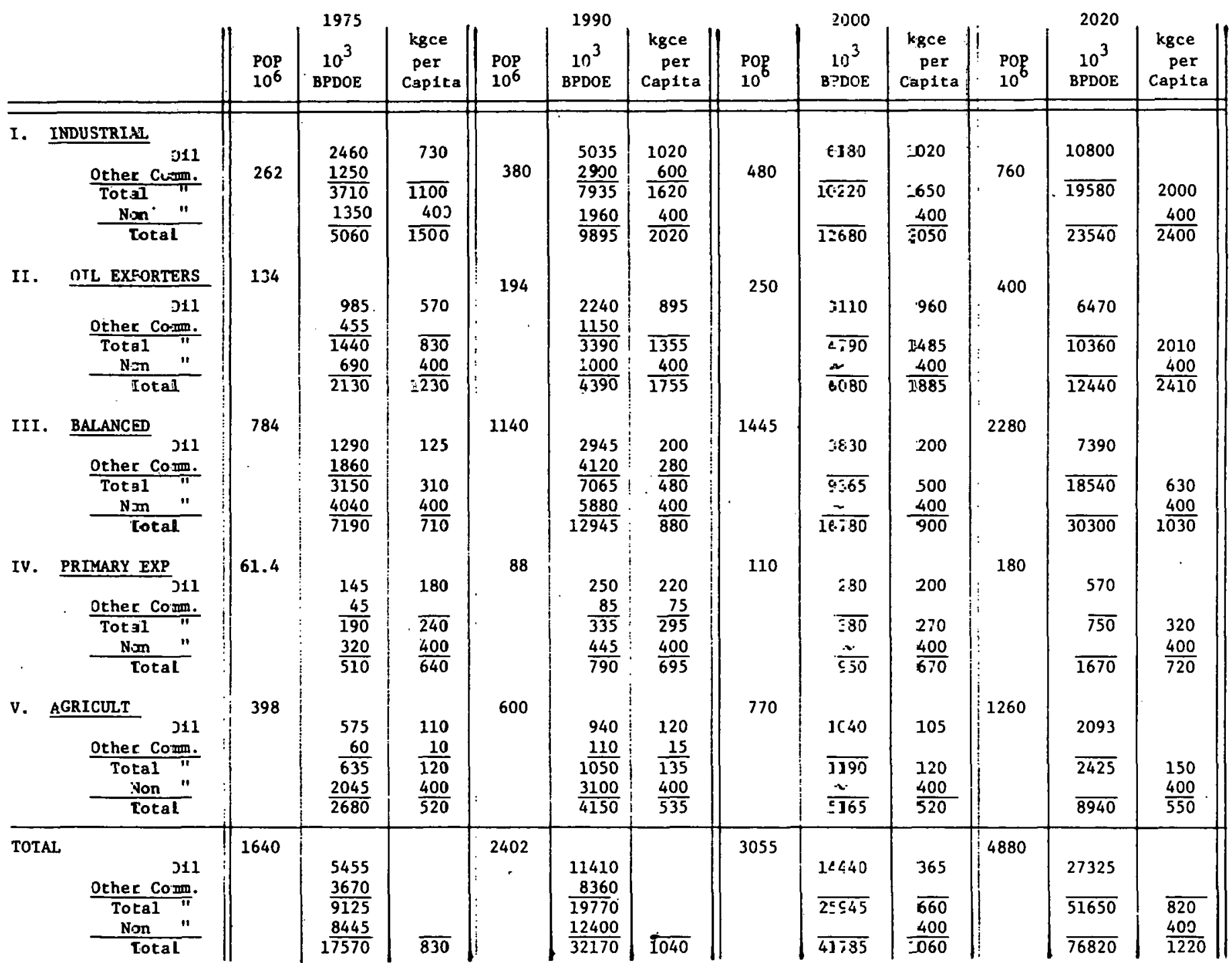


FIGURE B-3

TOTAL ANNUAL ENERGY CONSUMPTION PROJECTIONS BY LDC COUNTRY GROUPS (CURRENT TRENDS CASE)

(MILLION BARRELS PER DAY OIL EQUIVALENT)

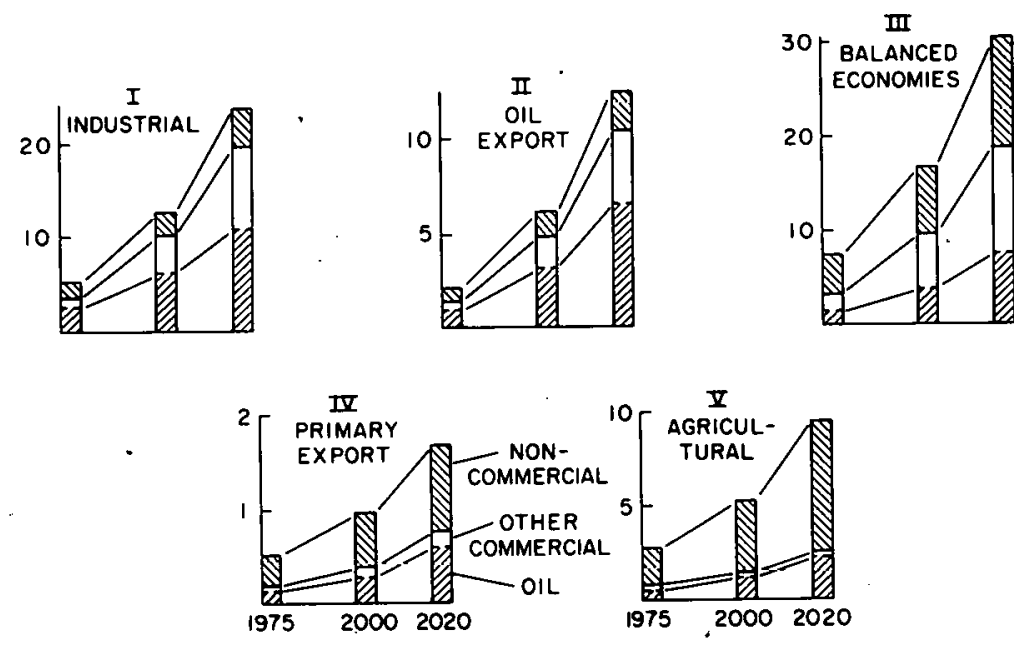

FIGURE B-4

ANNUAL PER CAPITA ENERGY

CONSUMPTION VS. TOTAL POPULATION

(CURRENT TRENDS CASE)

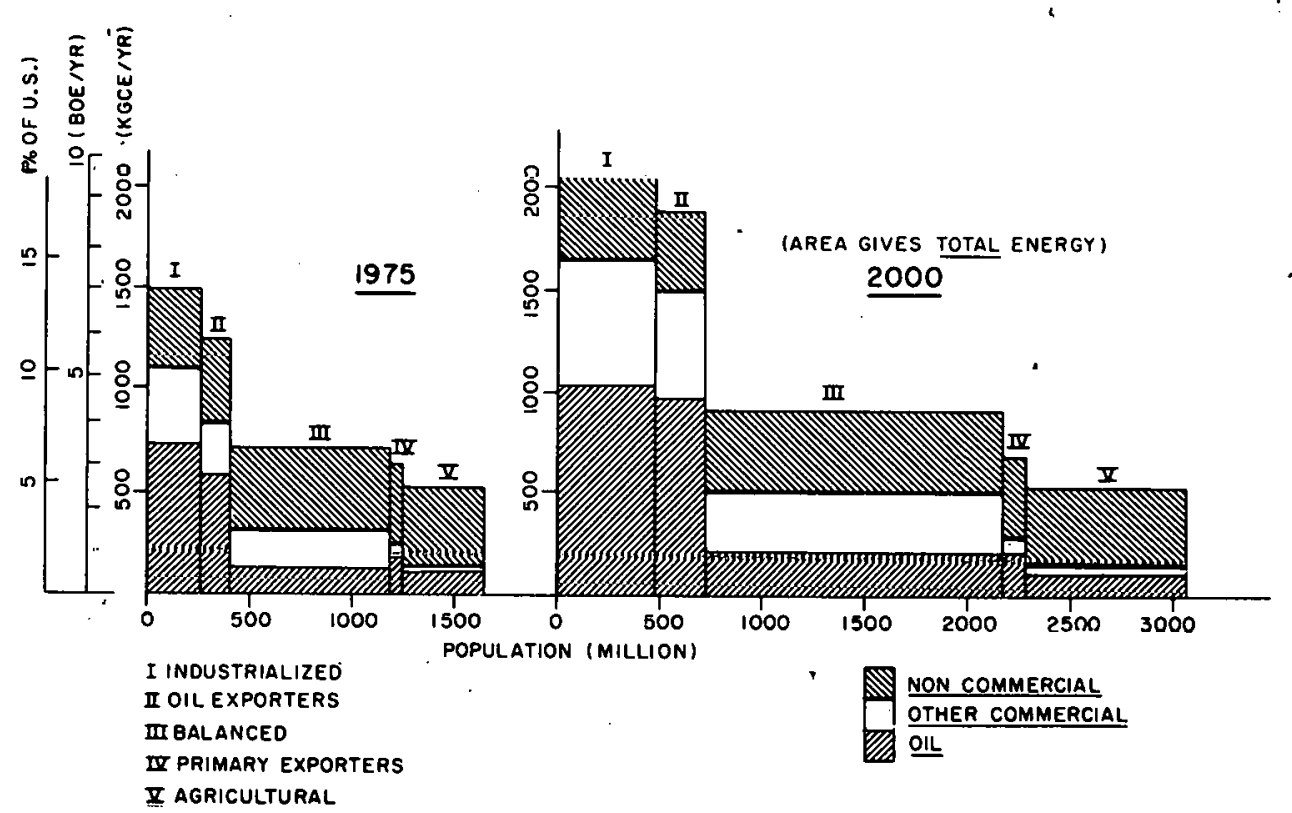


TABLE, $B-8$

TOTAL COMMERCIAL ENERGY DEMAND PROJECTIONS FOR THE YEAR 2000

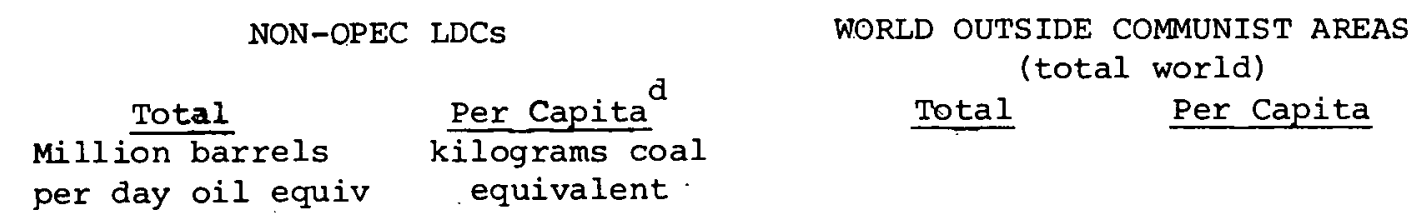

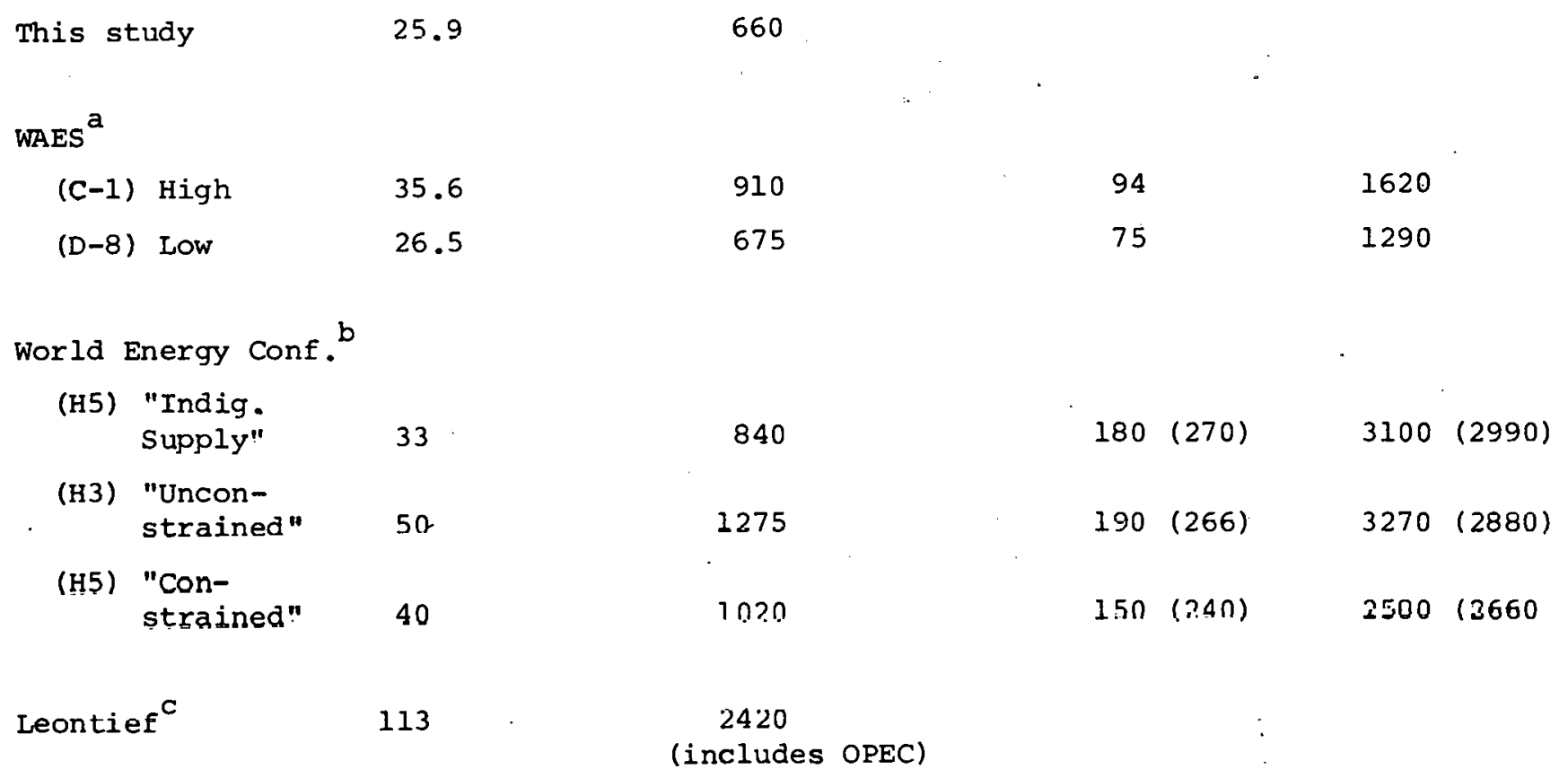

a Refictule 14
b Reference 24
c Reference 22
a Population assumptions:
$\quad$ Non-OPEC LDCs 3.1 billion
$\quad$ WOCA
World


progress on a per capita basis. For the other groups, energy growth is due solely to increasing population.

Even for the most advanced groups, however, the anticipated per capita consumption in 2000 is small compared to the developed countries. The 2000 kgce per year typical of the industrialized and oil exporting LDCs in 2000 is a mere $15 \%$ of the present U.S. per capita consumption. To raise the energy budget of all of the developing world to 158 of the U.S. per capita level would require almost twice as much energy as our "current trends" scenario anticipates. In Table B-8 we compare our projections of total and per capita energy demand with those of other sources. The table underlines the conservative nature of these projections.

3. WORLD AND IDC ENERGY SUPPLY

\subsection{Future World Oil Supply}

The future supply of oil on a worldwide basis is a subject of active conjecture and debate, but the debate can be carried out in only the most approximate quantitative terms. Current estimates of ultimate recoverable conventional petroleum resources range between 1200 and $2500 \cdot$ billion barrels with an "average" estimate of around 1800 billion barrels. 25 This estimate considers that the present recovery rate of $25 \%$ increases to 408 by the end of the century. If "unconventional sources" loil fram offshore depths greater than 200m, tar sands, oil shale," etc.) are included the total rises to about 2000 billion barrels.

With regard to the rate of additions to resources most experts are relatively optimistic in the near term, anticipating a rate of around 25-30 billion barrels per year. (68-82 MMBD). 25 Additions to reserves in 1977 were 50.4 billion barrels, a rate which most experts do not feel can be sustained. Roughly half of these gross discoveries would derive from reevaluation of old deposits based on the prospective use of enhanced recovery techniques. The WAES study ${ }^{14}$ estimated additions to reserves over a longer term to range from a "low" of 10 billion barrels per year to a "high" of 20 billion barrels. To place these numbers in perspective, it can be noted that the former would correspond to the discovery of one Alaska every two years, the latter a North Sea every two years. Put in other terms, were a discovery rate of 20 billion 
barrels to be maintained each year until the year 2000, the total oil discovered would represent an amount equal to the entire OPEC reserves remaining at the end of 1975 .

The ultimate limit on world oil resources means that there must be a peak in production at some time in the future. The exact time of this peak depends on a variety of factors including the total recoverable resources, discovery rates, technical limits on the ratio of production to reserves, the developmental policies of the large producers and other factors. Under a range of assumptions on these factors, and assuming a total resource base of 2000 billion barrels, virtually all estimates show world oil production peaking before 2000. By the year 2020, under most reasonable hypotheses, production will be considerably less than it is today.

By the year 2000 the range of possible world oil production levels is very wide. For the noncommunist areas, the WAES study identified a range between 55 and 70 million barrels per day. "The "unconstrained" world demand for that oil in 2000 was estimated at 75-90 million barrels per day indicating that a supply-demand adjustment process, ostensibly operating through the mechanism of higher oil prices would occur well before that time. Thus in the post 2000 period, at the latest for most countries (the exception being those with extremely large oil resources), a central challenge will be to convert their energy systems from an oil basis to other, presumably renewable, fuels.

\subsection{Future Commercial Energy Supplies to the LDCs}

Projections of aggregate world energy supplies are difficult and uncertain. Projecting supplies for individual country groups, such as the non-OPEC LDCs is even more difficult, and even more uncertain than demand projections. For commercial energy supply, these uncertainties are of two kinds. First, estimates of proven reserves and projected future additions to reserves are 
subject to immense variability. Much of the developing world has not been well explored, and "finds" are sudden. Smooth rates of growth do not provide a good model of reality. Secondly, production is far from assured even for already proved reserves. Production and distribution requires capital, skilled manpower, and infrastructure. The fraction of reserves that actually will be exploited by a given time is thus problematic.

Today in Mexico and the Middle East a large amount of natural gas produced in association with oil is burned (or "flared") as it is produced; testimony to lack of storage, utilization, or distribution facilities, and ample demonstration of the difference between reserves and production. As a result, most analyses of energy supplies in the LDCs have been limited to consideration of future supplies on the basis of large groups of countries, and to discussions of annual additions to proven reserves, then utilizing simple ratios of reserves to annual production. In the WAEs ${ }^{14}$ study, for example, LDCs were simply divided into two groups: OPEC and non-OPEC developing countries. Two assumptions were then made regarding annual finding rates of 2 and 4 billion barrels per year for the non-OPEC LDCs and annual production by this entire group has been estimated on this basis. The low finding rate permits an annual production of $6 \mathrm{MBD}$; the higher figure allows a production of almost $12 \mathrm{MBD}$. Although these figures represent 428 and 838 of the projected aggregate non-OPEC LDC oil demand given in the previous section, the numbers are misleading, for as the WAES study goes on to note, "most of this production is likely to be limited to a few countries." (These are the countries classified as oil exporters in Table B-1.) It has been estimated that "three countries--Mexico, Brazil and Egypt--could account for as much as $40 \%$ of total non-OPEC developing country oil production by 1985. 27 clearly the oil produced in those countries, beyond their own needs, will not necessarily flow to other non-OPEC LDCs. Much of the "excess!" production in Mexico, for example, will probably go to the US. Thus, the conceptual model which groups the supply pirospects of various countries together--imposed by the impossibility of allocating projected discoveries 
TABLE B- 9

INDIGENOUS PRODUCTION OF COMMERCIAL ENERGY

MILIION BARRELS PER DAY OIL EQUIVALENT

(1975)

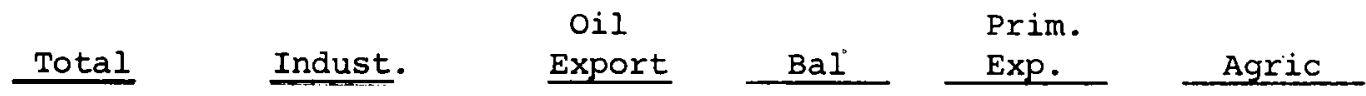

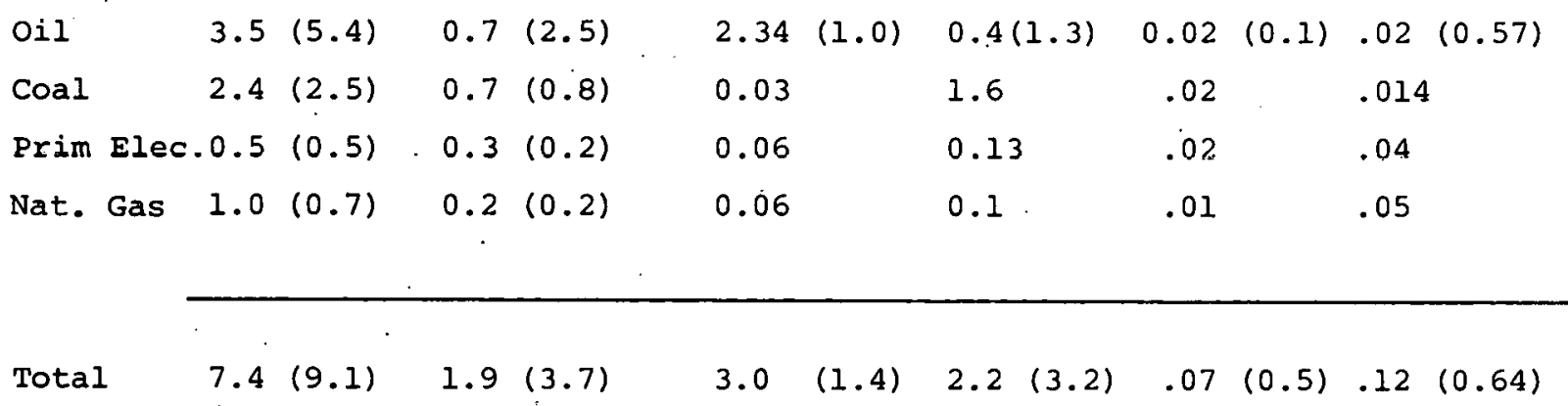

Consumption figures from Table $B-7$ in parenthesis

Source: Gordian Associate, using U.N. "World Energy Supplies 1y/1-1975". 
to individual countries--can give an overly optimistic assessment of the supply-demand picture for individual countries. Even larger uncertainties apply to estimates of additions to coal and natural gas reserves because of the almost complete lack of exploration for coal and natural gas over the period when oil prices were low.

In the remainder of this chapter we describe the current situation with respect to development of commercial and noncommercial energy resources in the non-OPEC LDCs. Given the impossibility of creating credible projections of supply we then concentrate on those elements--primarily economic-which will determine whether available resources are indeed produced.

As a point of reference, Table B-9 summarizes current production levels for the various country groups.

\subsection{Oil Reserves and Future Production}

The most important determinants of oil production in the non=OPEC LDCs through 1980-90 will be the size and location of proven reserves and current trends in production. To some extent this will be influenced by the world supply-demand situation, government policies regarding restrictions on "production, and the participation of foreign companies. Beyond 1990, potential production will also depend on the actual resources base as it emerges, oil exploration drilling costs, and the prevalling economics of recovery and exploitation, policies of private and international lending institutions, and the financial positions of the individual countries.

Proved Crude Oil Reserves, Production, and Additions to Reserves

As shnwn below in Table B-10, some 78 of the world's present proved crude oil reserves, or 44 blllion barrels, is in non-OPEC LDCs. of the reserves in non-OPEC LDCs, 34 billion barrels or $7.7 \%$ are in oil exporting countries. This group also accounts for over 708 of non-OPEC LDC production. Two countries, Mexico and Oman, account for 468 of non-OPEC LDC reserves; these two countries plus Egypt account for 418 of production. 
TABLE B-10

WORID SHARE OF ESTIMATED PROVED CRUDE OIL RESERVES AS OF $1 / 1 / 78$

Billion Barrels Percent

Non-OPEC LDCs

44.0

7

LDC Oil Exporters

33.8

(5)

Balanced Economies

5.5

(1)

Industrilized

4.4

(1)

Primary Exporters

.2

Agricultural Exporters

.02

Basic Agricultural

.02

Developed Countries

63.9

10

Communist Areas

98.0

15

OPEC

439.9

68

Total

645.8

100

Source: Gordian Associates (Reference 28)

TABLE B-11

WORLD SHARES OF ADDITIONS TO ESTIMATED CRIJNE OIL RESERVES BETWEEN 1/1/77 AND 1/1/78

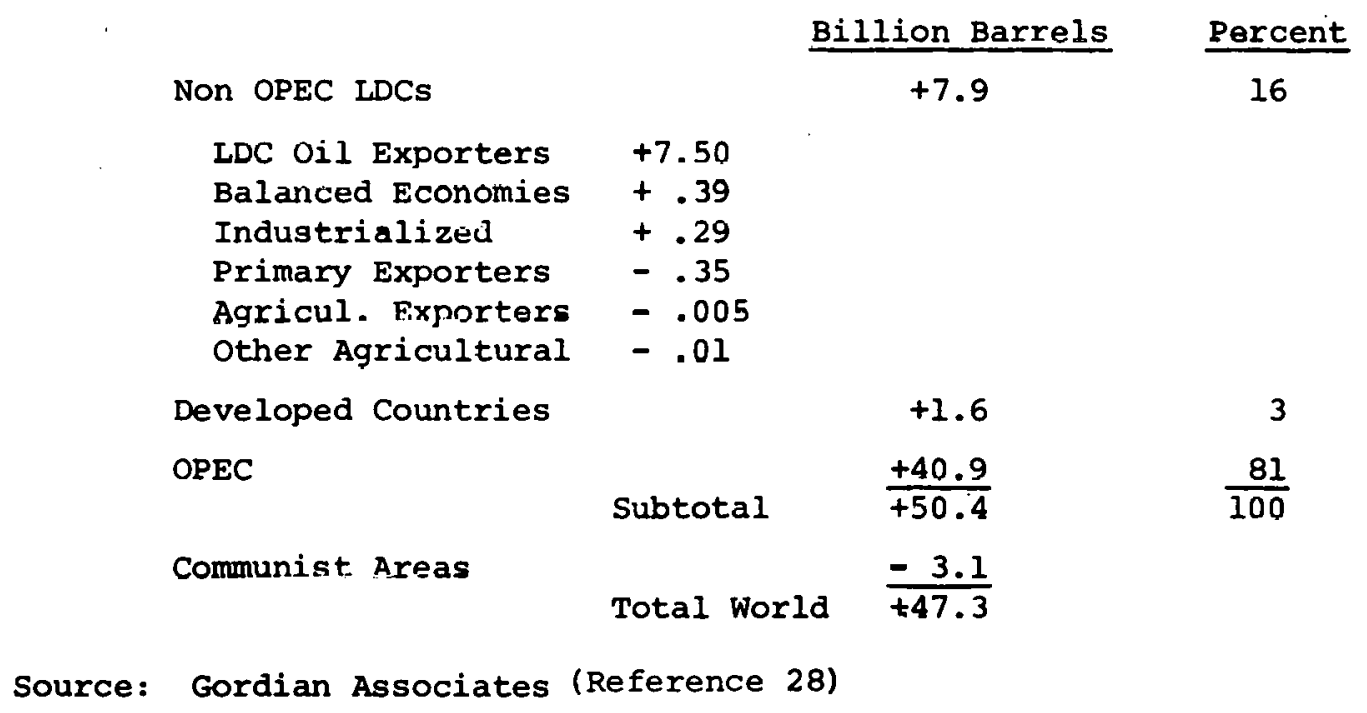


TABLE B-12

DRILLING DENSITY IN OIL-EXPORTING LDCS
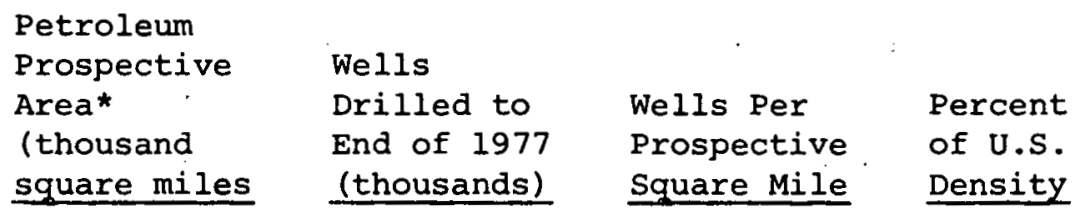

$\begin{array}{lrr}\text { Mexico } & 435 & 18.6 \\ \text { Oman } & 60 & .5 \\ \text { Tunisia } & 83 & .3 \\ \text { Egypt } & 355 & 1.4 \\ \text { Malaysia } & 91 & .4 \\ \text { Syria } & 40 & .3 \\ \text { Brunei } & 6 & 1.5 \\ \text { Angola } & 45 & .6 \\ \text { Trinidad/Tobago } & 13 & 9.2 \\ \text { Congo } & 31 & .1 \\ \text { Bolivia } & 254 & .9 \\ \text { Bahrain } & 0.3 & .2 \\ \text { Source: Gordian Associates, Inc. } & \text { (Reference 31) }\end{array}$

TABLE B-13

GAS PRODUCTION 1977 (Jan. - Oct.)

Billion Cubic Feet

Non-OPEC LDCS

Oil Exporters

Balanced Economies

Industrialized

Primary Exporters

Agricul. Exporters

Other Agricultural

Developed Countries

OPEC

Communist Areas

World Total
2305

1448

201

523

24

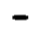

108

24106

3897

12952

43350
.045

$.008 \quad 1$

.004 . 0.4

$.004 \quad 0.5$

$.004 \quad 0.6$

.0081

$.25 \quad 32$

.0132

$.71 \quad 90$

$.003 \quad 0.4$

$.004 \quad 0.5$

$.67 \quad 85$

.4
0.5
.6
2
0
0.4
0.5




\section{Distribution of Oil Resources Among Countries}

Table B-11 lists the 1977. additions to estimated oil reserves. While the non-OPEC LDC share of 1977 additions to reserves suggest their share of total proved reserves is increasing, virtually all of their additions were due to Mexico's (conservatively estimated) addition of 7 billion barrels to its proved reserves. Of the eight other LDCs whose contribution was 0.1 billion barrels or more, all were small compared to Mexico. 29

Drilling Densities and Wildcat Success Rates

As noted above, geologically advantaged locations, drililing densities, and trends in wildcat success all enter into the projections of non-OPEC LDC oil reserves and production.

While OPEC countries have 4 million square miles of petroleum prospective area (sedimentary basins onshore plus offshore to 200 meters depth) and the US 3 million, the non-OPEC developing countries as a whole have some 13 million square miles, distributed as follows: Latin America, 4.5 million; Africá, 3.6 million; Mideast, 2.8 million; and Asia, 2.0 million.

Within each of these areas, however, the drilling density (the total number of wells drilled in this century per square miles of petroleum prospective area) averages only 18 of U.S. drilling density (African and Mideast LDCs, 0.18; Asian LDCs, 0.78; and Latin American LDCs, 28).

In fact as shown in Table B-12, only three of the oil-exporting LDCs have drilling densities comparable to the US: Trinidad/Tobago (908 of US), Bahrain (858), and Brunei (328). Mexico, where considerable reserves additions are expected, has had only 58 of US density. Similar densities hold for Argentina, French West Africa, and other areas of growing interest. Non-OPEC IDCs as a whole also improved their wildcat well success rates eight percentage points between 1975 and 1977 (from 228 to 308). Oil 
exporters drilled 55 successful exploratory wells for a success rate of 478 . LDC balanced economies improved their rate to 408 from 15\%, while other agricultural LDCs improved their rate to 258 from 108 (with completions in Cameroon, Chad, and Tanzania). Industrialized economies, primary exporters, and agricultural exporters, however, remained constant or declined slightly. Both the LDC oil exporters and the balanced IDC economies exceeded the world average of $30 \%$. Particularly high success rates were achieved by Angola ( $80 \%$, Brunei (64\%), Tunisia (67\%), and Peru (498).

While these data reinforce the suggestion of a number of geologists that proven oil reserves in the non-OPEC LDCs will. undergo a dramatic increase should the density of drilling increase, they also make evident the fact that some of the poorest of these countries may not share in such finds. They also suggest that incentives to international oil companies to drill will play an important role in. increasing proven reserves. It should further be noted that the above figures do not include the potential contribution of small oil deposits which in the past have not been considered economic (defined as deposits containing less than 10 million barrels of oil with an assumed rate of recovery of 338). Such "stripper" wells, which produce only a few barrels of oil per day, have contributed $17 \%$ of total us crude oil to date. ${ }^{30}$ up to now a deliberate search for small deposits has not been made. Their discovery is associated with search for large deposits. Should exploration and drilling techniques undergo substantial improvement and the price of oil increase there would seem to exist considerable potential for such wells to produce oil in significant amounts for some of the non-OPEC countries with more modest energy demands.

\subsection{Natural Gas}

The non-OPEC developing countries as a group produced 6.6 billion cubic feet per day of natural gas in 1977, or 58 of world production. This compares with OPEC's 98 and the advanced industrial countries share of 568 . Huge quantities produced in association with crude oil are still flared or reinjected into oil fields to maintain pumping pressure. As shown in 
Table B-13, gas production in these countries is somewhat more uniformly distributed than oil among the different country groups, the two exceptions being the primary and agricultural exporters.

Non-OPEC IDCs added 26.9 trillion cubic feet (TCf) to their natural gas reserves in 1977 which was $15 \%$ of world additions, and the non-OPEC LDC oil exporters account for $88 \%$ of this addition to reserves and have a ratio of reserves added to production of 15.9 By contrast, developed countries reserves declined by 9.2 Tcf. (See Table B-14.)

Most gas jiolucliun in these countries is remote trom population centers where it might be consumed. These urban areas, moreover, lack lines to distribute the gas. These pipeline networks are not only capital intensive but can be justified economically only where there is some assurance there will be a supply for years to come. Long distance transport costs for natural gas in liquified form are also high. Increased shortages in the U.S. and some other developed countries where natural gas is highly valued as an environmentally clean fuel are likely to lead to greater willingness to pay higher prices for imported gas. This has renewed interest in long distance gas export projects.

The usefulness of natural gas in most of the non-OPEC developing countries is not likely to be limited by supply in the near future. Over a longer period of time, however, as intra-country pipelines are built and consumers shift to this fuel, shortages are likely to result. The major question facing most developing countries in this group, therefore, is whether or not to risk the very large investment in natural gas distribution systems. This points up a fact noted earlier in this report, namely the unique features of oil as an energy carrier for most LDCs.

\subsection{Coal}

Although in most of the advanced industrial countries coal acted as the transition fuel from wood to oil, this has not been the case in the developing countries. Coal is used primarily in connection with a few energy intensive industries such as steel and transport systems (mainly in India). Exploration for coal in most of the non-OPEC countries has been essentially nonexistent until recent years when oil prices quadrupled. In 1975, coal production in the non-OPEC LDCs as a group was equivalent to 2.5 MMDOE. This comprised only 68 of world production. As shown in Table B-15 
TABIE B-14

WORLD SHARES OF ADDITIONS TO ESTIMATED GAS RESERVES

BETWEEN $1 / 1 / 77$ AND $1 / 1 / 78$

1977 Gas Additions

(trillion cubic feet) Percent

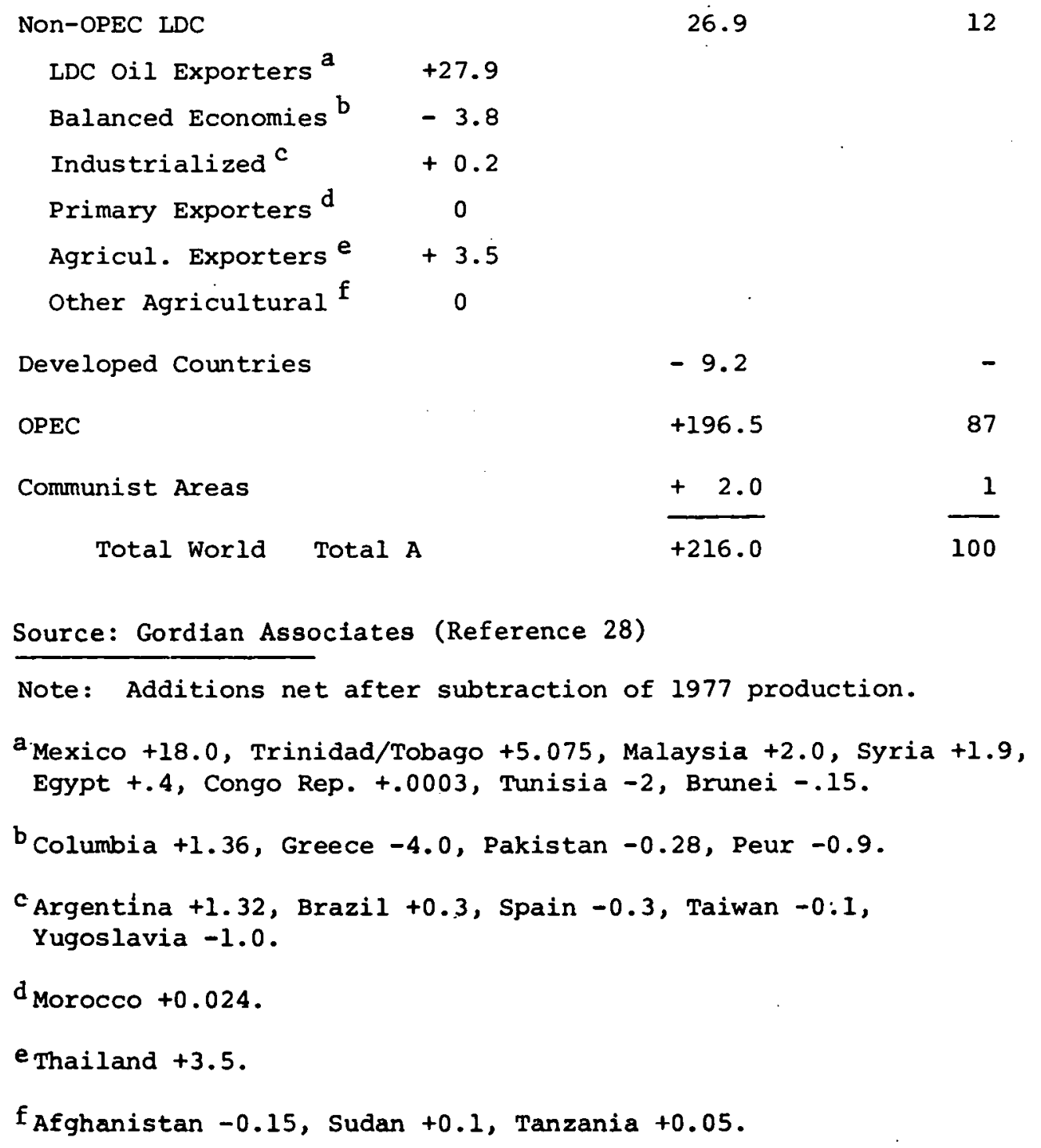

$-9.2$

$+196.5$

$+2.0$

$+216.0$

87

1

100

Source: Gordian Associates (Reference 28)

Note: Additions net after subtraction of 1977 production.

a. Mexico +18.0, Trinidad/Tobago +5.075, Malaysia +2.0 , Syria +1.9 , Egypt +.4 , Congo Rep. +.0003 , Tunisia -2 , Brunei -.15.

b Columbia +1.36, Greece -4.0, Pakistan -0.28, Peur -0.9.

c Argentina +1.32, Brazil +0.3, Spain -0.3, Taiwan $-0: 1$, Yugoslavia -1.0 .

$\mathrm{d}_{\text {Morocco }}+0.024$.

e Thailand +3.5 .

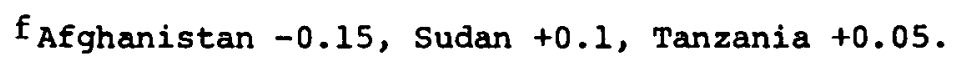


TABLE B- 15

1976 WORLD COAL PRODUCTION

\begin{tabular}{|c|c|c|c|c|}
\hline & $\begin{array}{c}\text { World } \\
\text { Production } \\
1976 \\
\end{array}$ & $\begin{array}{c}1976 \\
\text { Production } \\
\text { MMBDOE } \\
\end{array}$ & $\begin{array}{r}1971-1976 \\
\text { Annual \& } \\
\text { Increase }\end{array}$ & $\begin{array}{r}1973-1975 \\
\text { Annual \& } \\
\text { Increase } \\
\end{array}$ \\
\hline NON-OPEC LDCS & 6.4 & 2.5 & 5.4 & 7.2 \\
\hline Oil Exporters & 0.002 & 0.0007 & - & - \\
\hline Balanced Economies & 4.0 & 1.74 & 6.7 & 8.8 \\
\hline Industrialized & 2.0 & .76 & 2.6 & 4.3 \\
\hline Primary Exporters & - & .02 & - & - \\
\hline Agricul. Exporters & - & .004 & - & - \\
\hline Other Agricultural & - & .01 & - & - \\
\hline Developed Countries & 41 & 15.2 & 1.3 & 2.3 \\
\hline OPEC & 0.0006 & 0.0002 & 63.0 & 2.5 \\
\hline Communist Areas & 53 & 19.6 & 3.2 & 3.2 \\
\hline Total & 100 & 39.5 & 2.5 & 3.0 \\
\hline
\end{tabular}

Source: World Energy Supplies (Reference 8) 
this production is confined to two groups--the industrial and balanced economies. Both show a small increase in annual percentage increase in coal production. India continues to remain the dominant member of this entire group producing 528 of the total non-OPEC coal production. Korea and Yugoslavia account for an additional 28\%. Noteworthy is the fact that all the remaining groups produce essentially no coal. Coal comes in many kinds and qualities. Approximately one-third by weight of the coal production in the non-OPEC LDCs given above is in the form of lignite, whose heat value ranges between 338 and 508 of hard coal.

Most geological experts believe that abundant coal reserves exist in many parts of the world. The problem for most developing countries will be to develop the mines after these reserves are found. Entering too are the associated manpower training requirements, the costs and lead times to develop and upgrade rail and for barge transportation systems, or alternatively to construct mine-mouth electric generating stations. In the near term, it is clear that coal though abundant cannot be utilized to meet energy demands in the overwhelming fraction of non-OPEC LDCs. Over a period of several years, depending on their obtaining suitable financing and other infrastructure inputs, coal production. should be able to be increased to a point where it can meet a significant fraction of energy demands.

LDCs are concentrating to varying degrees on increasing coal production. For example, since the Arab oil embargo, India has increased production at an annual rate of 128, and Coal India Limited (CIL) has begun an active effort to increase exports over the 500,000 ton level of 1975. The government is investing in mine modernization, expansion and upgrading of track and railcar capacity, and development of mechanized coal handling facilities at their coastal ports. Korea; on the other hand, so far has taken little action to rationalize its Balkanized coal industry, improve mine productivity, or raise government controlled prices which have severely limited the profits of and investment in the industry (part of which is government-cunlrulled). 
TABLE B- 16

ELECTRICITY GROWTH IN LDCS

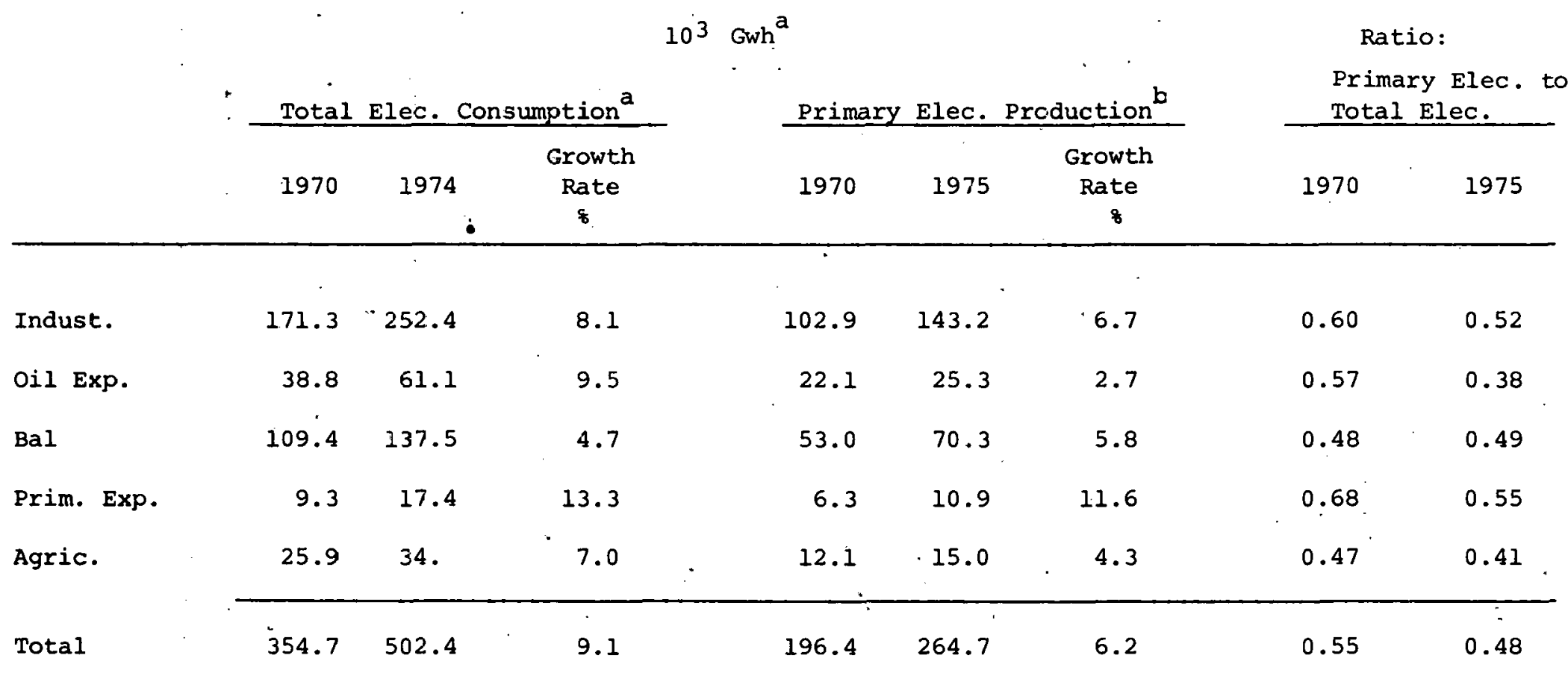

${ }^{a} \mathrm{Gwh}=$ Gigawatt - hour $=10^{3}$ Megawatt hours

primary electricity includes hydropower, nuclear, and geothermal.

b 1974 Total figure was first increased by the calculated growth rate to get a value for 1975. This was then divided into the 1975 primary electricity figure. .

Source: U.N. (Reference 32) 


\subsection{Electricity Supply}

The consumption of electricity in LDCs has grown more rapidly than that of any other fuel and is expected to grow even more rapidly in the future. Electricity is believed to be a crucial element of economic development, although its appeal as a symbol of social progress, particularly in rural areas, may play an equally important role in explaining the 118 annual growth rate projected for these countries.

Recent growth, though high in all LDCs, is not uniform among country groups. Table B-16 shows total electricity consumption in 1970 and 1974, the average growth rate, as well as data for primary electricity. The average electric growth rate in these countries of 98 per year is to be compared to the US figure in the 1963-73 period of around 78.

Primary electricity includes only nuclear, hydropower, geothermal and solar--those sources of electricity other than generation by fossil fuels. This distinction prevents double counting of primary resources, but complicates the discussion of the electric sector (the oil, gas and coal used to generate electricity is not usually distinguished in data for total consumption of those fuels).

The growth rate of total electric energy is higher than that of primary electric energy. This disparity in growth rate reflests an increasing gap between total electric energy requirements of LDCs and the quantity available from hydropower. Table B-16 shows also the ratio of primary to total electric energy for 1970 and 1975. The proportion of primary electric energy to total electric energy has decreased by some 148 in the period 197019\%. Ihe laryesl single incrcace in primary electricity, 38.7 Gwh $\times 10^{3}$, occurred in Brazil as a consequence of massive hydroelectric development. without that one country the absolute increase in primary energy would have been only $30 \mathrm{GWh} \times 10^{3}$ and the annual growth rate in primary electricity over this period 2.98 rather than 6.28. (The increase in Brazil was accompanied by a very large effort in the construction of transmission systems.)

Production of nuclear energy on a commercial scale in the LDCs has occurred in only six countries, production figures for which are shown in Table B- 17 . 
TABLE $\quad B-17$

LDC NUCLEAR PRODUCTION - 1975

\begin{tabular}{lc} 
Country & $\begin{array}{r}\text { Electric Energy From Nuclear Power } \\
\text { Gwh } \times 10^{3}\end{array}$ \\
\cline { 2 - 2 } Argentina & 2.5 \\
Spain & 9.0 \\
India & 2.6 \\
Pakistan & -.6 \\
&
\end{tabular}

Source: U.N. World Energy Supplies 1971-75. (Ref. 8)

Production of electricity from geothermal sources in the IDCs is limited to $.5 \times 10^{3} \mathrm{Gwh}$ in Central America, thus hydro production in 1975, $249 \times 10^{3}$, accounted for $94 \%$ of all IDC primary electricity.

\section{Hydropower}

Whether ađd̄itional hydropower resources can be developed in any specific country depends on topography, the distribution of population centers and industries, estimated electric lnad grnwth, altornativc investmeil upunrtunities and other local characteristics. Of the more general concerns, most important obviously is the availability of sites. Another is the relatively long gestation period of conventional hydroelectric facilities. This may be a significant deterrent to hydro supply when load is increasing rapidly as the planned growth rate of 118 implies a doubling of demand in 6.5 years. Requirements for irriqation or navigability may seriously limit the availability of the resource for electric generation, resulting in seasonal variability of power availability, possibly requiring 1nvestment in stand-by electricity production facilities.

Following the pattern common to the exploitation of all natural resources hydro development to date has been at sites which are, less costly to exploit and nearer to load centers. Remaining sites are likely to be more difficult to 
develop and to require costly transmission systems connecting generating facilities with the points of use.

These agruments are not generally applicable to "mini-hydro", that is small installations in the sub-megawatt range. Depending on local conditions, some hydropower production is likely to be available from installation of small low-head facilities supplying local villages and small industries and agrobusinesses and not integrated into a national grid.

Geothermal Electricity

The development of substantial geothermal sources of electric production in underdeveloped countries in the next 10 years seems improbable. As we have already noted, only in Central America has commercial exploitation of this resource for electric generation been successful to date. Even in the developed countries, experience with this resource is scanty. Furthermore, geothermal energy resources are highly localized and are not always near load centers. Finally, required technology is still in the developmental stage.

Nuclear Power

To date, nuclear power has augmented electricity supply only in the industrialized group of the less developed countries. One significant reason for this, which is likely to remain effective into the foreseeable future, is the matter of scale. Nuclear power plants in capacities less than $220 \mathrm{Mw}$ (the rating of units operating in spain and India) are not available. In fact, units that small are not available from manufacturers in the developed countries. 33 Installation of a unit as small as $220 \mathrm{Mw}$ on a system of less than $2000 \mathrm{Mw}$ capacity would be impractical from an engineering viewpoint. Such a system capacity Implies an annual production of 10,000 Gwh. Besides those LDCs already operating nuclear plants perhaps as many as 20 more countries may have electricity needs in this range. Aside from problems of unit size and total capacity, the gestation period 
(10 years in the United States) is likely to inhibit nuclear power plant additions in context of rapidly increasing loads. High capital costs and the necessarily large import requirements of nuclear power also argue against the choice of nuclear. And the questions of fuel supply, spent fuel disposal, and general acceptability are far from answered even in the developed world. Nonetheless, nuclear power still has an aura of prestige for many countries.

All in all, increased primary electricity production is unlikely to offer a solution to planned rapid expansion of electrification in LDCs, at least under existing patterns of supply organisation.

\subsection{Noncommercial Energy Supply.}

For noncommercial energy the situation is no less serious for lack of hard data. The real picture of rural energy availability must allow for one of the great ironies of the world's energy distribution: those who have the least also use it with the least efficiency; i.e., they receive the least output per unit of energy consumption. ${ }^{34}$ In the use of most noncommercial fuels in the third world: wood, dung, and crop residues, the useful work derived from energy inputs may average less than 58 compared with roughly 208 overall efficiency of use for commercial energy.

Meanwhile, the result of this present inefficiency in traditional energy use--coupled with rapid population growth and a lack of affordable or available commercial energy alternatives--is a growing scarcity of flrewood that is reaching crisis proportions in large parts of South Asia, African countries bordering the Sahara from Senegal to Ethiopia, the Andian countries, Central America, and the Caribbean. 35

This shortage has a direct immediate impact on the daily life of the 908 of the inhabitants of these countries who rely upon wood as their primary fuel for warmth, cooking, and cottage industries--at a rate of more than a ton per person per year in most areas. 


\section{Environmental Consequences}

The indirect longer term consequences of this energy shortage include a drastic alteration of the natural environment. In Nepal, it is not unusual for villagers to spend several hours each day trekking up to ten kilometers from home in search of firewood. In Niger, a manual laborer now typically spends a full quarter of his income to purchase firewood for his family. Around ouagadougou, Upper Volta, the quest for wood has left a virtually treeless landscape of $70 \mathrm{~km}$ radius around the city. 36

The shortage and high price of wood has forced many people in these areas to turn to the use of animal dung for fuel and has intensified the use of dung in regions where it is a traditional fuel source, such as in India, Nepal, the Sahelian countries, Ethiopia, Iraq, and the Andean area. ${ }^{35}$ Farmland is thereby robbed of badly needed nutrients, directly reducing future crop yields. The raking of mountain scrub and crop debris to use as fuel has had a similar effect in South Korea and eastern Nigeria and has simultaneously increased the dangers of flooding and landslides. 36 Increased siltation resulting from deforestation and erosion of the Himalayan foothills in Nepal and northern India has almost certainly contributed to recent incidents of serious flooding of the Indus, Ganges, and Brahmaputra rivers. Indonesia's largest reservoir is rapidly filling in due to a siltation load that has increased more than sevenfold in recent years, due, again, in large part to deforestation of its watershed. 37

\section{Deforestation}

The principal causes of deforestation are the clearing of land for agriculture and wood gathering for food. 35 Nearly a third of the original tropical forest area has been destroyed within recorded history, and it has been predicted that by the year 2000 or shortly thereafter virtually all humid tropical forests will have been transformed into deserts and unproductive wasteland. 38 Large parts of Indonesia now have less than an eighth of their original forest cover. In the Philippines less than a fifth of the land area is still forested. Aerial photographic surveys show a $30 \%$ reduction in area of the Ivory Coast's dense rainforest during the decade from 1956 to 1966.37 At present rates of deforestation, the last trees would disappear from Niger within about '5a: years--even allowing for present reforestation programs. 39

Different estimates of. world forest resources vary considerably. Table B-18 quotes two sources on forest area, growing stock, and annual growth increment. If consumption becomes a significant fraction of the amount which grows each 
TABLE B-18

WORLD FOREST RESOURCES

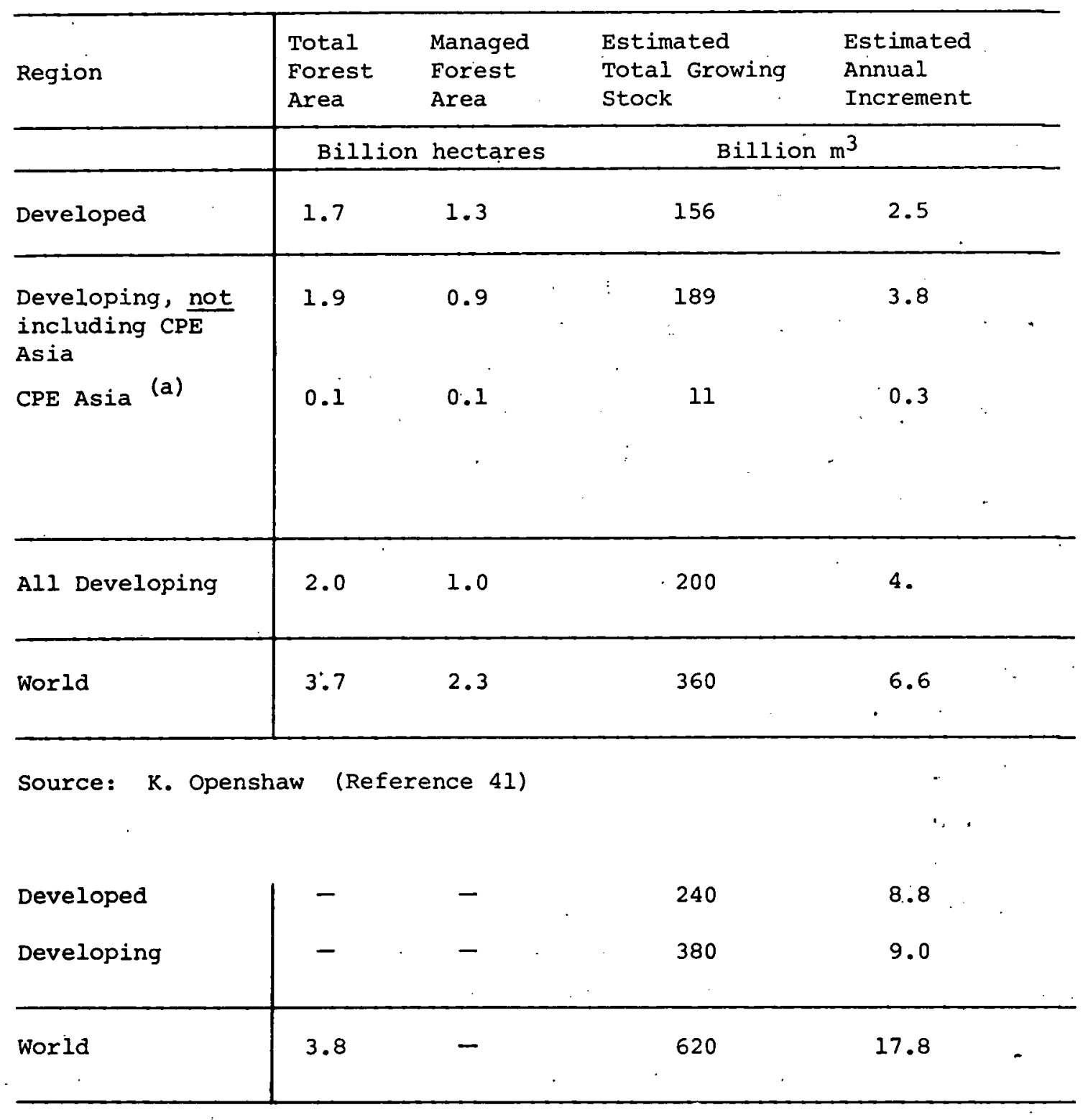

Source: D. E. Earl (p. 46, Reference 40)

(a) Central Planned Economics in Asia (China, N. Korea, Vietnam, Laos, and the Khmer Rep). 
year, then deforestation must be the result. On a worldwide basis these estimates differ by a factor of 3 ; from 6.6 to 18 billion cubic meter per year. World consumption estimates by FAO and others are acknowledged to be extremely conservative--they are on the order of $1-2$ billion $M^{3}--$ with varying proportions attributed to use as fuel. 40 A more recent estimate 41 is that current wood consumption is about 7 billion $M^{3}$ and is expected to grow to 9 billion $\mathrm{M}^{3}$ by the year 2000, against an annual growth of 7-18 billion $\mathrm{M}^{3}$, depending on which estimate one chooses. The annual increment may be reduced in future years by destruction of the growing stock and expanding agricultural land needs.

Even if annual growth is sufficient for consumption on a global basis, the trees are not always where the people are. The greatest fraction of this wood use is for fuel in developing countries. As attested to above, deforestation and desertification are a grim fact in many LDCs.

\subsection{Financing and Other Constraints on LDC Energy Resource Development}

Availability of capital will be critical for indigenous energy resource development in these non-OPEC countries. Annual investment in energy resource development in the non-OPEC LDCs would have to increase $50 \%$ in real terms by 2000 to meet IDC energy needs. The present uneven access by these countries to international investment capital aggravates further the problem of uneven exploration of commercial primary energy. resources. Futher, present international public and private lending policies have resulted in most investment capital available to the poorest countries being used for the most capital intensive energy development alternative (primary electricity). Consequently, the poorest countries have gained less useful energy per dollar of investment than have the better-bff countries with access to a broader range of capital sources.

A continuation of present financing policies will make it very difficult for the worst-off LDCs to improve their position as a group. Not only do these poorest countries have a disproportionately small share of the known currently economically recoverable commercial primary energy resources, but these countries will continue to be in an energy-poor position even in those cases where their actual resource position is favorable, because. present financing policies limit future energy exploration in these countries. 


\section{Energy Financing Requirements}

It should be stressed that the development of even the least expensive commercial primary energy source is highly capital and foreign exchange intensive for a large fraction of the non-OPEC LDCs. Table B-19 presents the range of investment costs to increase daily production capacity by the energy equivalent of one daily barrel of oil. Since energy facility construction costs are projected to continue to increase faster than the general inflation rate projections using these costs are on the whole conservative.

Based on these estimates in Table B-19 and consumption projections presented earlier one can estimate the aggregate investment necessary for the non-OPEC IDCs to develop sufficient indigenous commercial energy supplies to achieve, as a group, "net self-sufficiency"--which does not at all imply individual LDC self-sufficiency. This assumes there are sufficient economically recoverable resources in the ground to permit the adoption of such a goal. This requirement, shown in Table B-20 derived below, is approximately $\$ 125$ billion through the year 2000. With a present estimated investment level of $\$ 4.2$ billion per year, this would require investment levels to increase to approximately $\$ 6$ billion per year in real terms (an almost 50 increase by 2000). According to current trends, projections over one-third of this amount would be required for primary electric power development even though it accounts for only 58 of the additional energy supply capacity. Oil, coal, and gas account for 408,218 and 38 , respectively, of the investment required. 
TABLE B-19

ESTIMATED INVESTMENT COSTS FOR NON-OPEC LDC ENERGY RESOURCE DEVELOPMENT

(per incremental daily barrel of oil equivalent in 1976 dollars)

$\begin{array}{lr}\begin{array}{l}\text { Crude Oil Exploration, Development } \\ \text { and Transport }\end{array} & \\ \text { Refining } & \\ \text { Natural Gas Inland Distribution } & \\ \text { Coal Exploration, Development, } & 1,800 \\ \quad \text { and Transport } & 3,000 \\ \text { Fossil-Fuel Electricity } & \\ \text { Primary Electricity } & 5,000 \\ \text { High Btu Coal Gasification } 7 & 37,000 \\ \text { Oil Sands } & 46,000 \\ & 24,000\end{array}$

Source: Gordian Associates Inc.

1. Costs are weighted onshore and offshore costs and vary by region from $\$ 3300$ in North Africa to $\$ 7900$ in Asia/Far East.

2. Based on simple topping refinery of 3000 barrels per stream day.

3. Exploration and development costs for associated gas are included in crude oil development costs. Costs for non-associated gas have not been estimated. Costs vary from $\$ 1600$ per daily barrel equivalent capacity in North Africa/ Mid East to $\$ 3900$ in Asia/Far East.

4. $\$ 3400$ for strip mined coal and $\$ 6000$ for deep mined coal, assuming a 908 capacity factor for strip mines, $70 z$ for deep mines, exploration costs of $\$ 4$ per annual metric ton and inland transportation development costs of $\$ 24$ per annual metric ton.

5. Based on mine-mouth coal-fired plant without flue gas desulfurization $(\$ 600 / \mathrm{KW}, 658$ capacity factor $=\$ 2,000 /$ daily barrel equivalent generation plus $\$ 6000$ for transmission and $\$ 10,000$ distribution). Included for illustrative purposes only.

6. Estimated generation-transmission-distribution costs per daily barrel equivalent: nuclear light water, 41,000; hydro, 46,000; nuclear high temperature gao, 47,000, nuclear heavy water, 56,000 .

7. Included for comparative purposes only, based on USDOE cost estimates. Costs do not include gas distribution or refinery facilities. 
TABLE B-20

PROJECTED NON-OPEC LDC ENERGY FINANCING REQUIREMENTS, 1975 - 2000

(Million Barrels Per Day Oil Equivalent/Billion 1976 US Dollars)

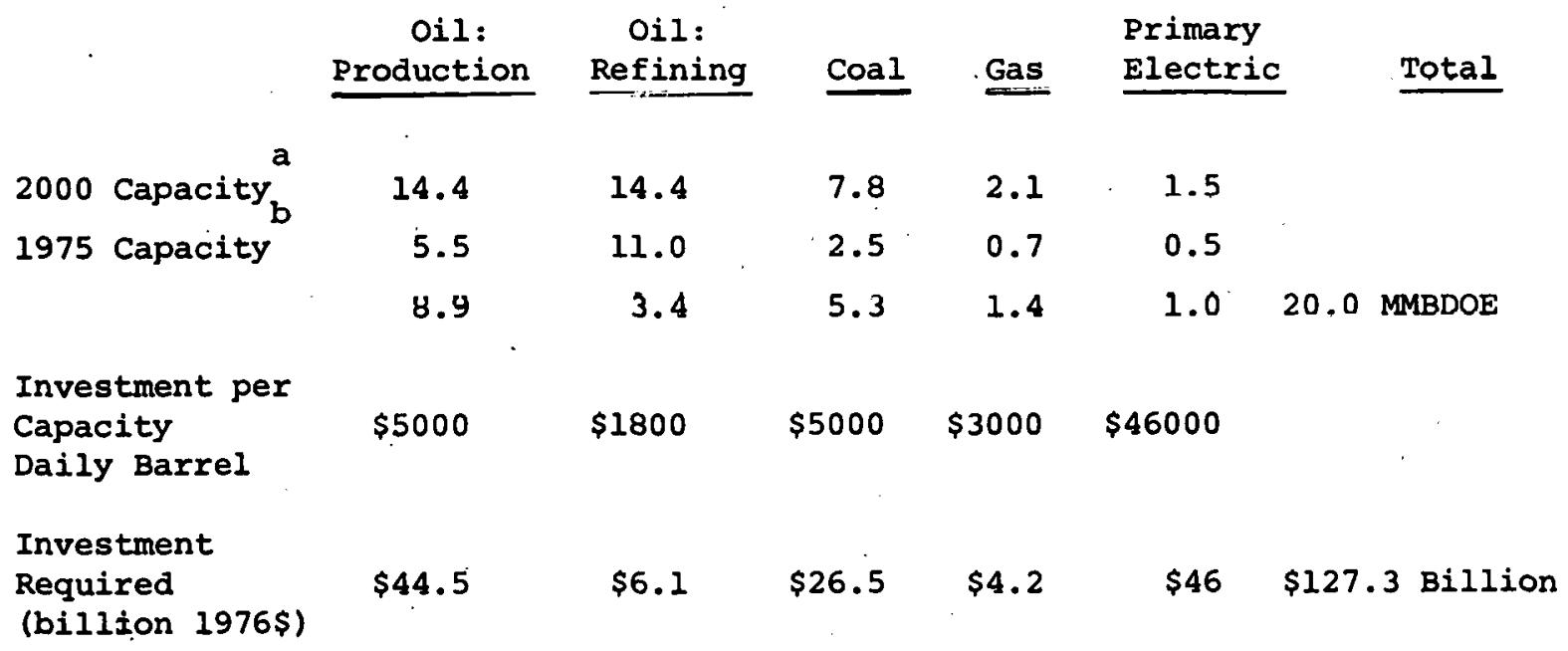

a 2000 capacity requirement equals projected pear 2000 non-OPEC LDC consumption (total of all country groups). 1975 capacity is actual reported projection capacity. Difference (additional capacity required) times capital cost per daily barrel capacity (from preceding table) equals investment required to have sufficient projection capacity to satisfy projected year 2000 consumption. 
Constraints Imposed by Present Financing Policies

Of the five primary sources of LDC investment capital--domestic savings, private international (primary Eurocurrency) credit, private international equity (risk) capital, supplier credits, and public international credit (official development)-- the share available to oil-poor non-industrialized LDCs is inordinately small for each source, except official development assistance and, to a lesser extent, supplier credits. The latter two sources, however, have been available almost exclusively only for electric power. Each financing source is summarized briefly below:

Domestic Savings rates are only 138 of GNP for low income LDCs (those with per capita GNP below $\$ 200$ ) versus 19-21\% for medium and high-income LDCS. Since GNP per capita is less than one-fourth the average for the other countries, domestic savings per capita in the low-income countries are only about one-sixth the average level in other LDCs.

Private International Credit is heavily concentrated in a few countries-primarily those with attractive oil or mineral resources and/or high and rapidly growing GNP per capita. For example, 778 of Eurocurrency bank credits outstanding to non-OPEC LDCs at the end of 19.76 went to just eight countries; Mexico, Philippines, Brazil, Argentina, South Korea, Taiwan, Peru, and Malaysia. 44 Thus, low-income LDCs other than India and one or two others have extremely limited access to the private international credit markets. Moreover, such financing as is available is likely to be short-term (under 5 years) and is unlikely to be available for high risk exploration or for long-term energy development projects. Finally, due to increasing concern that private lending institutions have overextended themselves to LDCs it is likely that the availability of such financing will be more limited in the future.

International Equity Capital historically has been available in significant quantities only for oil (and more recently and to a lesser extent for uranium and exportable natural gas) exploration and development--in short, development of energy resources where a large international market exists. Most such capital has been invested by international energy companies in areas ; with significant known reserves and relatively developed economies. Also, such companies historically have refused to invest in many LDCs where 
they (a) were unable to negotiate satisfactory equity participation or other incentive arrangements or (b) feared expropriation were they to be successful in the exploration phase. Most, (although not all), of the countries which have been bypassed by this process are low-income countries. International (developed country) supplier credits have been readily available only for nuclear power plants. Aside from being very expensive, such plants are applicable only to relatively highly developed or relatively large LDCs because of minimum plant scale requirements, as discussed above. Only officlal development assistance has systematically favored the LDCs most in need. This assistance was reviewed in Chapter A in more detail. Such assistance has largely concentrated only on electric power development. For example, the World Bank historically has allocated well over 908 of its energy investment funds to electric power. Recently it has begun to allocate a somewhat larger share to coal mine development and has funded its first project in oil field development, wood energy plantations, pilot solar power projects, etc.; however, electric power still accounts for the bulk of its new commitments.

\section{Impact of Financing Constraints}

If present public and private financing policies are continued, it is likely that most of the low-income and perhaps many of the medium-income LDCs will be unable to undertake the exploration necessary to ascertain their true resource base and, even in those areas where they have known resources, they will be unable to exploit all their reserves. This will affect total world energy supply-demand balances as well as those of the countries themselves. The following table suggests the magnitude of the problem: a mere six countries control 508 of all non-OPEC LDC financial reserves. The more than 70 countries which must share the other 508 account for $76 \%$ of known natural gas, 918 of hydro, and 188 of coal reserves. 
TABLE B-21

DISTRIBUTION OF RESERVES BY AVAILABILITY OF FINANCIAL RESOURCES

$$
\text { Percent of Known Energy Reserves }
$$

$\begin{array}{ccccc}\begin{array}{c}\text { Percent } \\ \text { of Funds }\end{array} & \begin{array}{c}\text { Number of } \\ \text { Counties }\end{array} & \text { Natural Gas } & \frac{\text { Hydro }}{\text { Coal }} \\ 25 & 2 & 6.7 & 8.7 & \frac{56.6}{50} \\ 50 & 6 & 24.0 & 9.2 & 82.0\end{array}$

\section{Other Constraints}

Other constraints to the IDC energy resource development also are likely to operate unevenly to the detriment of the poorest LDCs. Availability of skilled construction and operating manpower is likely to be a more serious problem for these countries. Physical, social and institutional infrastructure bottlenecks--energy transport capacity, government agencies' ability to deal effectively with international energy companies, ability to put together the extensive organization necessary to establish decentralized village-level energy systems, etc.--all are likely to be more severe constraints for these countries. Finally, to the extent that economic deprivation and political/social instability may be linked, these countries are likely to suffer more serious disruption which will affect their economic and energy development.

In many countries at various stages of development energy prices have traditionally been subsidized. The increase in world oil prices since 1973 has, in many cases, meant a significant increase in these subsidies. This policy, recognized as economically inefficient, is maintained because of political necessity. It not only affects the self-generation of savings in the energy sector but creates an artificial context for investment. These constraints anc characteristics must be addressed in any assistance program which would improve the energy position of the poorest LDCs. 


\section{Climate for Private Investment}

As noted above, most private investments in energy in the non-OPEC LDCs are associated with the exploitation of known petroleum reserves. This has been a well established area of private investment and is likely to grow if investment is perceived to be profitable and secure. Foreign companies are thus assured of 1 ) continued access to crude oil discovered as a result of their investments, 2) a net operating margin at least as favorable as present OPEC per barrel margins (currently ranging from $\$ .20$ to more than $\$ 1.00$, plus transportation). Over and beyond these continuing commitments, investing companies must be allowed adequate return on capital investment relative to the other alternatives available to them. The extent to which compensation for increased risks must enter into such negotiation is tied to the stability of past agreements on the part of the participating government. It also depends on the size of the reserves and level of indigenous oil development expertise. Compensation for perceived increased risks can take a number of forms but it has generally taken the form of increases in per barrel return.

The brief review of some aspects of the terms of agreement between LDCs and foreign companies is given in Table B-22. Although most of these countries have retained the traditional form of foreign company concessions, a number of diverse arrangements have been developed. More are likely to occur in the future. It is noteworthy that a number of countries, including Brazil and Chile, who had previously nationalized oil production and distribution have recently chosen to invite foreign companies to participate again. Also, the entrance of the World Bank into this area is bound to increase private investment because of the Bank's stabilizing influences. 
Tablè B-22

SOME RECENT IDC AGREEMENTS WITH FOREIGN COMPANIES

Country

Brazil

Chile

Perú

Egypt

Tunisia

Morocco

Zaire

Cameroon
Terims

Reversed 22-year state oil monopoly policy to attract foreign companies to explore unexplored areas under risk contracts.

Reversed state oil monopoly policy, opened seven offshore and onshore areas to foreign participation, but initial stringent terms discouraged any takers.

Relaxed stringent model contract terms to lure back oil companies who had abandoned operations.

Traditional concessions: Egypt has offered the companies the following commercial terms: the companies are required to spend a specified investment signature bonus of several million dollars and a promise of a certain amount of exploration investment over a period of time. If the company discovers oil, it is granted 20 to 508 of total commercial production to repay its investment, and access to crude for export.

Egypt has received over $\$ 100$ million in revenue from contract signature bonuses; companies invested some $\$ 700 \mathrm{mil}-$ Lion on exploration between May 1973 and the end of 1977. In 1977 they spent an estimated $\$ 360$ million in exploration and development while the Egyptian government's 1977 buaget for the Egyptian General Petroleum Corporation was some $\$ 2.2$ billion.

Traditional concessions

Minor participation concessions

Traditional concessions

Traditional concessions
Companies

BP Elf/AGIP Eensearch Exxon

$\begin{array}{ll}\text { BP } & \text { Conoco } \\ \text { Amoco } & \text { AGIP } \\ \text { Socal } & \text { Marathon } \\ \text { Texaco } & \text { Mobil } \\ \text { Exxon } & \text { Gulf } \\ \text { Shell Deminex } & \text { Dellatine } \\ \text { Elf/Aquitain } & \\ \text { Exxon Sun } \\ \text { Philips } \\ \text { Shell Petrofina } \\ \text { Amoco } \\ \text { Mobil Shell } \\ \text { Gulf }\end{array}$


Table B-22 (Continued)

Country

Oman

Malaysia

Argentina

Greenland

Trinidad

Guatemala

Nicaragua

Belize

Netherlands Antilles

Costa Rica

El Salvador
Terms

Production sharing

Production sharing: maximum cost recovery of 208 for oil and 258 for gas; royalty of 108 to government. Remainder to oil or gas 708 to state oil company, $30 \%$ to companies. Companies pay $25 \%$ income tax. Above a $\$ 12.72$ first year base price, plus $5 \%$ per year, $70 \%$ of profit-oil proceeds must be refunded.

Reversed state oil monopoly policy to a attract back foreign oil companies.

Danish government gets 508 carried interest plus 12.58 royalty interest plus 558 tax on any net profits. Government gets 808 of oil from any commercial discovery.

Government has 15-258 equity in all blocks awarded since 1974 .

Traditional concessions

Traditional concessions

Traditional concessions

Production sharing; if commercial discovery producers can take up to $40 \%$ of annual production to recover exploration and operating costs.

Drilling stopped after government nàtionalized crude and product operations.

Asked for U.S. and Canadian consulting help to establish prospecting regulations after no companies met stringent state concession requirements.

\section{Companies}

Shell

Elf/Aquitaine

Shell, numerous companies
Atlantic Richfield

Cities Service Hispanoil

Hubbay Mobil Amoco Deminex Pan Canadian

Amoco Texaco Tesoro

Elf Aquitaine

nrreidẹntal

Exxon Canadian Superior

Marathon Amerada Hess Getty AGIP Phillips Hispanoil 
Table B-22 (Continued)

\section{Country}

Columbia

Bolivia

Greece
Terms

Opened new offshore and onshore areas for exploration via 60-408 production sharing requirements.

Production sharing controls.

Government gets 658 of oil produced.

\section{Companies}

BP Aquitaine Intercol Phillips

16 companies. Occidental

Tesoro

Wintershall Dennison Mines Hellenic Oil 


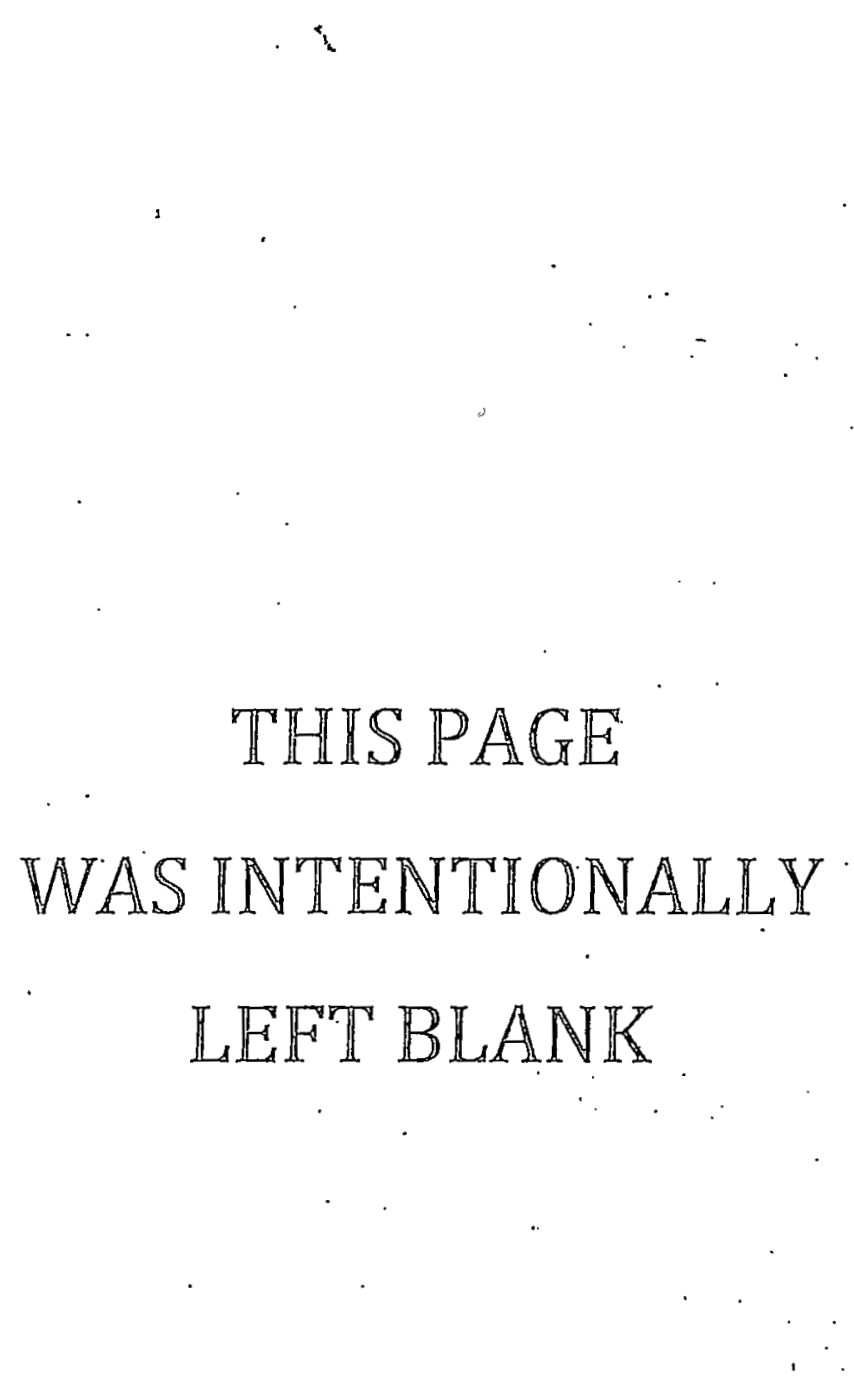


CHAPTER C

ENERGY FOR BASIC HUMAN NEEDS

\section{INTRODUCTION}

1.1 The Outlook

Man's need for energy began with the discovery of fire and its use for cooking, heating, and light. In much of the world today those needs are still being met--inadequately--by the burning of wood. International energy statistics uniformly neglect the worldwide use of "noncommercial" fuels. " Two and a half billion of the world's population nevertheless rely not on oil and gas but on the same traditional sources that have provided man with energy for all human history, save for the last two centuries. These sources are wood, dung, straw, and human and animal power.

Figure $\mathrm{C}-1$ shows the dependence of developing countries on noncommercial fuels indicating the total population of those countries having a given percentage of noncommercial energy use as compared with the total energy consumption. Even with this conservative estimate of noncommercial energy use (400 kgce for rural population only), it is clear that much of the world's population relies heavily if not exclusively on noncommercial sources.

Viewing the rural scene as a partially closed ecosystem, energy is intimately interwoven with all other factors of life. Photosynthetic production in plants provides fuel and food, enabling the production of more food, in a cycle which might be self-sustaining were it not for the pressures of rapid population growth. 2 The process of emergence from this pattern has historically involved the gradual adoption of modern technologies fueled by oil, and the entering of markets to pay for it, though recent oil price increases have made this path far more arduous.

A view of energy as a set of separable problems in different sectors, to be approached with particular supply solutions, is even more inappropriate in the LDC rural context than it is in the developed world. All aspects of rural life are tightly interconnected. Heat energy from the burning of fuels and mechanical energy, often furnished only by animal and human power, are used in ayricultural 
FIGURE C-I

NONCOMMERCIAL ENERGY USE

AS A PERCENTAGE OF TOTAL ENERGY USE, vs. POPULATION, BY COUNTRY

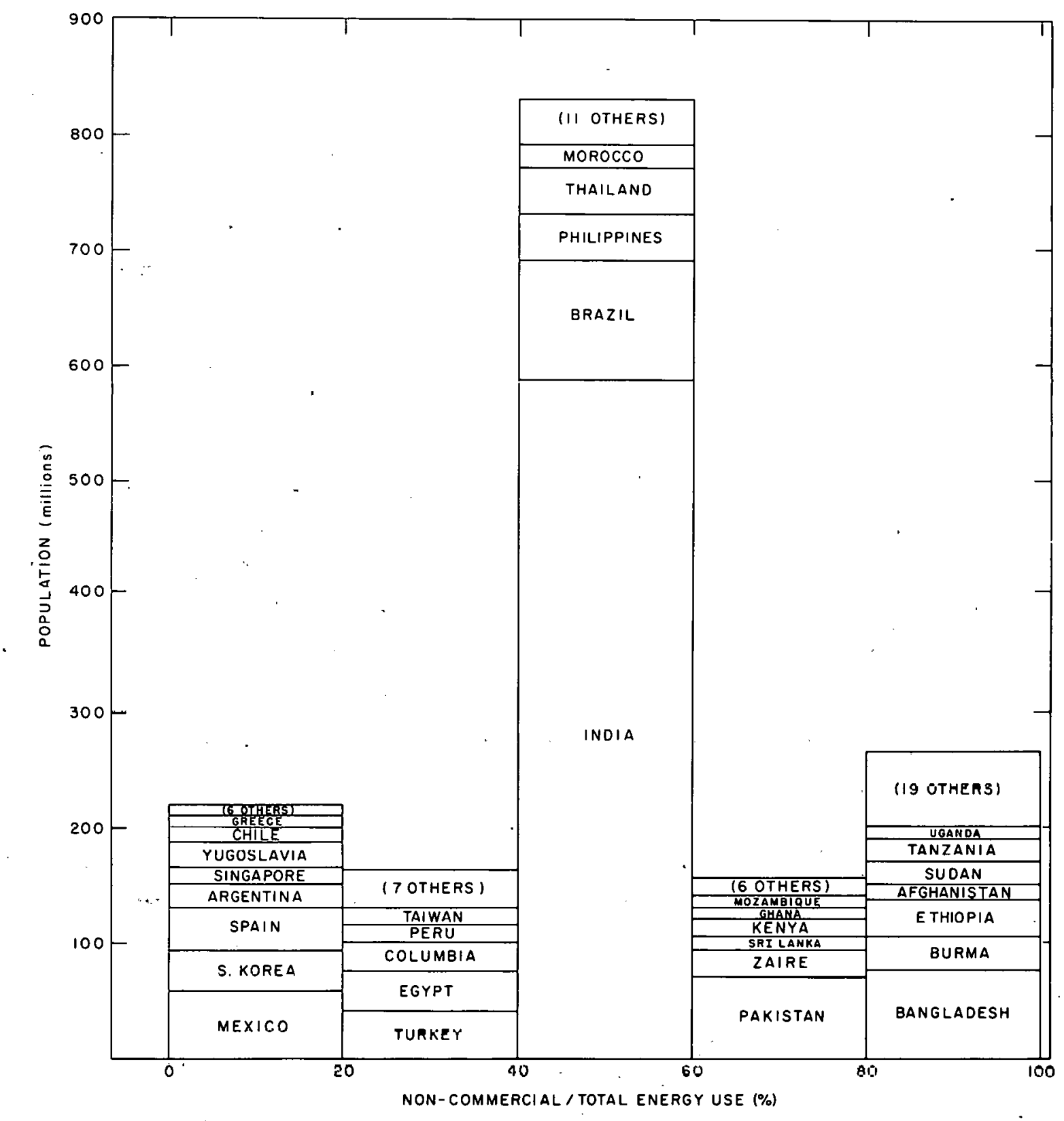

Sources:

- 1974 (est.) Population (Table 18, U.N. Statistical Yearbook 1975.)

- Commerclal Energy Use: (U.N. World Energy Supplies 1971-1975, 1977)

- Noncommercial Energy Use: $400 \mathrm{kgce/}$ rural population 
production (mechanical), agricultural processing (mechanical/heat), cottage industry (heat/mechanical), and domestic cooking (heat). Lighting, though a small energy user, is usually the first point of entry of petroleum into the ruxal sector.

As population increases the first threat of disruption comes from lack of wood as nearby forests are depleted. Dung and vegetable wastes are burnt as fuels instead of being returned to the soil to maintain fertility. Depletion of forests leads to run-off and erosion, so crop yields drop further. Villagers are forced to choose between spending their time and energy to gather wood fuel from farther forests or to increase food production.

In this chapter we describe the domestic and rural activities which consume energy, the fuels, and the difficult trade-offs they involve. We also discuss the apparent relationship between levels of energy consumption and subsistence living standards. This type of analysis is sorely hampered by the lack of adequate data or models of the role of energy in the life of the rural poor. There are studies now emerging, however, which do begin to indicate the extent of traditional energy use in rural areas and also the complex interactions between various fuels and the local economy and environment.

\section{RURAL LIFE AND ENERGY}

A detailed study ${ }^{3}$ was recently carried out in the town of Bara, Kordofan Province, in Sudan, (pop. 10,050) a very poor area undergoing progressive desertification. Kerosene, firewood, and charcoal were examined for their use by different income groups, the impact of price changes, effects on the environment, and degree of substitution of different fuels.

The consumption of kerosene in Bara, at $17 \mathrm{~kg} . /$ capita/year, was much higher than typical all-Sudan figures (around $4.3 \mathrm{~kg} . /$ capita/year). Bara is not electrified and the pressure of the population on local traditional fuels is great. (National figures include electrified areas and areas where firewood is more plentiful, suggesting the need for caution when considering national figures.) Second, the survey indicated that the prices of kerosene has jumped to eight times its level of a decade ago, with a doubling of the price in just the last two years. The causes seemed to be increased population in the area, more children in school 
(hence more reading at night) and a decrease in available wood and charcoal supplies. For the largest group of the survey, the poorer people, kerosene was increasingly available only from the high priced black market and many families simply did without.

In the past ten years it has become increasingly impractical for women to get their own firewood. What used to be available on a journey of 15-30 minutes now takes 1-2 hours. And, it was found that per capita fuelwood consumption in this rural market town was $55 \%$ more than in urban areas of Sudan. Substitution of other fuels, especially charcoal, or doing without, was reportedly significant.

The market for wood is dependent on supplies brought in primarily by former peasants who have lost their land to the desert. Much of the cutting is illegal; and prices tend to be erratic. Like kerosene, firewood tended to be consumed more by the upper income groups. Since wood gathering is labor-intensive, prices rose 258 during the harvest season when labor was at a premium.

A11 but a few households bought locally made charcoal rather than make it themselves. Previously no estimates had ever been made of rural charcoal consumption in Kordofan Province and the Bara figure significantly exceeded the existing urban per capita consumption of charcoal. Little difference in consumption was noted between income groups, though it was slightly higher in upper groups than in lower ones. During the last ten years, the price of charcoal has tripled in the area, again due largely to the deforestation of the surrounding areas. An even greater price increase (66\%) was ubsexved for charonal than for wood at harvest time due to the greater number of manhours needed to produce it. Due to its desirability as a fuel, however, only a modest decline in consumption was noted. Presumably the higher prices meant less disposable income for other necessities, especially for the poor.

Three-quarters of the households that purchased kerosene used it only in lamps (the others also had primus stoves). Most families purchased wood rather than gather it themselves and used it mostly for cooking though some was used in commercial businesses. Charcoal is used most extensively in cooking but also for space heating, melting soap, and ironing. The charcoal was used in stoves/ heaters made from recycled petrol cans. 
The environmental impacts of the changing energy situation in Bara were severe. Progressive desertification was leading to greater soil erosion. Local people even attributed recent short-falls of rain to the deforestation. Increasingly, a trade-off developed between using local gum arabic trees for their marketable sap, or cutting them for firewood. Likewise, the population reported a lowering of their standard of living in the face of higher energy prices and scarcities of various fuels.

Life in a Rural Village

In an attempt to get a better picture of the evolving energy structures of the developing countries the Overseas Development Council commissioned a series of case studies on energy use and needs. 4 They were written by former Peace Corps volumteers who had recently spent two or more years living in the areas they described. These vignettes reveal a great deal of variety but at the same time they reveal important similarities to be found throughout the rural Third World. Table $\mathrm{C}-1$ summarizes the domestic and agricultural activities in six villages: two in Africa, two in Asia, one in Latin America and one in Micronesia.

In each of the villages studies, except in Latin America, all soil preparation was done by animal or human energy. Without exception planting and harvesting was done by hand as was weeding and initial processing (except for sugarcane in the Dominican Republic). Grinding is an exceptionally onerous chore--every community that grew cereals had a machine to do part of it. In the remote Nepalese village a water wheel was used--the one example of a machine powered by renewable inanimate energy. All communities depended in whole or in part on wood or charcoal for cooking. Two used kerosene as a supplement. Firewood supply for cooking was a major problem only in Niger. Though none found it essential to haul water from a remote stream, in only two cases were wells used chiefly for drinking. Four communities had electric lights, in three of which electricity was fairly common in homes. All home construction was done without the aid of powered machines. Transport and travel was available via motor vehicles to all viliages except in Nepal.

This adds up to a picture of very great reliance on primitive energy sources, especially outside Latin America. In all cases (except the Nepalese water mill) where machines are beginning to replace muscles, and other fuels to replace wood, 
TABLE C-1

ENERGY SOURCES AND APPLICATIONS IN SEVEN VILLAGES

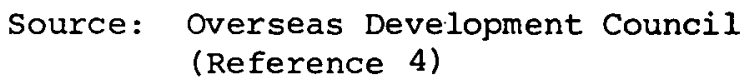

\begin{tabular}{|c|c|c|c|c|c|c|c|}
\hline & Task & Dom. Rep. & Ethiopia & Korea & Micronesia & Nepal & Niger \\
\hline 1. & Soil Prep. & $\begin{array}{l}\text { tractors; } \\
\text { burro; } \\
\text { oxen }\end{array}$ & $\begin{array}{l}\text { hand hoe; } \\
\text { oxen; } \\
\text { horses }\end{array}$ & oxen & $\begin{array}{l}\text { hand; (nuts, } \\
\text { fruit, bread- } \\
\text { fruit gather } \\
\text { ed wild) }\end{array}$ & $\begin{array}{l}\text { bulls; } \\
\text { hand }\end{array}$ & hand \\
\hline 2. & Planting & hand & hand & hand & hand & hand & hand \\
\hline 3. & Irrigating & $\begin{array}{l}\text { electric } \\
\text { pump }\end{array}$ & $\begin{array}{l}\text { occasion- } \\
\text { ally by } \\
\text { gravity }\end{array}$ & none & none & none & $\begin{array}{l}\text { hand } \\
\text { (with } \\
\text { scoops) }\end{array}$ \\
\hline 4 & Harvesting & hand & hand & hand & hand & hand & hand \\
\hline 5. & $\begin{array}{l}\text { Initial } \\
\text { Processing } \\
\text { (threshing) }\end{array}$ & $\begin{array}{l}\text { (sugar- } \\
\text { elec. } \\
\text { machine) }\end{array}$ & $\begin{array}{l}\text { cattle } \\
\text { trod }\end{array}$ & $\begin{array}{l}\text { ox } \\
\text { trod: } \\
\text { hand }\end{array}$ & hand & hand & hand \\
\hline 6. & Grinding & none & $\begin{array}{l}\text { diesel; } \\
\text { hand }\end{array}$ & $\begin{array}{l}\text { gas } \\
\text { (rice); } \\
\text { hand } \\
\text { (beans) }\end{array}$ & no cereals & $\begin{array}{l}\text { water } \\
\text { powered } \\
\text { mill }\end{array}$ & $\begin{array}{l}\text { hand; } \\
\text { diesel }\end{array}$ \\
\hline 7. & Preserving & none & sun dry & $\begin{array}{l}\text { kimrhi: } \\
\text { drying }\end{array}$ & $\begin{array}{l}\text { copra in } \\
\text { sun; salt or } \\
\text { smoke fish; } \\
\text { breadfruit } \\
\text { buried }\end{array}$ & oun dry & $\operatorname{sun} d x y$ \\
\hline 8. & Cooking & $\begin{array}{l}\text { wood, } \\
\text { char- } \\
\text { coal }\end{array}$ & $\begin{array}{l}\text { dung; wood, } \\
\text { charcoal }\end{array}$ & $\begin{array}{l}\text { charcoal } \\
\text { coal, } \\
\text { rice, } \\
\text { straw }\end{array}$ & $\begin{array}{l}\text { coconut husks; } \\
\text { wood; } \\
\text { kerosene }\end{array}$ & wood & wood \\
\hline 9. & $\begin{array}{l}\text { Drinking } \\
\text { Water }\end{array}$ & $\begin{array}{l}\text { towin } \text { pifes: } \\
\text { water } \\
\text { trucks }\end{array}$ & $\begin{array}{l}\text { well, } \\
\text { stream }\end{array}$ & $\begin{array}{l}\text { we ll; } \\
\text { hand } \\
\text { pump }\end{array}$ & $\begin{array}{l}\text { runoft; wells } \\
\text { with bucket } \\
\text { or pump }\end{array}$ & $\begin{array}{l}\text { stream } \\
\text { nearby }\end{array}$ & well \\
\hline 10. & $\begin{array}{l}\text { space } \\
\text { heating }\end{array}$ & none & $\begin{array}{l}\text { cooking } \\
\text { fircs }\end{array}$ & $\begin{array}{l}\text { char- } \\
\text { coal; } \\
\text { oil }\end{array}$ & none & $\begin{array}{l}\text { wood } \\
\text { fire }\end{array}$ & none \\
\hline
\end{tabular}


TABLE C-1 (continued)

Task Dom. Rep. Ethiopia Korea Micronesia Nepal Niger

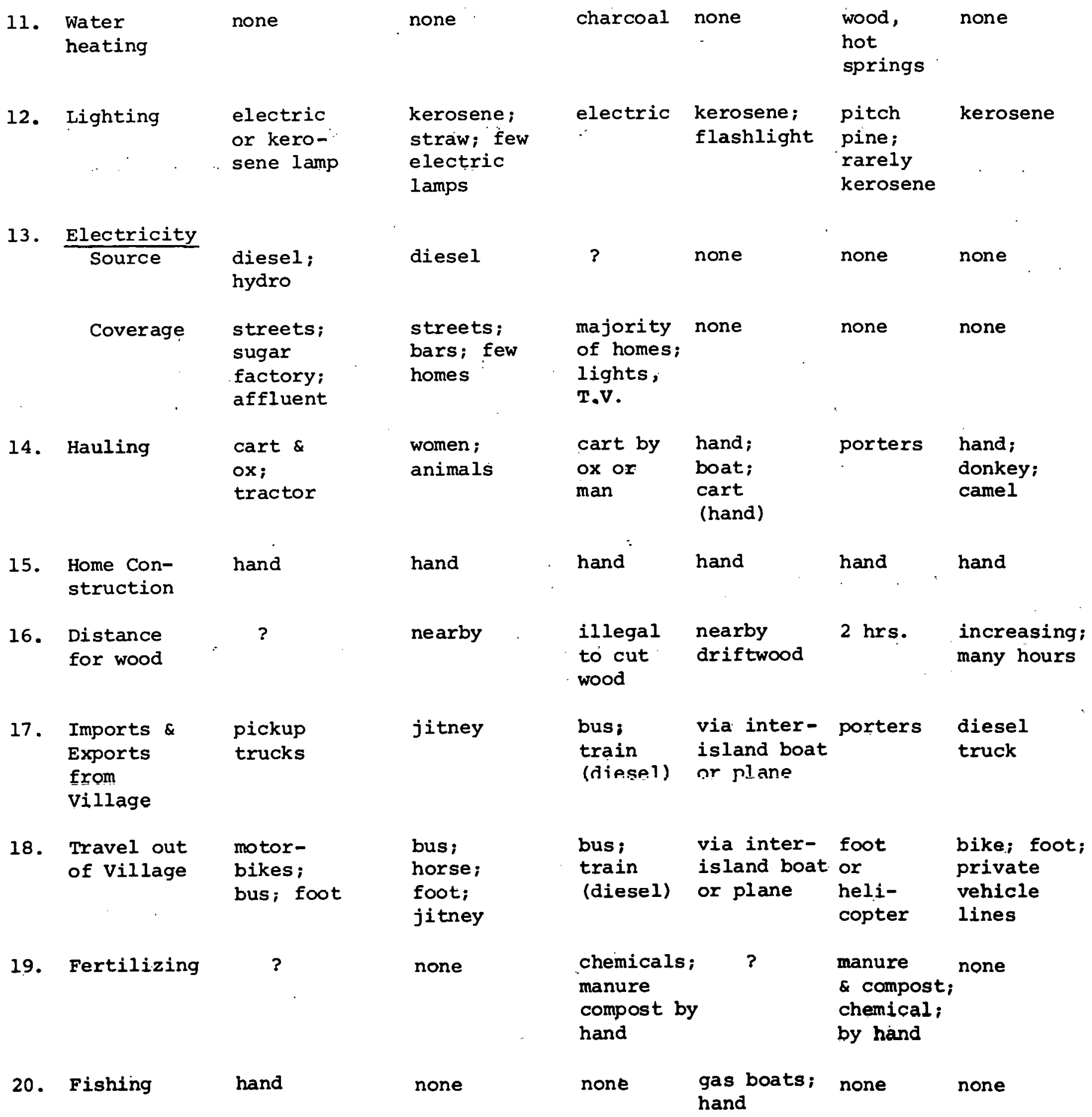


TABLE C-2

. COMPARISON OF ENERGY USE IN LDC RURAL VILLAGES

(kilograms of coal equivalent per capita)

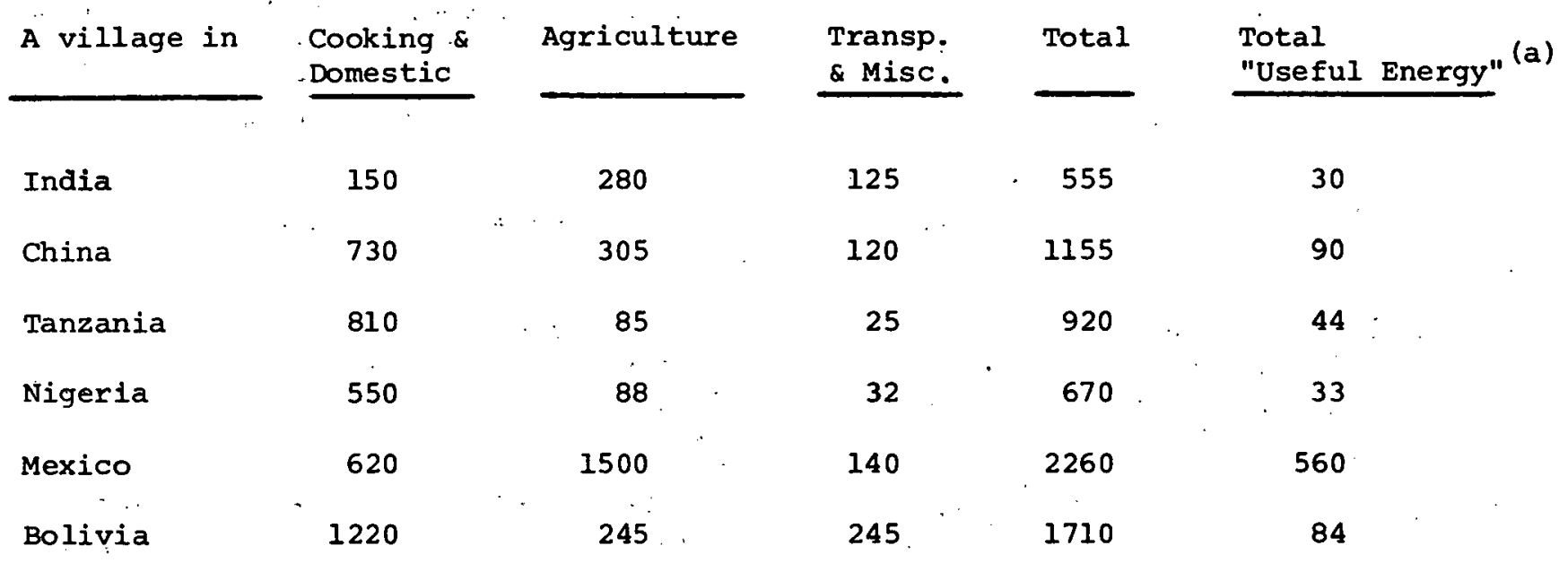

Source: Makhijani and Poole (Reference' '5)

.(a) Useful Energy is calculated as primary (resource) energy times the nfficiency of use. 
the replacement takes the form of petroleum. If these cases fairly represent the rural areas of developing countries, it appears those areas are starting down an energy path based on oil.

\section{FOOD PRODUCTION AND PREPARATION}

Other studies have examined the detailed structure of energy use in rural villages and have attempted to quantify the amounts of energy use to perform various functions. The critical finding is that cooking and growing of food dominate the lives and the energy budgets of the rural poor.

In Revelle's study ${ }^{2}$ of an Indian village, cooking accounts for 608 and agriculture 228 of the total energy consumption of 7,100 kcal/capita/day, which is 380 kilograms coal equivalent per year (kgce). Makhijani and Poole 5 calculated energy budgets in six hypothetical villages around the world and found agricultural and cooking needs to absorb from $77 \%$ to $97 \%$ of total per capita consumption, which ranges from 670 to $2260 \mathrm{kgce}$, as shown in Table C-2. Reddy and Prasad ${ }^{6}$ suggest an estimate of $130 \mathrm{kgce}$ for cooking alone, out of a total per capita consumption of $300 \mathrm{kgce}$, whereas $\mathrm{J}$. Parikh ${ }^{7}$ estimates that $300 \mathrm{kgce}$ is necessary for cooking alone. In a detailed scenario of a Bangladesh village $^{8}$ the annual energy needs for cooking alone were estimated to be from $500 \mathrm{kgce}$ for the landless poor to $2000 \mathrm{kgce}$ for the village rich, calculated as 1.7 times the caloric value of food consumption. The difficulties of comparing and interpreting these estimates will be discussed later. What is of interest here is the unanimity of the importance of cooking and the implications for subsistence in the face of declining energy supplies. This demand is "inelastic" in economics terms. A decrease in the activity level is not feasible. Furthermore, substitution options are limited and difficult, each with severe concomitants. Kerosene is expensive, irregularly available, and requires expensive capital equipment to use. Wood is also expensive or too far away to gather, and denuding of the landscape carries extreme long term consequences. Charcoal is only converted wood, so it offers no relief. Dung and agricultural residues, if used for fuel, are not returned to the soil tormaintain its fertility and condition. The efficiency of fuel use in cooking is on the order of 5 to 108. This very low value is striking, a major contributor to the magnitude of the problem, while tantalizingly the most significant of the possible averues 
of change. Introducing a more efficient stove would ease the fuel demand, releasing money for other needs, or time and labor from wood-gathering for more productive tasks. Such an "intervention" is by no means easy, however.

\subsection{Energy in Food Production}

Getting enough food is a serious problem for some 450 to 500 million of the world's people. The FAO world Food Conference Assessment reported that two-thirds of the developing countries had inadequate food supplies in 1970 . The problem was particularly acute in Africa, South Asia and portions of the Far East, and more recently in the drnught stricken Sahel. It hac becn catimated that $50 \%$ of the children in developing countries are inadequately nourished, often to the point of stunting their future physical and mental capabilities. In addition, poorly nourished people are more susceptible to disease. Although FAO cites 2,300 calories as an adequate per capita intake in developing countries, it estimates that half a billion people consume between 1,700 and 1,800 calories each day. 9

Energy is vital to food production. Soil preparation (plowing, drainage, removal of rocks and trees) may be done by hand or by heavy machinery. Plowing in African countries is often done with human labor using a large hoe to break open a clod of soil for one or a few seeds. In South Asia bullocks are used for plowing, and in Southeast Asia, water buffaloes. In Taiwan hand guided walking tractors are common and on more modern farms of many countries tractors might be employed. Cultivating almost always involves a great deal of hand labor with relatively little use of machinery. Irrigation, when done, is generally powered by animals or motors since human labor is often not adequate to the task. Harvesting is usually by hand. Preparation, or grinding of grain, may be hy hand or machine. Transportation of food is done by truck, animal drawn vehicles, pack animals, and humans. Water for cooking or drinking is normally hauled by hand from a nearby spigot or half a day's walk away. It may be pumped by hand or by machine or hauled up by rope and bucket from the well. Cooking is often over an open fire of wood, charcoal, crop residues, or dung. Preservation of meat involves the use of salt, sun drying, or smoking over wood or charcoal. Grain is dried in the sun but some crops such as tobacco require a wood fire to complete the drying process. 
Human energy plays a vital role, as it is often the only mechanical power available. Since such low food intake reduces muscle strength by $30 \%$ or more, and inasmuch as 508 of human work in developing countries is for farm tasks, it is not surprising that major shortfalls sometimes occur in labor available at critical times in the crop cycle. The result is a vicious circle, with low muscle energy reducing food production which in turn keeps muscle energy low.

In traditional agricultural practice this great expenditure of human labor gains a very limited amount of production. Much is lost to pests, bad weather, and inadequate storage. Agricultural production remains largely subsistence in nature and increasingly less able to meet peoples' needs, in part due to an inability, for innumerable reasons, to establish the productivity "multiplier" effects of efficacious energy use. Though usually tied to increased fossil fuel use, the case of China (see Chapter D, 4.3) demonstrates that major gains can be accomplished through more efficient use of labor and renewable resources.

\section{THE PROBLEM OF DATA AND MEANS OF ANALYSIS}

The problem of data on noncommercial energy use exists on three levels. First, there are very few reliable numbers ("measurements") available and what does exist exhibits serious inconsistencies. Secondly, there is little agreement as to what should be included in what categories of energy. Finally, we have yet to develop good understanding or conceptual models of how subsistance and development depend on energy so as to anticipate the future course of energy use.

Problems of data accuracy, accounting conventions, definitions of categories, how to reflect efficiencies, conversion factors (i.e. the different energy content of different kinds of coall,, all persistently confound discussions of energy, especially in the international context, even for commercial energy. Noncommercial energy, however, has not received the same scrutiny. and little usable information exists.

Information on the supply of noncommercial energy is not good. Figures for forest cover are rough for most developing countries, and detailed inventories of forest resources exist for only a very few countries. As pointed out in Chapter B various studies have uncovered discrepencies of a factor of 10 or 100 . There are no detailed inventories of crop residues, animal dung, or animal draft power for most developing countries (such information is inadequate even in the U.S.). Human wastes would be relatively easy to quantify (based on direct correlation to population and nutrition) but the actual recource potential ie complicated 
by cultural factors and again, no national or regional assessments are known, The situation for small scale hydro resources is also unknown because existing hydro resource inventories are based on exploitation of larger commercial scale sites.

For consumption the situation is even worse. Very few actual field studies have been done so estimates are largely based on guesses and suppositions. Furthermore, findings for one location are not generalizable to another. Even among these attempts to estimate village energy budgets there is disagreement about what to include, and how to include it. Makhijan $1^{5}$ established the critical role of human power and includes it as an integral feature. Other observers have focused instead on "fuels" apparently guided in part by the notion that human labor is a free by-product of metabolic maintenance. This assumption may be appropriate when studying more prosperous societies, In the subsistence situation, however, human labor is directly linked to diet. Furthermore, where human effort is the only source of mechanical energy, its allocation becomes an "energy" as well as a "labor" decision. Makhijani ${ }^{5}$ has also raised the question of efficiency, wisely noting that effective use of resources and optimal substitutions should be based on the actual function being performed.

Finally, there is the matter of "embodied" or indirect energy, that energy which is used to make goods and materials and to provide services. The proper handling of this aspect of energy is very important for making energy and development policy decisions because an apparently beneficial path can be quite the opposite when its hidden implications emerge. For example, one might fail to recognize that the purchase of energy intensive goods may not be so different from the purchase of energy itself.

The formalisms for treating embodied energy are only very recently approaching a degree of maturity in the U.S., where highly detailed information is available about the structure of the economy and the use of energy is its various sectors. In the less developed world no euch information is available, especially in the matter of energy flows in the non-market economy. Generally, the state of energy data, models, analysis and understanding is at a primitive stage, and these more sophisticated issues can be addressed only in preliminary fashion, all the more unfortunate for their importance to finding the means for a better standard of living for people. 


\section{LEVELS OF ENERGY AND SUBSISTENCE}

Obviously, the amount of energy now needed to provide "subsistence" varies with climate, region, and culturë. Figure B-2 (in Chapter B) showed the per capita levels of energy consumption for different parts of the world, ranging from $11,000 \mathrm{kgce}$ in North America, half that in Europe, and 5-10\% of that figure in the developing world, with noncommercial energy included. The world average is approximately $2000 \mathrm{kgce}$.

To interpret these figures in terms of human livelihood, three estimates of energy consumption levels and their corresponding standards of living are presented.

\subsection{Subsistence}

An approximate figure of 300-400 kilograms of coal equivalent per capita per year emerges from a number of studies $1,5,7,8$, and despite earlier reservations about data and methodology, is probably an adequate representation of energy budgets that would coincide with minimum provision of food and shelter for survival in a rural agrarian setting. The estimates are based. on suppositions about physical necessity and possibility. This figure rises as population density increases and will increase generally in the future because the agricultural productivity of a fixed amount of land can be increased only with increased energy use 5,10 . We term this lowest level of energy use the "Subsistence" level.

\section{2 "Basic Human Needs"}

A level of energy consumption necessary for an adequate life with some opportunity for emergence to improved health and well-being can be estimated. through the use of an index being developed by the Overseas Development Council. 11

The Physical Quality of Life Index (PQLI) focuses on three measures of well being: infant mortality rate, life expectancy, and literacy. (Whatever means are chosen by different political systems these indicators are assumed to reflect the most basic desire of people - to live longer with better health and opportunity.) The PQLI consolidates these three into a composite index, with each one first ranked from 1 to 100 on the basis of the countries of the world having the worst and best performance. All other countries can then be ranked accordingly.

Wodern advanced countries fall consistently in the mid to high 90's, though within countries the same analysis can distinguish considerable 
FIGURE C -2 .

RELATIONSHIP BETWEEN

PHYSICAL QUALITY OF LIFE INDEX AND

ENERGY CONSUMPTION PER CAPITA

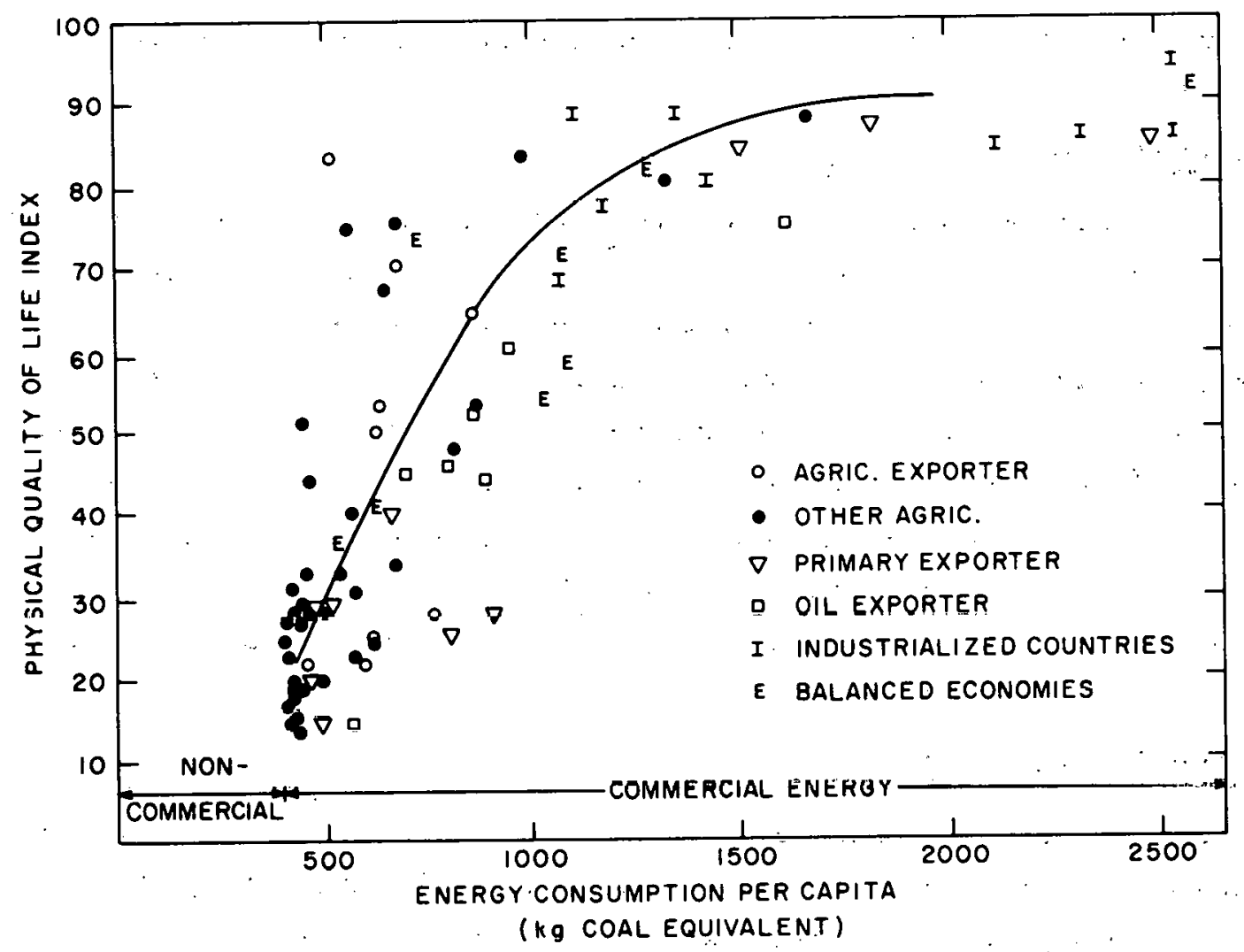


regional and racial differences. The developing countries fall everywhere from 15 to 90 . Detailed interpretations would be premature-the work is preliminary and undergoing further analysis. The initial findings are startling in some cases and sure to raise controversies. Figure C-2 shows energy consumption plotted against PQLI, which at first rises sharply as energy consumption increases from its lowest values. The marginal benefits of added energy would seem to be the greatest when starting from a low level. A threshold occurs rather abruptly at approximately 1200-1400 kgce per capita, the PQLI having reached into the 70 's. If we may interpret this range of the PQLI as representing a situation of minimal adequacy for human life, the concomitant energy requirement is evidently in this range. Attributing a part of this to noncommercial fuel, we arrive at a commercial energy consumption level of 900-1000 kgce, or a tripling of the current average level in the poorer country groups (all but the industrialized and oilexporting countries). Only a few LDCs use this amount of energy. To provide it for the rest would significantly alter the world demand picture.

\section{3 "Improyed L1v1ng standard"}

Reddy and Prasad, in their exhaustive discussion of the Energy Crisis in India ${ }^{6}$ calculate a consumption level of $1450 \mathrm{kgce} / \mathrm{capita}$ to provide "the minimum requirement for a satisfactory life. . " based on a breakdown of the energy required for food production, shelter, and transportation. They go on to describe the distributional inequities within India with that standard as a convenient point of reference.

\section{CONCLUSIONS}

We have deliberately emphasized the uncertainty attached to quantitative information in the links between energy and basic human needs. Even so, several broad conclusions emerge from this brjef review.

- Traditional noncommercial energy sources constitute the major, if not exclusive, fuel forms for most of the rural populations in almost all the LDCs. Every primitive energy from has at least one other important role in society. 
- Where noncommercial energy forms have been replaced by alternative fuels, the latter are almost exclusively petroleum based. In most rural areas nonmetabolic energy inputs are used to prepare food for consumption and little else.

- Increases in utilization of existing fuel sources is tied to improvements in efficiency of conversion of energy to useful services--a process which requires additional capital investments in energy end-use devices such as stoves and machinery.

- Any improvement in "living standards" is likely to require substantial increases in annual energy consumption per capita. 
CHAPTER D

CHARACTERIZING SOLUTIONS TO THE ENERGY PROBLEMS OF THE DEVELOPING COUNTRIES

\section{INTRODUCTION}

There can be no viable strategy for development without considering the associated energy implications. While the current energy problems of the LDCs have put the brake on development for many of the LDCs, there are actions available to policymakers which would ease the worst impacts of the situation outlined in previous chapters.

It is not our intention to characterize solutions to LDC energy problems in any great detail. Nor do we list the very large number of possible remedial actions that could be taken, or attempt to quantify the potential impacts of such solutions. Rather we aim at a general taxonomy of solutions to aid in dexiving assistance programs from an understanding of national solutions.

Two points should be apparent from the discussion in previous chapters. First, a thoroughly developed understanding of energy's intersection with the development process is not presently available. Second, individual countries face unique energy problems which are very different from one another. Thus the speculative nature of the discussions in this chapter reflects not so much an uncertainty in the technical feasibility of certain solutions, but rather an awareness that the extent to which they will be employed will depend on a wide variety of external conditions, on internal decisions by the individual governments, and on the kinds of outside assistance that will be forthcoming.

We categorize solutions according to the degree of change they will imply if undertaken by developing countries, with or without outside assistance. Energy system ${ }^{1}$ solutions are the most readily implemented. They are of two types. The first involves changes in basic energy resource development and production, difficult to accomplish except in the fortunate instances where indigenous oil and gas supplies can be discovered and dèveloped. 
The other category is technology and fuel substitution within existing energy systems. This includes implementation of more energy efficient processes and devices. Developmental solutions would modify established economic taxgets or developmental strategies to take account of the changed energy situation in the world. Such solutions are significantly more difficult to implement. Various types of solutions are examined for their technical feasibility, capital and infrastructure requirements, and probable constraints on implementation. We also assess the applicability of different solutions to the different IDC country groups identified in the previous chapter. The solutions discussed were chosen on the basis of their bearing on the three primary problems brought out in the previous chapter: the immediate problem of noncommercial fuels, the short-term problem of oil supply, and the longex range problem of shifting from an oil based economy.

\section{THE ESSENTIAL ROLE OF ENERGY IN DEVELOPMENT}

Although the general role of energy is development has long been understood, it is only within recent years that we have come to fully appreciate the critical influence that sudden changes in the price and availability of the basic fuels can have on the development process. The term development can be widely interpreted. But in the sense that development is associated with the accumulation of material resources and the productive resources embodied in capital, energy system development provides a critical support to economic and social development. In the past, this has meant an adequate supply of fuels at prices which would not limit their productive use, but more and more $1 t$ has come also to mean a diversity of energy sources, conversion systems, and end-use devices which allow a built in resiliency to. sudden changes in the availability of particular fuels.

In the lowest income developing countries, the largest consumer of commercial energy is the transportation sector. (Estimates range as high as 708.) Industrial and government use is next (208), and standing much lower is the use of commercial energy for food production and processing

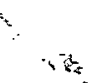


and use by upper class urban households (108). With few exceptions oil based fuels provide virtually $100 \%$ of the commercial energy requirement among these countries. The use of electricity is limited to lighting and motor drive. In these countries noncommercial fuels satisfy the basic subsistence requirements of most of the population, both urban and rural (95\%). Without cheap oil development will require greater use of alternative fuels, in turn necessitating greater diversity of the conversion devices for their use. In rural areas, for example, attempts to increase food production or to introduce manufacturing industries have brought sharp increases in commercial fuel use, more sophisticated energy delivery systems (rural electrification, for example), and an increased dependence on oil and oil based products (diesel fuel, fertilizer, gasoline). Attempts to improve the mobility of isolated ruxal populations through road building programs lead to greater reliance on energy and energy conversion systems (trains, buses, trucks). As noted previously, any increases in the well-being of rural households as evidenced by adequate supply of reliable cooking fuels, improved diets, better housing, health and sanitary standards implies greater energy use and more sophisticated energy systems. Most of this also applies to the urban poor for whom employment is often associated with the availability of energy (despite the labor intensiveness of many industries).

Most developing countries have thus come to associate all progress with greater production which leads to greater needs for transport, higher degrees of urbanization, and greater energy use. It is therefore safe to conclude that, whatever development strategies are employed, more energy and more elaborate systems of energy production, distribution and utilization will be viewed by these countries as basic to their future well-being.

Such a perception is in fact strongly supported by the direct and striking correlation between economic growth and energy consumption. This relationship for the countries considered in this study was shown in Figure B-1. In addition to the strong correlation between energy and GDP, the plot is also remarkable in the wide range of energy use per capita that can characterize a given GDP per capita. Singapore, for example, has an 
energy consumption/capita of $3367 \mathrm{~kg}$ of coal equivalent (kgce) /capita, while Brazil with double the GDP/capita uses less than half the energy/capita, $1412 \mathrm{kgce}^{3}$

A central question of energy and development is the degree to which economic growth and social development can continue with reduced requirements for energy. Rapid industrialization has often led to inefficiencies in energy use, and the fact that fuels are becoming more expensive does not guarantee their more efficient use in the immediate future. Energy prices in many of the LDCs reflect a combination of market influences and social policy. Human settlement patterns in the LDCs as a whole rely heavily on energy intensive food, construction and transport systems, promoting wasteful social use of energy. In Mexico City, for example, the total energy embodied in the food, municipal services, housing materials, and transport for median income households constitutes $78 \%$ of the total household energy budget. 4 Among the upper income groups this increases to $90 \%$. (This compares to 708 for the average consumer in Sweden.) To a considerable extent the processes involved and devices employed emulate those recently found to have the lowest engineering efficiencies and to be the most wasteful in the o.s.

These statistics underline an important fact. Already within the social structure of many more advanced IDCs there lie the seeds of much higher future energy use. The lifestyles of the higher income groups are already energy intensive, and to the degree that social aspirations-and social policy--identify with the existing ladder of economic advancement, the future is an energy intensive one.

The degree to which the developing nations of the world can or are willing to take a developmental path that is different from the Western industrialized nations will be a fundamental issue that lies behind or beyond the considerations discussed in this chapter. The fact that western countries are now coming to recognize--from an energy standpoint--the defects of their own condition may or may not affect the willingness of LDCs to reassess their development models. Continued pursuit of that development path on 
the part of the IDCs will undoubtedly lead to economic and social frustration. On the other hand, it may be that countries which pursue a thoughtfully redesigned development strategy taking into account the new energy realities will be able to establish a more favorable competitive position in the world.

3. ENERGY SYSTEM SOLUTIONS

Changes in the energy system can affect three basic areas: increased production or utilization of indigenous resources; more efficient conversion of energy from one form to another; and more efficient use of energy through development of more efficient end-use devices. Enhanced recovery of fossil fuels or use of solar radiation are examples of the first. The conversion of biomass to alcohol or coal to electricity are examples of the second. Increasing the efficiency. in the use of wood for cooking or increasing the efficiency of trucks are examples of the third.

\subsection{Energy Resource Solutions}

The applicability of a supply program depends entirely on a country's energy resource endowment, i.e., oil and gas, coal, arable land, coastal shoreline, hydro, wind, or sunshine. Each non-OPEC LDC will exploit those energy system solutions best adapted to its energy resource position.

Some countries like Mexico have exploitable coal deposits, but the largest known economically recoverable coal reserves are in India and Korea, as noted in Chapter $B$. The distribution of coal among the other non-OPEC countries is largely unknown because most areas of Africa and Latin America remain essentially unexplored. Because the energy content of coal varies widely, it is difficult to establish clearly what is and what is not economically recoverable. But deposits of low grade coal and lignite seem to be relatively widespread throughout the world.

The benefits of even a modest oil discovery would be so great that all non-OPEC developing countries, except possibly those with the bleakest geological prospects, could justify making oil resource surveys. This applies particularly to areas where there has been little or no past drilling. 
Coal follows oil as a priority fossil fuel in most of the oil importing LDCs. Availability of indigenous coal would permit its substitution for oil in electricity production, the production of process heat in industry and possibly diesel use on trains. India and China already provide examples of developing countries' use of coal.

Small fields (less than 10 million barrels of recoverable reserves) have contributed $17 \%$ of total U.S, oil production to date. ${ }^{5}$ These fields produce less than 10 barrels/day/well. These are the so-called stripper wells. They account for $80 \%$ of the oil discoveries in the U.S. between 19451969. If fields of this size were viewed as commercially exploitable at

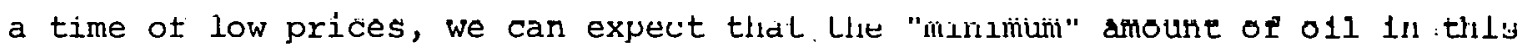
size field must have decreased in the face of the quadrupling in oil prices. In the past there have been few deliberate searches for small dejosits. The principal explorers for oil, the international oil companies; have not seen such deposits as of interest. Indeed they are not--on an international scale. At the national scale, however, they could be of great importance. There is also some evidence that small oil shale deposits, exploitable by labor intensive methods, could be a significant resource for some countries.

In the short-term coal can be used directly in most consuming sectors except transportation. The development of coal resources can provide extensive employment and can help in the development of rural areas. Increased direct combustion of coal has the possible problem of air pollution health effects: This is already evident in many LDC urban areas that use coal this way. pollution control adds to the costs of coal burning and requires enforcement-both make localized coal burning less attractive. New technologies such as fluidized bed combustion promise to allow clean burning of coal to produce electricity in small and medium sized facilities. In the long-term the role that coal can play will be determined by the success of technologies to convert coal to liquid and gaseous fuels.

The distribution of arable land can be treated as an energy resiource in that it offers the opportunity to consider the production of biomass for liquids or gaseous fuel production. Although such uses may compete with 
food production and place higher demands on scarce water resources, there are a number of potential biomass approaches which are adaptable to land only marginally useful for food production. Other biomass growth may be possible in the shallow water along coastal shorelines. ${ }^{6}$ Data on distribution of hydropower, wind, and solar insolation is more difficult to obtain.

Evaluating arable land and coastal waters in terms of their potential for reforestation or biomass material generation deserves further effort. Because the potential exploitations of these energy sources will vary widely from country to country and even within countries, these assessments will have to be specific to regions. Assessment of solar insolation is of particular importance. Almost all the LDCs are located where solar insolation is high, but the use of direct solar conversion is likely to be limited by other constraints.

Whether the oil importing LDCs will be able to exploit their indigenous resources effectively will depend on which and how much of their resources are commercially exploitable. While the division between commercial and subcommercial can be established only by cost analysis based on local conditions and estimates of the alternatives, the sharp increase in world oil prices has made it economically possible to drill with substantially smaller prospects in mind, even in the face of increased drilling custs. Other factors are transport access, sunk costs, and gas-oil ratios. In the case of coal the factors are heating value, impurities present, and the extent of the deposit. Also to be considered are conditions affecting recovery costs, including the depth of the deposit and thickness of seams.

For the lowest income LDCs who continue to rely on oil imports and who will be depleting their reserves of wood, considerations other than monetary cost will enter into decisions to try to exploit small size oil and coal resources. The determination to exploit indigenous energy resources is apt to be based on elements that go beyond the narrow engineering and economic criteria that might apply in other capital intensive resource projects. 


\section{3,2 Energy Conversion Solutions}

\section{Electrical Energy Conversion}

The largest share of electricity in the developing countries is used by industry (in India it is 75\%). This stands in contrast to the U.S. where only $40 \%$ of electricity is used in industry. Electricity is consumed in urban areas in upper income households, commercial buildings for air conditioning, and a small amount in public transportation. In seeking alternatives to reduce dependence on petroleum in the oil importing LDCs it is clear that electricity can play a much more signifirant role. In the agricultural sector elẹtricity ran he user to increasc imigativin pumpluy and to replace existing diesel operated systems. Electricity can also be used to produce fertilizer. Electricity can also provide refrigeration to reduce food spoillage. It may be able to substitute for liquid fuels in short haul trucks. Finally, it can be used much more extensively in industry. This assumes of course that non-oil based energy resources are used to generate electricity. It also assumes that ways can be found to maintain the high capital inputs that electricity systems require.

It was pointed out in Chapter B that many developing countries face increasing difficulties in seeking to expand their electric generating stations, either large scale hydro or nuclear power, both because of their size and long delays in construction. Small and medium scale on-site electric generating stations (100 kw - $1 \mathrm{Mw})$ using low grade coal, agricultural waste, wind, hydro, and solar may offer more appropriate, less costly solutions and involve less delay, particularly if standardized designs could be set. China has already put into operation numerous small scale hydro plants having capacities of $6 \mathrm{Mw}$ or less. Wind systems, although they require battery storage, could also be usable in certain locations. Snlar electric power generation employing use of solar generated steam to drive small capacity turbines (less than $1 \mathrm{Mw}$ ) is being developed. Finally, some industries which yenerate steam in their industrial processes may find it economic to cogenerate electricity. Most of these systems can be set at or near the site where they axe to be used, thus limiting distribution investments and maintenance expenses. Whilo conoiderable develupilient remains to be done 
on all these systems, collectively they may offer many LDCs, particularly those with low present demands for electricity, an opportunity to both switch away from oil used now to generate electricity and to accelerate the substitution of electricity for oil and noncommercial fuels in remote areas.

\section{Solar Energy Conversion}

There is considerable potential for the use of solar energy as decentralized LDC energy sources provided that the high capital costs for solar devices can be reduced, costs and reliability of related equipment improved, and obstacles to introduction of a new technology overcome. Solar thermal collections systems are now being used increasingly for drying fruit, grain and timber. They are also being used for water desalination and for heating and cooling. In conjunction with heat engines (Rankine cycle engines) they can be used to power irrigation pumps or produce direct electric current for local consumption. Demonstration U.S. and French units are currently operating in French West Africa and elsewhere. Solar photovoltaic systems are potentially much more flexible (since they convert solar energy directly into electrical energy) and are also appealing as LDC energy sources because they are totally encapsulated, have no moving parts, require little or no maintenance, have potentially very long useful lives, and are modular (if one unit fails, the system still operates). High capital costs, however, have limited their use to satellites, remote weather stations, and other remote applications where price of energy is not a determining factor. For the LDCs the high capital intensity and import fraction militate against solar photovoltaic systems.

Windmills and wind turbines, which capture solar energy in the form of wind energy, have been used for centuries but still account for an insignificant fraction of LDC energy production. Finally, it is possible to capture solar energy via photosynthesis, by producing and harvesting herbaceous plant species which are relatively efficient in capturing solar energy (e.g., sugarcane or sorghum, each capable of storing 38 of the sun's energy during the growing season, versus less than 18 for a highly efficient photovoltaic cell). 
More than any other present or prospective energy source, solar energy holds the promise of providing otherwise energy-poor LDCs with substantial indigenous energy. However, problems must be overcome before solar energy use becomes widespread. Current capital costs per kilowatt of installed capacity are substantially higher for solar photovoltaic systems than for, say, hydropower, except for very small facilities. Capital costs will decline only with volume production, which in turn is likely to develop only if the developed countries place multi-year orders for very large quantities. 7 While solar thermal collectors are less expensive, the Rankine cycle engines necessary to convert to mechanical energy are both expensive and relatively unproved in field conditions and would appear to require fairly sophisticated operations and maintenance. Moreover, even at lower costs, larqe scale implementation of solar thermal, solar photovoltaics, or wind energy systems will require substantial capital.

Almost as significant a constraint as capital availability in installing potentially hundreds of thousands of decentralized energy systems is the "institutional" aspect: how to convince villages and farmers to commit to a new source, how to transfer necessary technical and economic and systems operations knowledge, how to assure quality on-site erection, how to arrange for local operation and maintenance supplemented by infrequent outside assistance, etc. Finally, there is the whole issue of the impact of such systems on the structure of the local economy and society. Studies of many newly introduced technologies (including one study of Indian biogas systems) suggest that many such new systems have made the rich richer and the poor poorer. The introduction of solar-based decentralized energy systems will present the challenge of avoiding this pattern.

\subsection{Demand Sectors}

The Industrial sector

The industrial sectors in the advanced industrial countries consume 30-37\% of total energy. 8 In all but the lowest income non-OPEC LDCs this percentage tends to run at least this high or higher. (In Mexico, the industrial fraction of total energy consumption is 36z; in India, 528; 
in Brazil, 448; in Egypt, 44\%; in Turkey, 25\%.) Even so, in these countries industry contributes much less to total GNP than it does in the advanced industrial countries. Two explanations of this difference have been offered: the greater production of products with high energy input per unit of output, and the somewhat reduced efficiency in the manufacturing processes of the LDCs. Strout makes this point in his analysis of the high correlation in most LDCs between increases in GNP and increased energy consumption. 3 He shows that production in the IDCs of basic metals, paper, pulp, fertilizer and cement is closely related to the use of basic energy fuels and electricity at all different stages of development. This does not mean, however, that most of these countries are self-sufficient in these energy intensive materials, nor does it imply they should avoid becoming so. Japan, a major supplier of energy intensive materials to both the developing and developed countries, imports essentially all its fuel in the form of oil, yet has managed to turn this heavy industrial emphasis to its advantage.

The importance of industrial use of energy in almost all but the lowest income LDCs has meant that industrial energy requirements have often dominated the priorities in national energy policy. This role is likely to continue. It also means that new energy supply technologies or changes in fuel dependence introduced into industry will set precedents for other sectors.

Energy in the industrial sector is used to produce process heat and steam and motive power. Coal, naptha, fuel oil and other feedstocks are required primarily in the chemical, fertilizer and steel industries. In most developing countries oil has been used as the primary industrial. fuel. Electricity for motor drives usually comes from central grids and not on-site systems. Although the production of fertilizer that takes place in the developing countries is based on oil, it is possible to use coal or electrolysis. Because India and Korea have coal reserves which they have sought to exploit, they represent perhaps the only two members of this entire group who use coal extensively in inductry. 
Energy system solutions in the industrial sector in most of the other oil importing LDCs will have to reduce the use of oil by modernizing inefficient facilities, switching from oil to electricity (to the degree to which the added electricity can be generated from sources other than oil), or developing relatively sophisticated solar based systems. The possibility of upgrading facilities will depend on the overall growth of the economy; in general the retrofitting of existing industries is less apt to be economical. Fuel switching from oil to coal or electricity if available at comparable prices is a relatively inexpensive capital investment and is more likely to take place. Assuming solar devices becoilie more reliable and less costly over the next decade, it is possible they w111 be used In the lluse advanced LDCs; such as Singapore, Korea, Taiwan, India and Brazil. In the. lower income LDCs fuel switching from oil to charcoal is being reported with increasing frequency in industries requiring relatively small amounts of steam such as leather, pottery and brick kilns. This is placing a further strain on the already scarce resources of wood and diverting the supplies from rural households.

In some developing countries, Ghana for example, energy intensive industries are deliberately being expanded to take advantage of large reserves of untapped hydropower. The capital investments required often derive from multinational companies which enter into long-term agreements with the governments concerned. In such cases excess capacity can be developed to accommodate the needs of other industrial users.

The Transportation Sector 9

Transportation provides the indispensible channel by which resources, capital, labor and market can be linked. Except for the lowest income LDCs where the portion of GDP required for all transport and communication services is modest, the capital investment and operating expenses required for reliable transport rights of way and for development of venicle fleets can range from 5-20\% of GDP. This percentage parallels or in some cases exceeds the transport share of GDP in developed countries. Nevertheless, the the Third World, transportation capacity almost universally is inadequate to 
countries' needs for movement of goods and people. For example, in India, whose transport sector is relatively highly developed by LDC standards, broad areas of the country still are inaccessible by rail (the predominant form of transport in India) or by conventional road vehicles. South of the Sahara, black African nations have only one mechanized vehicle per 30 to 200 inhabitants. Most of these are public or commercial vehicles (in fact, worldwide, public service trucks and buses comprise 30-50\% of all vehicles in an LDC's fleet).

Although there are significant opportunities for increasing the efficiency of petroleum based transportation, the transport sector is unquestionably one of the most difficult energy end-use sectors in which to find oil substitution possibilities. Most LDCs other than India have found highway transport to be responsive to their needs and rapidly available, relative to other suface transport. Hence over the last two decades they have increased their dependence on this mode. In fact, prior to 1973, most IDCs were experiencing 10-20\% annual increases in domestic petroleum product sales.

Within urban areas of medium to high residential density and concentration of work locations, non-oil options of passenger transport (for example, electrified rail) may at times be feasible. However, a multitude of other factors--including the need to accomodate shifts in activity centers, social requirements for maximization of employment, and high capital costs of conversion to rail--suggest that this option will have only limited appeal. Bicycles and walking already are relied on extensively in most LDC cities and can be expected to be given up rapidly as personal incomes increase. A few high income developing countries (notably in Latin American and the Mediterranean) may have limited potential for restricting private passenger cars, as South Korea and a few other countries are doing. The potential energy savings in the transportation sector relative to that in developed countries will be small. 
In most LDCs, transport outside the cities not only does not afford energy conservation opportunities but in fact may be an area of rapid growth in energy, and particularly petroleum, requirements. Despite increased urbanization trends in LDCs, by the year 2000 , only in Latin America will the majority of the population be residing in urban areas. There will be more population in the rural areas of the other LDCs in the year 2000 than existed in the entire world in 1950. This population increase when combined with the goal of broadened rural development will accelerate transportation energy demand. This will be particularly true if a heavy emphasis is placed on food self-sufficiency and the use of emald coaln trenhnologies:

Similarly non-motorized means of transport will not provide the high-tonnage, long distance capacity required for economic progress in areas larger than neighborhoods. Non-motorized vehicles can provide a preliminary collection function within the network of transport requirements and can satisfy localized demands for daily goods movement of up to 75-100 tons over a distance of less than 10 kilometers. While much intra-zonal movement within urban and village settings can be accomplished with bicycles, animal-drawn vehicles, and other non-mechanical or low-power vehicles, these are similarly limited by effective transport radius and, carrying capacity.

In the long term there is the possibility of alcohol or electrically puwered veh1cles. Various nations, including Japan, Germany, USSR, USA and Brazil, have been experimenting with vegetation-derived alcohol fuel sources. Although such liquid fuels are technically successful, the wIdespread development of such industry has not yet been found to be attractive in either centrally planned or western-style economies. Brazil is at the forefront of experimentation of this fuel option being in the process of adding methanol plants alongside its numerous sugar refineries. Whllc officials there still genexally reyard the enterprise as speculative, they hope that methanol eventually will furnish 20-258 of Brazil's total domestic transport fuel consumption. Particularly within west Africa where substantial vegetable matter potentially could he available, methanol production may have promise if it does not endanger production of basic food grains. This option will be available only to those countries with sufficient land for much increased biomass production. 
Battery powered long-distance heavy-duty vehicles have not yet proven economically feasible for large scale application; and this appears to be at least 15 years into the future. Such systems have only marginal efficiency advantages (on an overall system basis), and require large capital investments in power plants and grid systems.

Although the industrialized nations could conserve sizable amounts of petroleum fuel by conversion to more energy-efficient methods of transport and organization of transport, the LDCs are not in a position of having large amounts of inefficient or unnecessary private transport within rural and urban areas. In short, there are limited options available to the LDCs in the transport sector for responding to the rise in oil prices.

The Food and Agricultural Sector

Any attempt to use energy to improve the position of the majority of the people in the developing countries must begin with the food system-that is, with food production, processing, storage, transport, distribution and preparation. Most traditional agricultural economies neither produce nor distribute enough usable food to meet the minimum nutritional needs of their people without food grain imports nor provide enough real income to allow the people to reach even minimum subsistence levels. There are of course, many reasons for this situation, including overall economic and social conditions, landlord-tenant relationships which provide no incentive to increase production, lack of agricultural extension and credit services, population pressures, etc. A substantial number of the problems however, are energy related.

The appropriate use of energy can dramatically improve an LDC's food/ agriculture position. Additional energy inputs can directly increase yields manyfold over traditional agricultural methods which rely primarily on human and/or animal energy. Small tractors reduce the time for plowing, planting and harvesting and overcome bottlenecks at critical labor shortage times, increasing yields $25 \%$ or more. Irrigation systems employing small powered pumps may more than double yields in some cases. Fertilizers 
are the largest single energy input in developed countries' food systems, and yields in some cases have increased as much as fivefold. Pesticides, mechanized harvesting, and/or improved transport can reduce pre- and post harvest pest and spoilage losses which in many LDCs exceed the amount of usable food remaining. Indirectly, the above energy inputs can both free up valuable farmer time and--by increasing food production, enabling human drinking water to be pumped from uncontaminated underground supplies--increase human energy available for other tasks. 10

Unfortunately, there are many constraints to improving energy use in the food system in LDCs:

- Most of the above energy uses currently require hydrocarbons. Substitutes are either commercially available now (e.g., methanol for use in tractors, in Brazil; coal-based fertilizers, in India; wind-powered pumps, worldwide; and biogas, in India and China), or have advanced to the demonstration phase (e.g., solar powered pumps). However, because of higher cost, perceived lower reliability, or other reasons, they have not gained wide acceptance.

- Because of the extremely low incomes in most LDCs of all but the very few farmers with large holdings, the lack of agricultural credit and the relative lack of cooperatives or other mechanisms for combining purchasing power, there is no obvious way most of those in the agricultural sector could afford to purchase such energy systems. Basically, it is hard to separate these groupsi lack of energy from lack of virtually every other financlal and nonfinancial resource.

- Experience with other "innovations"--sturdy village handpumps for drinking water which were unusable after a short period, oversized tractors unsuited to local farmers' needs, etc., suggests the difficulty of successfully achieving change in traditional agricultural economies, particularly where change is imposed from outside. 
The issue of energy use in food and agriculture is of central importance to every developing country category, since even in the most highly industrialized LDCs one-third or more of the population is engaged in agriculture. Generally, current use of inanimate energy in agriculture is highest in the more advanced countries. At the other extreme, in the African agricultural countries, the traditional agricultural sector in many cases engages over $90 \%$ of the population. In most of these countries President Julius Nyerer's statement about Tanzania applies--placing a bullock cow on every farm would be equivalent to an "Industrial Revolution." In between are the agricultural economies of South Asia, which have a mixed pattern of mechanized and nonmechanized energy.

The Urban Sector ${ }^{11}$

While no reliable data exist on this point it is safe to say that the lion's share of "residential" conventional energy use in the LDCs is consumed in the large urban regions. This is also one area in which significant opportunities exist for more efficient energy use both in terms of direct energy use and the energy employed in construction.

Urban populations of the LDCs are increasing rapidly. Table D-1 presents the most dramatic instances of metropolitan growth worlwide to the year 1995. The fourteen large conurbations in this table will jointly add a population of 163 million over the next seventeen years; all but two are located in developing countries. While in many other developing countries the absolute growth figures are smaller, in percentage growth terms they are entirely comparable to the instances included in the table. In view of the very high urbanization rates to be found in the majority of developing countries (frequently involving a doubling of their populations in fifteenyear intervals), measures that alter the structure of new additions to urban areas today will have a significant impact within five years, when they can affect 208 of the urban population. Within 15 years fully one half of the urban population can be affected. 
TABLE D-1

POPULATION PROJECTION FOR THE WORID'S LARGEST

METROPOLITAN GROWTH AREAS

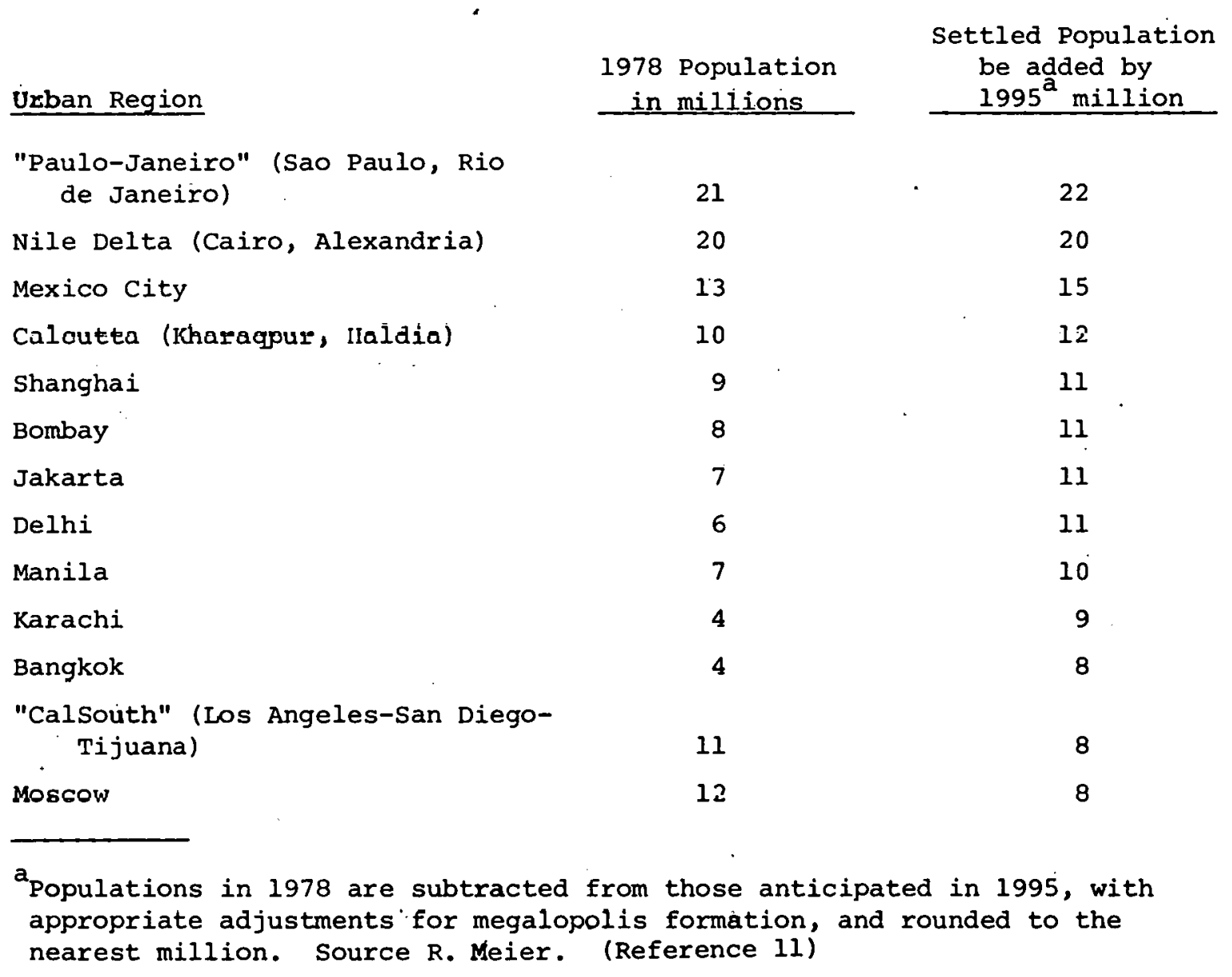

The energy conservation options available in regard to construction and urban infrastructure lead to large benefits both in terms of the energy embodied in the construotion materials and procesges, and in terms of the ongoing energy costs of operating the buildings and other urban structures. As a few examples of energy saving solutions we would note the following: 
Steel and glass office buildings, with their highly energy intensive construction materials and enormous lighting and cooling loads, account for 10-208 of commercial energy consumption in many urban areas of developing countries. The formidable institutional pressures in the U.S. behind the construction methods used to build these structures have been described in detail in a recent study.by Richard stein. ${ }^{12}$

These practices are imitated in developing countries, giving rise to heavy energy burdens, especially for cooling. Energy efficient building designs can cut the use of cement, steel, glass, metals, plastics, synthetic fibers, and other energy intensive materials while still providing comfortable, well-grouped working and living spaces. Wood, adobe, natural fibers, and other low energy locally available materials can be substituted. Palm fronds and similar thatching for roofs and walls are now extensively used in rural shelter construction; with modern architectural design methods they can be elegantly incorporated into urban residential structures, even of more than single story design. Insect-proofing and periodic renewal needs are important considerations in such design, but the problems they give rise to can be solved, especially if the attractiveness of self-help construction and maintenance methods under the excess labor conditions of developing countries are taken into account.

While the use of energy efficient construction materials cuts the embodied energy content of structures, it also can reduce renewal. Under the conditions of most developing countries, these considerations are not only important in terms of future energy commitments, but also require consideration when inherently short-lived materials may offer great energy advantages, in spite of their periodic renewal needs.

Impliclt in the earlier points is the consideration that structures must be designed for the lowest possible operating energy requirement. Natural lighting should be preferred to artificial light and building depth limited in deference to this requirement; mechanical services for heating and 
cooling should be either totally eliminated or their loads drastically reduced by control of sunlight and air penetration into the structures. ${ }^{12}$ Clustering of structures should be designed with attention to avoiding mutual increase of energy loads, e.g., by the reflection of radiant heat, blocking of wind, etc. Methods of solar heating and cooling more efficient for groups of residences than for individual houses can be designed. Urban designs in developing countries that provide for a clustering of residences to take advantage of such effects can make solar heating and cooling methods more cost-effective and more competitive with conventional alternatives.

Conventional sewer construction with its energy intensive material inputs such as cement and steel can be replaced by modern dry composting methods for sanitary wastes which not only save these costs, but by recirculating nutrients to agriculture, conserve the high energy inputs of synthetic fertilizer.

Most of other urban infrastructure needs, especially utility lines, street surfacing and transport network lengths, are sensitive to settlement densities. ${ }^{13}$ up to a point their costs and therefore their embodied energy and operating energy needs decrease with higher densities; beyond that point they increase again. Where the critical turnabout occurs is not well known but probably corresponds to the densities of the central residential neighborhoods in medium-sized United States cities. Apart from density, city size itself affects energy efficiency. The largest urban centers with their congestion and pollution problems are far less energy-efficient than closely spaced networks of smaller urban nuclei. The energy efficiency of decentralized, nucleated urban development will be taken up again in the section of developmental solutions below.

The energy system solutions discussed in this section though they pose few serious technical problems will undoubtedly meet resistance rooted in cultural conditions and established economic interests. For example, the comfortable and efficient "rancho" type thatched rural shelters in Guatemala are entirely suited to satisfying urban mass housing needs, espectally with some intelligent architectural redesign, though they meet with 
resistance from the middle-class. Such resistance cannot be lightly dismissed as irrational, since it is not only effective but indispensable for success in the competitive culture in which it arises. Widespread and serious resistance must therefore be anticipated in the introduction of many energy efficient technical solutions that may go against the grain of prevailing attitudes. Only greatly increased energy prices and/or fuel shortages are likely to change social values sufficiently to allow their usage.

\section{The Traditional Sector}

As noted above, in the traditional sectors of most developing countries, cooking accounts for the bulk (generally over 80\%) of rural household energy use. Of this amount, it is estimated that well over $50 \%$ of the energy source is firewood, which is followed by charcoal, cow dung, crop residues, and, in better-off areas, commercial fuels (primarily kerosene). The noncommercial energy which is used is used extremely inefficiently. The open fires generally used consume an estimated 3-6 times the energy of a modern gas stove to produce the same useful heat. In fact, it has been estimated that twice as much energy is used in cooking and space heating as is found in the food that is cooked. 14 In many areas in Asia and Africa, such use is causing rapid depletion of forest reserves leading to water run-off and resultant soil erosion. Also, in some cases increased use of cow dung and vegetable wastes previously returned to the land is depleting soil productivity. In some areas in Africa, for example, the lack of energy for some important domestic uses--most notably pumping for human water supply--causes very serious health problems.

A number of "appropriate technology" designs have been developed for very inexpensive cooking stoves which can be produced with locally available materials. 15 solar cookers and ovens have been designed and tested in some LDCs. Simple "passive" solar cooling designs have been developed to keep tropical homes cool. Fuelwood plantations, village woodlots, and increased use of secondary forest fuels are being demonstrated to show that traditional LDC renewable wood energy cycles can be developed and maintained. Biogas systems which use animal dung to produce both methane and fertilizers are extensively used in China and less widely so in India and some other Asian countries. 


\section{Fuelwood Plantations}

Fuelwood plantations permit close control of the nature and quality of the wood produced. The species planted is selected for its ability to grow quickly, and thus the rotation time can be reduced to as little as six to eight years. Annual production on plantations can be very high. In Africa eucalyptus plantations have achieved levels of $50 \mathrm{~m}^{3} / \mathrm{ha} . / \mathrm{yr}$. under optimal conditions. More representative figures are $20-70 \mathrm{~m}^{3} / \mathrm{ha} / \mathrm{yr}$. in South America, and 15-25 $\mathrm{m}^{3} / \mathrm{ha} . / \mathrm{yr}$. in tropical Africa. Due to their high productivity, plantations may reduce the land needed to grow the same quantity of fuel by as much as one fifth, which would be important where agricultural land is expensive.

There are some disadvantages to fuelwood plantations, however. Since they are monocultures, they tend to be more susceptible to disease. Such intensive use of the land will deplete nutrients and require fertilizers to be diverted from food production.

Fuelwood from plantations is relatively expensive due to the high capital and operating costs. For large plantations, costs run $\$ 200 / \mathrm{ha} . / \mathrm{yr}$. to produce 15 tons of fuelwood, enough to satisfy the cooking needs of 40-50 people. However, village woodlots may be more attractive since the labor now expended in the collection of fuelwood could be applied to a communal plantation which would reduce costs significantly. ${ }^{16}$

\section{Secondary Forest Fuels}

Secondary forest fuels are the result of the conversion of primary woody material to more valuable fuels by carbonization, distillation, or gasification. ${ }^{17}$ The first two processes are of most interest here as they produce fuels that are lighter and less bulky than the raw material, and thus can be transported more readily to potential markets. This would allow remote forest regions that are too far from population centers to supply fuelwood to be exploited for their energy.

\section{Biogasification}

Biogasification, or the anaerobic fermentation of organic material such as animal dung, human wastes, and crop residues to produce methane is 
another attractive technology for energy production in the rural areas of LDCs. ${ }^{18}$ Under optimal conditions, biogas contains about $65 \%$ methane $\left(\mathrm{CH}_{4}\right)$ with the remainder being largely carbon dioxide $\left(\mathrm{CO}_{2}\right)$ along with traces of hydrogen, nitrogen; and hydrogen sulphide. Furthermore the residue remaining after completion of the digestion process retains the nutrients of the organic material and is a good organic fertilizer. Thus, biogasification leads to production of both fuel (methanol) and fertilizer in a manner which does not compete with, and may even enhance, food production.

Another attractive feature of biogasification is its adaptability: systems can be designed to meet the energy needs of single families or whole communities. Since the beginning of the decade, China has made much progress in both simplifying this technology and implementing it in rural areas. In Szechwan province alone, 17 million people use biogas for cooking and lighting. In some counties of this province fully $80 \%$ of all rural households are served by biogas. 19

Biogasification could prove to be an important source of energy for rural communities in non-OPEC LDCs which have sufficient quantities of animal wastes and crop residues available, if the numerous technical, institutional, social and economic barriers to its rapid adoption can be overcome. In most LDCs outside of China which have promoted this technology, biogas systems to date have been too expensive for an average farmer to buy, and there has been a general lack of the technical expertise required to maintain the necessary control variables and supplies for optimal gas production. Moreover, institutional conditions to promote the requisite degree of cooperation necessary for operating community-size biogas systems are also generally lacking.

Solving the rural energy problem is complicated by a number of factors. For example, difficult problems are encountered in attempts to implement more efficient fuel burning practices or new cooking devices in millions of remote rural households. Earlier efforts in this area reveal the dangers of a simplistic approach. Solar cookers were actively promoted by Indian agencies in the early fifties and a commercial manufacturer was induced to begin production. This effort failed and subsequent analysis revealed that 
the failure was due to a neglect of the social cultural, climatic and economic factors involved in such a "personal" area as cooking. For example, without a storage medium, cooking had to be done in the open with the food exposed to dust, flies, birds, and even monkeys, and with the cook exposed to the sun. 20

Another approach being tested by workers at ASTRA ${ }^{21}$ (Appropriate Science and Technology for Rural Application, Bangalore, India) is based on making marginal changes in the design of traditional stoves ("chulas") to increase fuel efficiency. Preliminary results indicate that small design changes can increase efficiency as much as threefold, which would lower consumption of scarce firewood and other noncommercial fuels correspondingly. ASTRA personnel are carefully promoting the new stoves by installing pilot demonstrations in selected villages with high visibility to excite maximum interest in a large number of potential users.

Finally, in many LDCs there is no viable village institution which can finance, construct, operate or maintain a village energy system to say nothing of equitably distributing the energy produced, charging for service, etc. Although these problems have been addressed and "solved" in other contexts--for example, rural electrification--they demonstrate again that the LDC "energy problem" cannot be divorced and handled separately from economic, social and institutional aspects of the countries involved. 


\section{DEVELOPMENTAL SOLUTIONS}

Implementation of the energy system solutions outlined in the previous section could have profound effects on the development of individual countries and the non-OPEC LDCs as a group: Nevertheless, underlying the discussions of these solutions was the continuation of the role of energy in supporting development along historical lines. In this section we explore solutions that deal with changes in the structural paths of development without modifying the overall rate of growth or its general goal. As noted earlier in this chapter the existence of solutions which maintain economic and social development while making substantially lower demands on energy systems cannot be taken for granted. Almost all of the generally recognized manifestations of progress in the LDCs, such as urban migration, imports substitution, improved health services and increased life expectancy, have been associated in the past with increased energy demands. If such trends continue in the face of existing energy resource limitations, the result, at least in the intermediate term, will be a rush to "quick and dirty" development solutions to accommodate the immediate crises. Growth in industrial activity will stagnate; large fractions of the populations will have to reduce their subsistence energy requirements even further; progress toward self-sufficiency in food production will suffer, balance of payments will become further distorted. Over a longer period there will be an accommodation in which both development and energy system solutions will play major roles. The development solutions outlined below concentrate on defining the means of accommodation from an energy pexspective. They are illustrative and by no means exhaustive.

\subsection{Stabilization of the Rural and Handicraft Sector}

In the course of rapid development in predominantly private enterprise and mixed economies, major population transfers generally are accompanied by shifts from handicrafts to manufacturing industries.

This transformation has an energy impact. Handicraft-type operations are simpler and make use of more manual work and less mechanical energy than manufacturing processes. The transformation accompanying development will, accordingly, put a greater energy burden on the economy. Moreover, manufacturing operations both assemble their inputs and distribute their outputs from and 
to wider areas than handicraft operations which are typically local in their inputs and markets. The transport energy burden therefore increases with this change. Slowing the pace of rural-urban and handicraft-manufacturing shifts also alleviates many of the serious social problems of development. Retaining persons in handicraft-type or agricultural pursuits, even at low levels of productivity, and often even by the use of special subsidies, reduces the need to provide urban infrastructure at high capital and energy costs. In Mexico City, for example, drinking water can no longer be obtained from the local watershed but must be pumped up to an altitude of several thousand feet at great energy cost. 'l'he same consideration applies to municipal services, housinq, transportation and food processing. Such solutions would not aim at stopping the processes of transformation but rather would attempt to slow them and reconfiqure them so that the true goals of development might actually be attainable.

These points are of additional benefit when energy in the form of liquid fuel becomes the focus of attention. Locally renewable energy resources, such as small scale hydropower, agricultural waste and feasibility of human and animal powered methods of transit are more readily attainable in rural rather than in urban settings.

\subsection{Urban Redesign}

Although there is some qucstion as to how much leeway planners have in changing the location of economic activities, there seems little doubt that many of the largest cities in the developing countries have reached a physical size where their spatial configuration imposes severe constraints on attempts to provide more energy efficient services. Decentralization of work places, manufacturing sites and residences would not only reduce transport energy demands, but would also reduce some of the large energy consumption differentials between rural and urban settlements. Greater use of renewable construction material alluded to earlier in this section, on-site electricity generation and use of solar devices would also be possible. In many IDCs thẹ settlement structure already provides nuclei to support growth of decentralized communities. Moreover, aside from increasing energy production and use efficiencies, this kind of urban design provides additional 
benefits to residents and the government by allowing the modern sector to become more dispersed throughout the country. Although the energy advantages offered by decentralization have not been explored, the past obstacles to such decentralization have been amply documented. Even in the U.S., however, energy availability has already influenced locational decisions. The question of whether this can happen in the LDCs must therefore still be considered an open one.

\subsection{An "Alternative" Development Strategy}

Entering into almost any discussion of whether there are alternative patterns of development requiring less total energy inputs as well as less sophisticated energy systems is the example of the People's Republic of China. In what follows we try to present in minimum terms the salient features of China's energy production and utilization. The discussion draws on the work of Vaclav Smil of the University of Manitoba.

Eighty percent of the Chinese population is rural and $70 \%$ of its agriculture is still traditional in that it almost fully depends on human and animal labor. These not only fulfill directly the tasks involved in agriculture, but also are used for capital construction such as the building of water dams, irrigation systems and clearing of new land. Some 50,000 small hydro stations were operating in China in 1974, and reforestation is occurring at the rate of 500,000 hectares/year (although survival rates have been no more than 10\%). Extensive use is made of wood both as a household and an industrial fuel. Wood is also used for buildings in cities. By-products from rice, wheat, corn and other crops are used both as fuel and in the manufacture of hats, sandals, and paper.

Although Smil estimates that 808 of China's population live in a balanced "solar-dominated" ecosystem, the Chinese government has been trying to increase the use of tractors; also, the use of fertilizer tripled between 1965 and 1974. Rural coal mined with human and animal labor and electricity from small hydro systems provide some of'the energy inputs to local industries. Rural electrification to outlying villages is spreading as is the use of refined oil products. All of this represents an attempt by the government to modernize the countryside and to increase food production. 
To sustain this growing dependence on fossil fuels china is seeking to exploit its rich resources of hydropower, coal and oil, all of which it has in abundant supply. Since 1949, commercial energy consumption has increased from 23 to 500 million tons, a large share of which has gone to industry. Personal transport has been restricted and still accounts for a relatively small fraction of the commercial energy use. Electricity is generated almost exclusively from coal, and coal is burned directly to produce industrial process steam and household heating. Given industrial and agricultural aspirations and the size of the population, China seems to be intent on shifting away from what was a total dependence on renewable sources and metabulic enerqy towards a more conventional reliance on more sophisticated systems based on its plentiful supplies of fossil fuels.

Because their development solution is so tied to the unique cultural and social structure of traditional China, the conclusions drawn from the Chinese case may offer few lessons for other LDCs, especially for those. seriously deficient in energy resources. It.is possible to draw many varied and contradictory conclusions from their experience. The fact remains, however, that they have demonstrated the workability, at least for a time, of a form of development which relied almost exclusively on renewable energy resources and small scale technologies and which was able to provide an adequate energy-food balance for the total population--rural and urban. This has considerable importance for other countries in similar circumstances. On the other hand, the transition to a system relying heavily on conventional fuels for industry suggests that the decentralized renewable based form of development is likely to be chosen only as an interim strategy even in the most conducive cultural setting.

\section{THE ACCEPTABILITY AND TIME SCALE OF SOLUTIONS}

We have discussed solutions to the energy problems of developing countries in order of increasing difficulty of implementation. The most acceptable solutions, those which are easiest to implement, are those involving increased supplies of conventional fuels. These are the least disruptive of traditional "ways of doing things". We have even found this to be the case in the U.S. The next easiest to implement are modifications in 
energy conversion and then energy utilization technologies. The most difficult to implement, and the least socially acceptable, are those solutions which alter traditional developmental strategies or paths.

The time scale of these categories of solutions also follow a general trend. Enhanced conventional supply strategies can be implemented in a relatively short time scale, but do not generally solve the long-term supply problem. Technology substitutions are also a short-term palliative, unless they involve conversion to renewable resources. Long-term benefits accrue to altered development strategies, but such strategies can be implemented only over long time periods.

\section{SOME FINAL CONSIDERATIONS}

In this chapter we distinguished several kinds of approaches to the energy problems of the developing countries. In general the energy system solutions are found to be easier to implement than the solutions which alter development strategies. Among the energy system solutions those involving resource enhancement are more compatible with the existing energy system than those affecting energy conversion or end-use. Because the acceptability of foreign energy assistance programs will be greater in those areas in which the implementation of solutions is the easiest, this criterion of acceptability should be strongly emphasized into the establishment of program priorities.

Although the perceptions of the developing countries must be a paramount consideration in arriving at assistance proqrams in energy, their shortcomings must also be recognized. For example, the degree of applicability of small and medium scale technologies may be underestimated by many governments if they identify progress only with large scale, modern technologies. Although the "too poor to paint and too proud to whitewash" syndrome is difficult to overcome, the legitimizing of these technologies may constitute an important aspect of assistance.

In this country it is now widely accepted that what we term "energy conservation" is one of the most effective short-term solutions to energy problems. By conservation we usually mean two things: 1) increased efficiency in converting energy from one form to another (say from coal to electricity) 
or in converting energy to goods and services (say from electricity to cooled spaces or gasoline to vehicle-miles), and 2) reductions in the services provided by energy (such as lowered temperatures in winter, driving fewer miles, etc.). There is great sensitivity in the LDCs to the second concept, and developed countries who talk to LDCs about energy conservation run the risk of being criticized for wanting to reduce the economic growth and energy consumption of those countries. Thus, energy conservation programs, important as they are, must be approached with sensitivity to this perception, and with the emphasis placed on the first definition above. One should aim at improving the efficiency with which energy is used in order to make more feasible tho attainment of coonomio and oocial goals.

A final point of great importance is that wo should not prejudge or impose solutions. There is a strong tendency in the energy fleid to advocate certain technical solutions on the basis of philosophical commitments. The advocate of nuclear power, or of small scale technology is able to cloak his advocacy in a mantle of "hard technical data and analysis." But in many cases the technical solution has been imposed on the problem rather than solutions being derived from a clear understanding of the problem. In this respect the current LDC Energy Program of the Department of Energy and the Agency for International Development is following a productive strategy. Collaborations are being formed with countries to analyze on a systematic basis their energy supply-demand situation and to identify opportunities for resource and technology substitution. That analysis can then form the basis of identifying collaborations in resource evaluation, technology $R D \& D$, training, and planning.

One encouraging feature of the LDC energy picture which we have not stressed is that the world energy "crisis" has been a boon for some developing countries. The OPEC countries, and the oil exporting group considered in this report, have the opportunity of creating an unprecedented increase in the welfare of their people. 22 It should be pointed out, however, that the oil exporting countries share many energy related development problems with their oil-poor cousins. Their rural populations are still using energy at minimal subsistence levels. Many will also face major depletion of their oil resources within the next two to three decades and will face the necessity of replacing oil consumed internally and exported. 
A second encouraging aspect is that while there are significant obstacles to implementation the technical component of the problem as a whole is relatively large. This contrasts with many other important developmental problems, such as population regulation for which technological intervention has been complicated by strong social and political factors or counterproductive, as with the case of health aid without birth control. While recognizing the crucial social and developmental context of any intervention, there are many energy system solutions that can be dealt with at the technical level. Resource development, improvements in technical efficiency, introduction of renewable energy technologies are all areas in which technical transfer can be effective.

Thus, the increase in world oil prices which has caused the energy situation in the developing world outlined in this report has opened up a large number of solutions to the development crisis. Vast amounts of energy resources previously uneconomical have become commercially exploitable. Technologies which previously could not compete with cheap oil have virtually overnight become economical. A large number of technologies in the research and development stage have become far more interesting.

Many countries at the "take off" stage of development now have the opportunity to take advantage of the new set of factor prices. If the high growth rates of countries such as Korea can be maintained, their industrial plant will be doubled in under ten years. Thus, if they use the most modern, energy efficient industrial processes in that growth, by 1990 more than half of their industrial plant could be adapted to high energy costs. Developed countries, whose industrial sector will grow more slowly will have a less favorable mix of old and new plant capacity.

In this sense, the current situation presents a challenge and an opportunity to the advanced industrial countries. The opportunity is to bring the scientific and technical expertise of the western world to bear on a fundamental set of problems of the developing world. However, we also recognize that energy is important only as it satisfles social and economic needs. It drives the machinery of a nation in all its vast hıman, cultural and economic complexity. Programs of energy system development will succeed only if they are conceived and implemented with due respect for this underlying complexity. 


\section{THIS PAGE \\ WAS INTENTIONALLY LEFT BLANK}


CHAPTER A

NOTES AND REFERENCES

1. In this report we use the terms "developing couritry" and "less developed country" (LDC) interchangeably to refer to the 93 countries so classified by the World Bank with the exclusion of the 13 major oil exporters who are members of the organization of Petroleum Exporting Countries (OPEC). The exclusion of OPEC is somewhat artificial since many of the problems and solutions discussed in the report apply equally well to countries such as Indonesia and Nigeria. The major oil exporting countries such as Saudi Arabia are not of concern in terms of potential energy related assistance programs and are not addressed implicitly or explicitly in the report.

2. By imported energy we mean the energy contained in imported fuels, particularly oil, and the energy embodied in other imported goods and materials. In the latter category the increased cost of fertilizer on the world market since 1973 is of particular significance.

3. The term "commercial" energy generally refers to energy forms normally actively traded in developed country markets such as oil, gas, coal and electricity. The primary categories of "noncommercial" energy are wood, agricultural wastes, and animal dung. The term "noncommercial" is in fact a misnomer, since there are monetary markets for these fuels. In some contexts, the tern must be extended to include human and animal power. Other terms sometimes used for "noncommercial" are "traditional", "primitive" (vs. "modern") or "nonconventional" (vs. "conventional").

4. Public Law 95-88, August 3, 1977, Section 114 (b) 1 .

5. The 7 developed countries in CIEC were Australia, Canada, Japan, Spain, Sweden, Switzerland and the U.S. The European Economic Community also participated. The developing countries were Algeria, Argentina, Brazil, Cameroon, Egypt, India, Indonesia, Iran, Iraq, Jamaica, Mexico, Nigeria, Pakistan, Peru, Saudi Arabia, Venezuela, Yugoslavia, Zaire and Zambia. The Conference lasted from January 1976 until June 1977.

6. See statement of Richard N. Cooper to the Joint Economic Committee, U.S. Congress, June 21, 1977. 
1. This chapter is based in part on studies performed for Brookhaven National Laboratory by Gordian Associates and the Overseas Development Council.

2. The term "commercial" energy generally refers to energy forms normally actively traded in developed country markets such as oil, gas, coal and electricity. The primary categories of "noncommercial" energy are wood, agricultural wastes, and animal dung. The term "noncommercial"-is in fact a misnomer, since there are monetary markets for these fuels. In some contexts, the term must be extended to include human and animal power. other terms sometimes used for "noncommercial" are "traditional", "primitive" (vs. "modern") or "nonconventional" (vs. "convontional").

3. H. Chenery et al, , Redistribution With Growth, World Bank, Oxford University Press, 1975.

4. Economist Intelligence Unit, "Quarterly Economic Review of India, Nepal: Annual Supplement", 1976, p. 6.

5. U.N. Statistical Yearbook, 1975.

6. Morgan Guarantee Trust Company, "World Financial Markets", July 1977.

7. The characteristics of the various country groups were analyzed in the draft report to Brookhaven by Gordian Associates, Inc., washington DC, January 1978, from which these descriptions are derived.

8. U.N. World Energy Supplies 1971-1975, 1971.

9. The Economist Intelligence Unit, "Quarterly Economic Review of India, Nepal: Annual Supplement 1976", 1976.

10. The role of energy in meeting basic human needs is discussed in Chapter $\mathrm{C}$.

11, E. Friedmann, "Financing Energy in Developing Countries," World Bank Reprint Series No. 27, March 1976.

12. World Bank, "World Economic and Social Indicators", August 1977. Terms of trade is defined as the value of exports divided by the value of imports. 
13. World Bank, "World Debt Tables", September 1977 and UNCTAD, "World Economic Outlook 1977-78", February 25, 1977.

14. WAES, (Workshop on Alternative Energy Strategies), Energy: Global Prospects 1985-2000, McGraw Hill, N.Y., $197 \%$.

15. See note 7 .

16. A. Lambertini, "Energy and Petroleum in Non-OPEC Developing Countries, 1974-1980", World Bank Staff Working Paper No. 229, February 1975.

17. Income elasticity of energy demand is defined as a percentage change in energy consumption as a result of a percentage change in consumers income, given that there is no change either in price of energy or in relative prices of energy with respect to non-energy goods and services. Income elasticity of energy demand varies among developed, semi-developed, and less developed countries. Income elasticities for LDCs in general are fairly high and gradually decreases as these countries go through the development and industrialization process. In the least developed countries where consumers have subsistance levels of energy consumption, noncommercial fuels constitute a large portion of total energy consumption; and labor intensive activities dominate their economies, one expects that increase in income will lead to a significant increase in both commercial and noncommercial energy consumptions. The income elasticity for energy consumption in these countries would be high.

Income elasticity of energy demand will be affected by conservation practices, relative abundance of energy reserves, relative energy intensity of imported goods as compared to domestically produced commodities. As the economic structure of LDCs grows, more energy efficient technologies will be utilized. To the extent, that more industrial LDCs have had wasteful patterns of energy consumption, their potential for conservation measures effecting their income elasticity will be greater.

Clearly an income elasticity is a single number which represents the agreegate effects of a very complex set of processes. It should be used with due recognition of that oversimplification.

18. (a) The figure for per capita use may be low by a factor of two or more lespecially in light of the uncertainties of enduse efficiency--if substitutability is to be inferred).

(b) To compare various estimates, we have assumed that a cubic meter of wood or a metric ton of wood have an energy value of about $400 \mathrm{kgce}$. This may be in error by a factor or two, Con- 
version factors present a considerable problem, as there is so much variation in the materials used for fuels.

19. Total, rather than rural population was used because in LDCs urban use can equal or exceed rural use of uncommercial energy.

D. E. Earl quotes several separate studies in Chapter 5 of his book (Ref. 40) all of which support both that total population, and constant or ever increasing per capita.figures, should be used for projections.

20. WAES, Energy Supply-Demand Integrations to the Year 2000, MIT Press, 1977.

21. World Bank Development Policy Staff, "Prospects for Developing Countries; 1978-85", Nov. 1977 and staff discussions.

22. W. Leontief et al., The Future of the World Economy -- A United Nations Study, 1977.

23. A. M. Strout, "The Future of Nuclear Power in the Developing Countries", MIT, 1977.

24. World Energy Conference 1977, Conservation Commission, "Report on World Energy Demand 1985-2000 -- Executive Summary", August 1977.

25. World Energy. Conference Conservation Commission, "Report on Oil Resources", Report prepared by Pierre Desprairies, Institut Francais du Pétrôle, based on a Delphi-type of study drawing on the opinion of 29 experts around the world.

26. A lower bound of 50 million barrels per day is given by WAES corresponding to an OPEC production ceiling of 33 million barrels per day and low reserve additions.

27. W. J. Levy Consultants, "OPEC in the Medium-Term", New York, September 1976, cited in WAES, op, cit.

28. Gordian Associates, using Oil and Gas Journal and World Oil, see note 7 .

29. Additions, in billions of barrels, for these countries were Egypt (0.5), Ch1le (0.26), Pakistan (0.2), Argentina (0.2), Columbia (0.1), Trinidad/Tobago $(0.1)$, Bolivia $(0.1)$, and the Philippines $(0.1)$. At the other extreme, Zaire had its reserve estimate reduced by 0.35 , Spain by 0.17 , and Oman by 0.16 . 
30. R. F. Meyer, The Potential Contribution of Small Oil and Gas Deposits, $p .298$, in conference proceedings "The Future Supply of Nature-Made Petroleum and Natural Gas", IIASA and UNITAR, 5-16, July 1976, Laxenburg Austria, Perganon Press, 1977.

31. See note 29; also sedimentary estimates of Bernardo Grossling.

32. U.N. Yearbook of Industrial Statistics, 1974 Edition.

33. India builds its own $220 \mathrm{MW}$ plants. The smallest unit available from Canada is $400 \mathrm{MW}$. Although other manufacturers might take up the challenge to develop a 100-200 MW plant, they haven't as yet.

34. A Makhijani, Energy Policy for the Third World, Interrational Institute for Environment and Development, London Washinyton, 1976.

35. E. Eckholm, Losing Ground, Worldwatch/w.W. Norton, New York, 1976.

36. J. W. Howe, James Bever, William knowland, and James Tarrant, Energy for Developing Countries, Overseas Development Council, Washington, 1978 (forthcoming).

37. L. R. Brown, P. McGrath, and B. Stokes, Twenty-Two Dimensions of the Population Problem, Worldwatch Paper \#5, Worldwatch Institute, Washington, 1976 .

38. J. G. Bene, H. W. Beall, and A. Cote, Trees, Food, and People: Land Management in the Tropics, International Development Research Centre, Ottawa, 1977.

39. West African Community and CILLS, from synopsis of committee discussions of the Solar Energy and Development Symposium, 29 September-2 October, 1976, Bamako, Mali.

40. D. E. Earl, Forest Energy and Economic Development, Clarendon, Oxford, 1975 .

41. K. Openshaw, Woodfuel, a Time for Reassessment, E. African Journal, January 1977.

42. Figures for the production and apparent consumption of fuelwood as reported by the FAO and U.N., in most cases substantially understate production, since forest produce removed from privately owned land, tree litter or illegal removel from forest reserves are not recorded. In an extreme case, it was discovered that the recorded production of fuelwood and charcoal in mainland Tanzania for 1960 was less than 1.58 of the esti- 
mated consumption determined by survey ${ }^{(a)}$. Two separate studies in Bangladesh resulted in order of magnitude differences in consumption estimates $(\mathrm{b})$.

(a) K. Openshaw, (1971). Present consumption and future requirements of wood in Tanzania. Technical Report 3 FO SF/Tan 15. F.A.O., Rome.

(b) UNDP Bangladesh Energy Study, for the Government of Bangladesh, Asian Development Bank, November 1976.

43. This section was prepared by Gordian Associates. 


\section{CHAPTER C}

NOTES AND REFERENCES

1. Traditional energy sources are those in widespread use in preindustrial economies, generally synonymous with noncommercial energy, or energy sources that are not normally bought and sold. Traditional and noncommercial energy sources are generally considered to include: (a) woodfuels (both fuelwood and charcoal) (b) crop residues (such as rice and millet straw) (c) animal dung (expecially cow dung), and (d) animal draft power (both for power such as in plowing and for transport), (e) direct solar energy for drying. "Metabolic" energy, or human muscle power is often included in calculations. Though not currently used in large quantities, wind and small-scale hydro (of less than 500 kilowatts in size or for direct mechanical power rather than for generation of electricity) might also be included.

It should be noted that all of these are or can be bought and sold to some extent, and in the future it is likely that an increasing proportion of each of them will enter the market. Therefore it is obvious that the commercial/noncommercial nomenclature is not entirely accurate. Most authors still use it, however, because it is usually preferable to breakdowns such as primitive or traditional vs. modern or conventional vs. nonconventional, etc.

In practice noncommercial fuels include all but fossil fuels (petroleum, natural gas, coal, and related hydrocarbons) and electricity produced eithher from conversion of fossil fuels, nuclear fission, or hydropower.

2. R. Revelle "Energy Use in Rural India", Science 192; 969, June $4,1976$.

3. Digernes, Turi Hammer, wood for Fuel, the Energy situation in Bara Sudan, Abstract of PhD dissertation, Dept. of fengranhy, Üniversity of Bergen, Oslo, Norway, July 1977.

4. J. Howe et al., "Energy for Developing Countries", (draft) Report to the Rockefeller Foundation, October 1977.

5. A. Makhijani and A. Poole, Energy and Agriculture in the Third World, Ballinger Publishing Co., Cambridge, Mass., 1975.

6. A.K. Reddy and K.K. Prasad, "Technological Alternatives and the Indian Encrgy Crisis", Ecunuilic and Folleical weekly, August 1977. 
7. J. Parikh (Private communication).

8. Meta Systems Workshop on Rural/Domestic Energy Issues, January 1978.

9. FAO, The State of Food and Agriculture (1974).

10. M. Slesser; Food, Agriculture and the Environment, edited by J. Lenihan and W. Fletcher, Blackie Press, London 1975.

11. J. Sewall and staff of the Overseas Development Council, The United States and World Development, Agenda 1977, Praeger, New York, 1977. 
NOTES AND REFERENCES

1. The energy system encompasses all the physical, technical, economic, and institutional structures which take primary energy resources from the ground or biosphere, and then transport them and convert them into fuels, and distribute and consume them. The term also refers to the flow of those resources and fuels, recognized as a distinguishable but intertwined part of the whole socio-technical complex.

2. See, for example, J. Darmstadter, J. Dunkerley, J. Alterman, How Industrial Societies Use Energy, Johns Hopkins Press, 1977; also V. Smil and T. Kuz "Energy and the Economy--A General and National Analysis", Long Range Planning, June 1976, p.65.

3. There are at least four reasons for doubting the significance of these statistical plots as a basis for predicting the relationship between GDP/capita and energy use/capita. First, official exchange rates are used to convert all national currencies to dollars. second, the effects of energy prices have not been included in such analyses. Third, the data reflects a past bias in development that has emphasized energy intensive industries. Finally, energy figures used in these statistical analyses represent primary energy inputs and not consumed energy and thus do not show widely varying efficiencies in resource conversion to useful fuel forms. See A.M. Strout, "The Future of Nuclear Power in Developing Countries," MIT Energy Laboratory Working Paper MIT-EL 77-006WP, April, 1977.

4. R. Nathans and P.F. Palmedo, "Energy Planning and Management in Developing Countries: Thoughts Concerning a Conceptual Framework", Brookhaven National Laboratory; BNL 23340, October 1977. R. McGranahan and M. Taylor, "Urban Energy Use Patterns in Developing Countries, a Preliminary Study of Mexico City", (araft) Institute for Energy Research, SUNY at Stony Brook, December 1977.

5. Rlchard F. Meyer, "Potential Contributions of Small Oil and Gas Deposits", in "The Future Supply of Nature Made Petroleum and Gas Deposits", paper delivered at conference on 5-16 July 1976, Laxenburg, Austria,

6. Interestingly, Brazil, which is planning to replace a major fraction of its motor fuels with biomass generated alcohol before the end of the century, possesses only $3.5 \mathrm{~km}^{2} / 1000$ population of arable land. This places it in the middle range of countries on a worldwide basis. 
7. C. Weiss and S. Pake; World Bank. One can argue (See Developing Countries Application of Photovoltaic Cells", paper presented to National Solar Photovoltaic Program Review Meeting, January 20, 1976) that photovoltaic systems are in the range of competitiveness now for some LDC applications (such as remote education TV reception, refrigeration in rural health dispensaries) and that market is sufficiently large to justify the large scale production required to bring costs down.

8. Organization for Economic Cooperation and Development, Statistics of Energy, Paris, OECD, 1973. See also J. Darmstadter et al., reference 2 .

9. This discussion is based on Gordian Associates "LDC Energy Supply/ Demand Balances and Financing Requirements", Report to Brookhaven National Laboratory, January 1978.

10. Workshop on Energy Needs, Uses and Resources in the Food Systems of Developing Countries performed for this study by Cornell University on December 23, 1977.

11. This section draws on a report by Richard L. Meier, "Urbanism and Energy in Developing Regimes", January 1978--and a report by Thomas Vietorisz "Perspectives of Transportation and Liquid Fuels in the Less Developed Countries", January 1978, both prepared for the Brookhaven National Laboratory.

12. Richard G. Stein, Architecture and Energy, Anchor Press, New York, 1977.

13. T.O. Carroll, R. Nathans, and P.F. Palmedo, "Land Use and Energy Utilization", Brookhaven National Laboratory, BNL 50635, June 1977.

14. R. Revelle, "Requirements for Energy in the Rural Areas of Developing Countries", in Norman L. Brown, Ed., Renewable Energy Resources and Rural Applications in the Developing World, American Association for the Advancement of Science, Washington, 1978.

15. A useful survey of technologies appropriate to the rural sector is contained in National Academy of Sciences, Energy for Rural Development, NAS, Washington, DC 1976.

16. A.: Makhijani and A. Poole, Energy and Agriculture in the Third

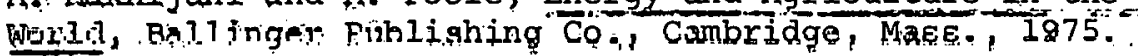

17. Carbonization, or charcoal production, which is the chemical reduction or wood, is the simplest method to upgrade the value of wood as a fuel. More than $70 \%$ of the energy content of the wood is retainer in the sharcnal and the energy content per unit weiqht is doubled as compared to air-dried wood. 
As charcoal is smokeless and almost sulphur-free, it is an ideal fuel for domestic use in towns and cities. Charcoal can be a valuable industrial fuel in direct and indirect drying processes, cement production, and even steel production where sufficient supplies are available.

Distillation: Wood can be distilled to obtain methanol, acetic acid, esters, acetone, various wood oils, and tars. Noncondensible gases are also given off which can be used as an energy source for the process. Methanol is a very high octane fuel which can be blended with petroleum. However, the yield is small, as one metric ton of wood produces only fourteen liters of methanol.

Gasification: Wood can be used as a raw material for the production of producer gas (carbon monoxide) and water gas (carbon monoxide and hydrogen). The most efficient use of producer gas is in boilers, since heat generated by the exothermic process is captured. In 1969, wood-fueled producer gas plants were operating in several LDCs (Kenya, Sri Lanka, India, and West Africa). Water gas can either be burned or used for the synthesis of methanol.

Source: D, E. Earl, Forest Energy and Economic Development, Oxford, Clarendon Press, 1976.

18. Jyoti K. Parikh and Kirit S. Parikh, "Mobilization and Impacts of Bio-Gas Technologies", Energy 2, pp. 441-445 (1977).

19. Vaclav Smil, "China Claims Lead in Biogas Supply", Energy International, June 1977, pp. 25-27

20. V. Mubayi, childhood recollection.

21. D. K. Subramaniam, ASTRA (private communication).

22. David Freeman was one of the first to stress the potential developmental benefits of oil price rises. (See S. David Freeman, Energy: The New Era, p. 116, Walker and Co., NY, 1974). One can argue, of course, that this benefit for a part of the developing world has been more than counterbalanced by the damage done to the rest of the developing world. 


\section{THIS PAGE \\ WAS INTENTIONALLY LEFT BLANK}


APPENDIX A

BASIC SOCIAL AND ECONOMIC

INDICATORS OF DEVELOPING COUNTRIES 
BASIC SOCIAL AND ECONOMIC INDICATORS (BY COUNTRY)

INDUSTRTALIZED COUNTRIES

\begin{tabular}{|c|c|c|c|c|c|c|c|c|c|c|c|c|c|c|}
\hline & Country & $\begin{array}{c}\text { GNP Per } \\
\text { Capita } \\
1974 \text { D.S. } \\
\end{array}$ & $\begin{array}{l}P C P \\
10^{6} \\
\end{array}$ & $\begin{array}{l}8 \text { Urban- } \\
\text { ization } \\
\text { (1975) } \\
\end{array}$ & $\begin{array}{c}\text { Conmercial } \\
\text { Energy } \\
\text { Consump- } \\
\text { tion } \\
\text { Per Capita } \\
\text { (1975) } \\
\end{array}$ & PQLI & $\begin{array}{c}\text { Crude } \\
\text { Dea=h Rate } \\
\text { (per } \\
1.000) \\
(=975) \\
\end{array}$ & $\begin{array}{c}\text { Infant } \\
\text { Mortality } \\
\text { Rate (per } \\
1,000) \\
(1970) \\
\end{array}$ & $\begin{array}{c}\text { Life } \\
\text { Expectancy } \\
\text { (1975) } \\
\end{array}$ & $\begin{array}{c}\text { Income } \\
\text { Received } \\
\text { By Lowest } \\
208 \\
(1975) \\
\end{array}$ & $\begin{array}{r}\text { Income } \\
\text { Received } \\
\text { By Highest } \\
58 \text { (1975) } \\
\end{array}$ & $\begin{array}{l}\text { Mnfg. } \\
\text { Value } \\
\text { Added (In } \\
\text { Producers } \\
\text { Values) } \\
\text { to GNP } \\
\end{array}$ & $\begin{array}{c}\text { Export } \\
\text { 8 of } \\
\text { GNP } \\
\end{array}$ & $\begin{array}{c}\text { Arable } \\
\text { Land (sq. } \\
\text { km 10-3) } \\
\text { Per Capita }\end{array}$ \\
\hline & Argentin $\mathrm{x}$ & 1,520 & 25.1 & 80.0 & 1,754 & 84 & 8.8 & 58.3 & 68.2 & 5.6 & 21.4 & --- & 8.3 & 8.5 \\
\hline I & Brazil & 920 & 104.2 & 59.1 & 670 & 68 & 8.8 & 110.0 & 61.4 & 3.0 & 35.0 & 44.0 & 7.8 & 3.5 \\
\hline & Chile & 830 & 10.1 & 83.0 & 765 & 77 & 9.2 & 79.0 & 62.6 & 4.8 & 31.0 & --- & 15.1 & 5.1 \\
\hline & S. Korea & 390 & 33.5 & 47.3 & 1,038 & 80 & 8.8 & ----- & 65.0 & 7.2 & 18.1 & --- & --- & --- \\
\hline & Singapore & 430 & 13.7 & 100.0 & 2,151 & 85 & 6.4 & 20.0 & 70.0 & $\cdots$ & ---- & $40.8^{*}$ & 88.0 & 6.7 \\
\hline & Spain & 2,490 & 35.2 & 59.1 & 2,147 & 94 & 8.3 & 27.8 & 72.1 & $\cdots$ & ---- & $28.7^{\star}$ & 4.7 & 6.4 \\
\hline & $\begin{array}{l}\text { Taiwan (Re- } \\
\text { public } \circ \equiv \\
\text { China) }\end{array}$ & 810 & 16 & 51.1 & 693 & 88 & 4.7 & 18.0 & 68.6 & 3.8 & 13.3 & $\cdots$ & 14.6 & 6.6 \\
\hline & Uruguay & 1,190 & 3.0 & 80.6 & 942 & 88 & 9.3 & 43.0 & 69.8 & 4.4 & 19.0 & $\cdots$ & 12.0 & 8.1 \\
\hline & Yugoslav=a & 1,310 & 21.2 & 39.0 & 1,930 & 85 & 9.2 & 56.0 & 68.0 & 5.6 & 15.1 & $\cdots$ & 10.7 & 4.2 \\
\hline
\end{tabular}

* Value edded in factor values. 
BASIC SOCIAL AND ECONOMIC INDICATORS (BY COUNTRY)

OIL EXPORTERS

\begin{tabular}{|c|c|c|c|c|c|c|c|c|c|c|c|c|c|c|}
\hline & Country & 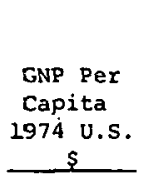 & $\begin{array}{l}\text { POP } \\
106 \\
\end{array}$ & $\begin{array}{l}\text { Urban- } \\
\text { ization } \\
\text { (1975) } \\
\end{array}$ & $\begin{array}{c}\text { Commercial } \\
\text { Energy } \\
\text { Consump- } \\
\text { tion } \\
\text { Per Capita } \\
\text { (1975) } \\
\end{array}$ & PQLI & $\begin{array}{c}\text { Crude } \\
\text { Death Rate } \\
\text { (per } \\
1,000) \\
(1975) \\
\end{array}$ & $\begin{array}{c}\text { Infant } \\
\text { Mortality } \\
\text { Rate (per } \\
1,000) \\
(1970) \\
\end{array}$ & $\begin{array}{c}\text { Life } \\
\text { Expectancy } \\
\text { (1975) } \\
\end{array}$ & $\begin{array}{l}\text { Income } \\
\text { Received } \\
\text { By Lowest } \\
208 \\
(1975) \\
\end{array}$ & $\begin{array}{r}\text { Income } \\
\text { Received } \\
\text { By Highest } \\
58 \text { (1975) } \\
\end{array}$ & $\begin{array}{l}8 \text { Mnfg. } \\
\text { Value } \\
\text { Added (In } \\
\text { Producers } \\
\text { Values) } \\
\text { to GNP } \\
\end{array}$ & $\begin{array}{c}\text { Export } \\
\text { 8 of } \\
\text { GNP } \\
\end{array}$ & $\begin{array}{c}\text { Arable } \\
\text { Land (sq. } \\
\text { km } 10^{-3} \text { ) } \\
\text { Per Capita }\end{array}$ \\
\hline & Ang̣ola & 710 & 6.4 & --- & 174 & 15 & --- & ----- & $-\cdots$ & --- & --- & $\cdots$ & -- & --- \\
\hline & Bolivia & 280 & 5.5 & 37.2 & 303 & 45 & 18.0 & 154.0 & 46.8 & 4.0 & 36.0 & 5.6 & 21.4 & 3.1 \\
\hline 1 & Congo & 470 & 1.3 & 38.0 & 209 & 25 & 20.8 & $-\cdots$ & 43.5 & --- & --- & $-\cdots$ & 34.7 & .03 \\
\hline & Egypt : & 280 & 36.4 & 44.3 & 405 & 46 & 14.0 & 103.0 & 52.4 & --- & --- & 12.0 & --- & ---- \\
\hline I & Malaysia & 680 & 11.6 & 26.8 & 552 & 59 & 9.9 & 41.0 & 59.4 & 3.5 & 28.3 & --- & ---- & $3: 4$ \\
\hline & Mexico & $L, 090$ & 58.1 & 63.3 & $1 ; 221$ & 75 & 8.6 & 61.0 & 63.2 & 2.1 & 30.2 & $-\cdots$ & 5.3 & 5.2 \\
\hline & Oman & $L, 660$ & 0.7 & 5.0 & 334 & N.A. & 18.7 & --- & 47.0 & --- & ---- & --- & $-\cdots$ & ---- \\
\hline & $\begin{array}{l}\text { Syrian } \\
\text { Arab Rep. }\end{array}$ & . 560 & 7.1 & 45.9 & 477 & 52 & 15.4 & 93.0 & \multirow{3}{*}{69.5} & --- & --- & 15.5 & 16.7 & .01 \\
\hline & $\begin{array}{l}\text { Trinidad and } \\
\text { Tobago }\end{array}$ & $L, 700$ & 1.2 & 25.1 & 3,132 & N.A. & 5.9 & 35.0 & & --- & --- & $\cdots$ & 62.1 & 1.7 \\
\hline & Tunisia & 650 & 5.6 & 47.5 & 447 & 44 & 13.8 & 106.0 & & --- & $\cdots$ & 9.9 & 13.5 & .01 \\
\hline
\end{tabular}

* value added in factor values. 
BASIC SOCIAL AND ECONOMIC INDICATORS (BY COUNTRY)

BR.LANCED GROWTH ECONOMIES

\begin{tabular}{|c|c|c|c|c|c|c|c|c|c|c|c|c|c|c|}
\hline & Country & \begin{tabular}{c} 
GVP Per \\
Capita \\
1974 U.S. \\
\multicolumn{3}{|c}{} \\
\end{tabular} & $\begin{array}{l}\text { POP } \\
10^{5} \\
\end{array}$ & $\begin{array}{l}\text { 8 Urban- } \\
\text { ization } \\
\text { (1975) } \\
\end{array}$ & $\begin{array}{c}\text { Commercial } \\
\text { Energy } \\
\text { Consump- } \\
\text { tion } \\
\text { Per Capita } \\
\text { (1975) } \\
\end{array}$ & PQLI & $\begin{array}{c}\text { Crude } \\
\text { Death Rate } \\
\text { Jper } \\
1,000) \\
(1975) \\
\end{array}$ & $\begin{array}{c}\text { Infant } \\
\text { Mortality } \\
\text { Rate (pex } \\
1,000) \\
(1970) \\
\end{array}$ & $\begin{array}{c}\text { Life } \\
\text { Expectancy } \\
(1975) \\
\end{array}$ & $\begin{array}{l}\text { Income } \\
\text { Received } \\
\text { By Lowest } \\
208 \\
(1975) \\
\end{array}$ & $\begin{array}{r}\text { Income } \\
\text { Received } \\
\text { By Highest } \\
58 \text { (1975) } \\
\end{array}$ & $\begin{array}{l}\text { Mnfg. } \\
\text { Value } \\
\text { Added (In } \\
\text { Producers } \\
\text { Values) } \\
\text { to GNP } \\
\end{array}$ & $\begin{array}{c}\text { Export } \\
\text { of of } \\
\text { GNP } \\
\end{array}$ & $\begin{array}{c}\text { Arable } \\
\text { Land (sq. } \\
\text { km } 10^{-3} \text { ) } \\
\text { Per Capita }\end{array}$ \\
\hline & Colombia & 500 & 24.0 & 53.0 & 671 & 71 & $\varepsilon .8$ & 70.0 & 60.9 & 3.5 & 31.9 & $39.9^{\star}$ & 10.0 & 2.6 \\
\hline & Greece & 2,090 & 9.0 & 53.2 & 2,090 & 91 & 9.4 & 29.6 & 71.8 & -- & --- & 4.1 & 5.7 & 4.4 \\
\hline & India & 140 & 586.2 & 20.6 & 221 & 41 & 15.7 & 130.0 & 49.5 & 4.7 & 25.0 & --- & 3.7 & 3.2 \\
\hline & Pakistan & 130 & 68.2 & 26.0 & 1.33 & $3 ?$ & 16.5 & 115.0 & 49.8 & 8.4 & 17.3 & 11.3 & 5.5 & 2.4 \\
\hline & Panama & $\therefore, 000$ & 1.62 & 49.5 & 855 & 81 & $\therefore 1$ & 41.0 & 66.5 & 4.6 & 22.2 & 19.4 & 11.9 & 4.3 \\
\hline & Peru & 740 & 15.4 & 55.3 & 632 & 58 & $1 \pm .9$ & 75.0 & 55.7 & 1.8 & 31.4 & 30.5 & 16.8 & 2.1 \\
\hline & Philippines & 330 & 41.5 & 29.0 & 326 & 73 & 10.5 & 80.0 & 58.4 & 3.9 & 24.8 & 15.7 & 14.3 & 2.3 \\
\hline & Turkey & 750 & 38.3 & 41.8 & 630 & 54 & 12.5 & 145.0 & 56.9 & 2.9 & 32.8 & --- & 5.3 & 8.3 \\
\hline
\end{tabular}

\footnotetext{
* value ałdec in faztor values.
} 
BASIC SOCIAL AND ECONOMTC INDICATORS (BY COUNTRY)

PRIMARY EXPORTERS

\begin{tabular}{|c|c|c|c|c|c|c|c|c|c|c|c|c|c|c|}
\hline & Country & $\begin{array}{c}\text { GNP Per } \\
\text { Capita } \\
1974 \text { U.S. } \\
\quad s \\
\end{array}$ & $\begin{array}{l}\text { POP } \\
106 \\
\end{array}$ & $\begin{array}{l}\text { Urban- } \\
\text { ization } \\
\text { (1975) } \\
\end{array}$ & $\begin{array}{c}\text { Commercial } \\
\text { Energy } \\
\text { Consump- } \\
\text { tion } \\
\text { Per Capita } \\
\text { (1975) } \\
\end{array}$ & PQLI & $\begin{array}{c}\text { Crude } \\
\text { Death Rate } \\
\text { (per } \\
1,000) \\
(1975) \\
\end{array}$ & $\begin{array}{l}\text { Infant } \\
\text { Mortality } \\
\text { Rate (per } \\
1,000) \\
(1970) \\
\end{array}$ & $\begin{array}{c}\text { Life } \\
\text { Expectancy } \\
(1975) \\
\end{array}$ & $\begin{array}{l}\text { Income } \\
\text { Received } \\
\text { By Lowest } \\
208 \\
(1975) \\
\end{array}$ & $\begin{array}{r}\text { Income } \\
\text { Received } \\
\text { By Highest } \\
58 \text { (1975) } \\
\end{array}$ & $\begin{array}{l}\text { Mnfg. } \\
\text { Value } \\
\text { Added (In } \\
\text { Producers } \\
\text { Values) } \\
\text { to GNP } \\
\end{array}$ & $\begin{array}{c}\text { Export } \\
\text { o of } \\
\text { GNP } \\
\end{array}$ & $\begin{array}{c}\text { Arable } \\
\text { Land (sq. } \\
\mathrm{km} 10^{-3} \text { ) } \\
\text { Per Capita } \\
\end{array}$ \\
\hline & Botswana & 290 & 0.66 & 12.3 & ,---- & 38 & 23.0 & 126.0 & 43.5 & 1.6 & 28.1 & ---- & -..- & 2.9 \\
\hline & Guinea & 120 & 4.3 & 19.5 & 92 & 20 & 22.9 & ----- & 41.0 & --- & --- & --- & 15.5 & ---- \\
\hline 1 & Guyana & 500 & 0.78 & $: 40.0$ & 1,114 & 84 & 5.9 & 38.0 & $67: 9$ & --- & ---- & --- & 47.5 & 2.8 \\
\hline & Jamaica & 1,190 & 2.0 & 37.1 & 1,427 & 87 & 7.1 & 32.0 & 69.5 & -- & ---- & 19.1 & 25.5 & 1.3 \\
\hline I & Liberia & 390 & 1.67 & 27.6 & 404 & 26 & 20.7 & 159.0 & 43.5 & 5.3 & 61.7 & -..- & 57.9 & .03 \\
\hline & Mauritania & 290 & 1.3 & 21.7 & 108 & 15 & 24.9 & --.-- & 38.5 & --- & ---- & $-\ldots$ & 42.5 & 2.1 \\
\hline & Morocco & 430 & 16.9 & 37.9 & 274 & 40. & 15.7 & 57.0 & 52.9 & --- & , ---- & ---- & 17.8 & 6.2 \\
\hline & Sierra Leone & 190 & 2.7 & 15.0 & 116 & 29 & 20.7 & 183.0 & 43.5 & 1.1 & 36.2 & ---- & 22.7 & .02 \\
\hline & Surinam & 1,180 & 0.38 & ---- & 2,063 & 85 & --- & ----- & --- & --- & --- & --- & ---- & ---- \\
\hline & Togo & 250 & 2.17 & 15.0 & 65 & 28 & 23.3 & $-\cdots$ & 41.0 & --- & ---- & 2.2 & 15.7 & .01 \\
\hline & Zaire & 150 & 24.2 & 26.4 & 78 & 28 & 20.5 & ---- & 43.5 & --- & --- & 7.7 & ---- & ---- \\
\hline & Zambia & 520 & 4.7 & 34.0 & 504 & 28 & 20.3 & ----- & 44.5 & ---- & ---- & 10.3 & 74.9 & 5.0 \\
\hline
\end{tabular}


BASXC SOCTAI AND RCONOMIC INDICATORS (BY COUNTRY)

AGRICULTURAL EXPORTERS

\begin{tabular}{|c|c|c|c|c|c|c|c|c|c|c|c|c|c|c|}
\hline & Country & $\begin{array}{c}\text { GNP Per } \\
\text { Capita } \\
1974 \mathrm{U} . \mathrm{S} . \\
\end{array}$ & $\begin{array}{l}\text { POP } \\
\underline{106} \\
\end{array}$ & $\begin{array}{l}8 \text { Urban- } \\
\text { ization } \\
\text { (1975) }\end{array}$ & $\begin{array}{c}\text { Conmercial } \\
\text { Energy } \\
\text { Ccnsump- } \\
\text { tion } \\
\text { Per Capita } \\
\text { (1975) } \\
\end{array}$ & PQLI & $\begin{array}{c}\text { Crude } \\
\text { Death Rate } \\
\text { (per } \\
1,000) \\
(1975) \\
\end{array}$ & $\begin{array}{c}\text { Infant } \\
\text { Mortality } \\
\text { Rate (per } \\
1,000) \\
(1970) \\
\end{array}$ & $\begin{array}{c}\text { Life } \\
\text { Expectancy } \\
\text { (1975) } \\
\end{array}$ & $\begin{array}{c}\text { 8. Income } \\
\text { Received } \\
\text { By Lowest } \\
20.8 \\
1(1975) \\
\end{array}$ & $\begin{array}{l}\text { I.acome } \\
\text { Received } \\
\text { By Highest } \\
58 \text { (1975) } \\
\end{array}$ & $\begin{array}{l}\text { Mnfg. } \\
\text { Value } \\
\text { Added (In } \\
\text { Producers } \\
\text { Values) } \\
\text { to GNP } \\
\end{array}$ & $\begin{array}{c}\text { Export } \\
\text { of } \\
\text { GNP } \\
\end{array}$ & $\begin{array}{c}\text { Arable } \\
\text { Land (sq. } \\
\text { km } 10^{-3} \text { ) } \\
\text { Per Capita }\end{array}$ \\
\hline 1 & Costa Rica & 840 & $1 . \subseteq 2$ & 40.6 & 544 & $N / A$ & 5.8 & 60.0 & 69.1 & 5.4 & 22.8 & --- & 17.6 & 3.9 \\
\hline טّ & Dom. Rep. & 650 & 4.56 & 42.0 & 458 & 64 & 11.0 & 50.0 & $5 ? .8$ & 4.1 & 26.1 & 2.4 & 12.9 & 2.7 \\
\hline 1 & Gambia & 170 & $0 . E_{1}$ & 14.0 & $\cdot 66$ & 22 & 24.1 & 83.0 & 40.0 & --- & --- & ---- & 45.4 & 4.8 \\
\hline & Guatemala & 58.0 & 5.6 & 33.8 & 237 & 5.3 & 13.7 & 83.0 & 54.1 & --- & -- & 10.2 & 12.4 & 3.1 \\
\hline & Honduras & 340 & $2 . \varsigma_{3}$ & 31.0 & 232 & 50 & 14.6 & ---- & 53.5 & 2.5 & 28.0 & --- & 23.6 & 3.3 \\
\hline & Ivory Coast & $4 \in: 0$ & $4 . \varepsilon$ & 34.3 & $\Xi 66$ & 23 & 20.6 & 140.0 & 43.5 & 9.0 & $\cdots$ & --- & 11.4 & 5.1 \\
\hline & Senegal & 330 & 4.3 & 29.0 & 195 & 22 & 23.9 & 156.0 & 40.0 & --- & --- & -..- & 16.6 & .02 \\
\hline & Sri Lanka & 130 & 13.7 & 22.4 & 127 & 83 & 6.3 & 50.0 & 67.0 & 7.3 & -8.6 & --- & $-\cdots$ & --- \\
\hline & Thailand & 310 & 41.0 & 16.5 & 284 & 70 & 10.8 & 80.0 & 58.0 & -- & --- & 5.7 & 3.4 & 3.4 \\
\hline
\end{tabular}


BASIC SOCIAL AND ECONOMIC INDICATORS (BY COUNTRY)

OTHER AGRICULTURAL

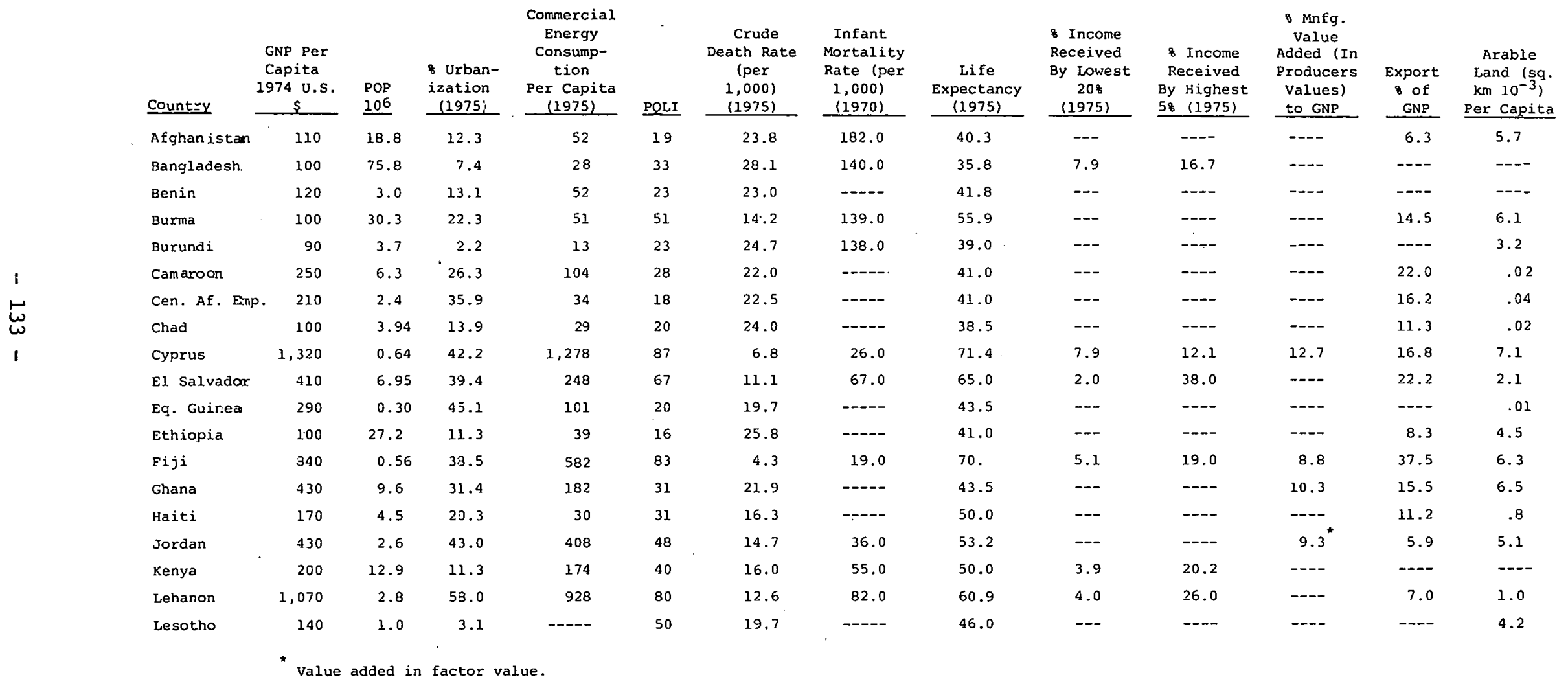


BASIC SOCIAL AND ECONOMIC INDICATORS (BY COUNTRY)

OTAER AGRICULTURAL (Continued)

\begin{tabular}{|c|c|c|c|c|c|c|c|c|c|c|c|c|c|}
\hline Country & $\begin{array}{c}\text { GNP Per } \\
\text { Capita } \\
1974 \text { v.S. } \\
\quad S \\
\end{array}$ & $\begin{array}{l}\text { PCP } \\
\underline{106} \\
\end{array}$ & $\begin{array}{c}\text { 8 Urban- } \\
\text { i=ation } \\
\text { 19?5) }\end{array}$ & $\begin{array}{c}\text { Commezcial } \\
\text { Enezgy } \\
\text { Consump- } \\
\text { tion } \\
\text { Per Capita } \\
\text { (1975) } \\
\end{array}$ & POLI & $\begin{array}{c}\text { Crude } \\
\text { Death Rate } \\
\text { :per } \\
1000) \\
(: 975) \\
\end{array}$ & $\begin{array}{c}\text { Infant } \\
\text { Mortality } \\
\text { Rate (per } \\
1,000) \\
(1970) \\
\end{array}$ & $\begin{array}{c}\text { Life } \\
\text { Expectancy } \\
(1975) \\
\end{array}$ & $\begin{array}{l}8 \text { Income } \\
\text { Received } \\
\text { By Lowest } \\
208 \\
(1975) \\
\end{array}$ & $\begin{array}{l}\text { Income } \\
\text { Received } \\
\text { By Highest } \\
58 \text { (1975) } \\
\end{array}$ & $\begin{array}{l}\text { Mnfg. } \\
\text { Value } \\
\text { Added (In } \\
\text { Producers } \\
\text { Values) } \\
\text { to GNP } \\
\end{array}$ & $\begin{array}{c}\text { Export } \\
\text { \& of } \\
\text { GNP } \\
\end{array}$ & $\begin{array}{c}\text { Arable } \\
\text { Land (sq. } \\
\text { km 10-3) } \\
\text { Per Capita } \\
\end{array}$ \\
\hline Madagasc:ar & 180 & 2.3 & 14.5 & 71 & 44 & 21.1 & 102.0 & 43.5 & --- & ---- & 8.0 & --- & ----- \\
\hline Malawi & 130 & 4.9 & 5.0 & 56 & 29 & 33.7 & $-\cdots-$ & 41.0 & 5.7 & 29.5 & $8.9^{*}$ & 19.8 & 3.3 \\
\hline Mali & 80 & 5.6 & $-\cdots$ & 25 & 15 & 25.9 & $-\cdots$ & 38.0 & --- & ---- & ---- & 5.6 & .01 \\
\hline Mauritius & 580 & 0.9 & 48.3 & 279 & 75 & 6.8 & 57.0 & 65.5 & 4.5 & 45.0 & 15.0 & 40.6 & 1.2 \\
\hline Mozambique & 340 & 90 & 55.0 & 186 & 23 & 21.4 & -- - & 41.0 & --- & ---- & $-\cdots$ & --- & ----- \\
\hline Nepal & 100 & 12.3 & 4.0 & 10 & 25 & 20.3 & -..-- & 43.6 & --- & --- & --- & --- & 6.8 \\
\hline Nicaragua & 670 & 2.0 & 49.0 & 479 & 53 & 7.1 & $45.0^{\circ}$ & 66.5 & 4.6 & 22.2 & ---- & 24.5 & 5.1 \\
\hline Niger & 120 & 0.9 & 9.4 & 35 & 14 & 25.5 & -..-- & 38.5 & --- & --- & -... & 8.8 & .040 \\
\hline $\begin{array}{l}\text { Papua N. } \\
\text { Guinea }\end{array}$ & 470 & 2.7 & 11.0 & 278 & 34 & --- & -..-- & 47.7 & --- & ---- & -...- &.-- & ---. \\
\hline Paraguay & 510 & 2.6 & 36.0 & 153 & 74 & 10.8 & 67.0 & 62.0 & 4.0 & 30.0 & $-\cdots$ & 13.2 & 4.1 \\
\hline Rwanda & 80 & 4.1 & 3.8 & 14 & 27 & 23.6 & 133.0 & 41.0 & --- & ---- & 6.7 & 10.6 & 3.0 \\
\hline Somalia & 90 & 0.5 & 28.3 & 36 & 19 & 21.7 & ----- & 41.0 & -- & ---- & -..- & 24.8 & 3.6 \\
\hline Swaziland & 390 & 0.5 & 7.9 & --- & -- & 21.8 & $-\ldots-$ & 43.5 & --- & --- & $\ldots-$ & $\star \star$ & 6.7 \\
\hline Sudan & 230 & 17.3 & 13.2 & 140 & 33 & -17.5 & ---- & 50.6 & 5.1 & --- & 5.0 & 13.7 & 4.9 \\
\hline Tanzania & 160 & 14.8 & 7.5 & 70 & 28 & 20.1 & 160.0 & 44.5 & 2.3 & 33.5 & -.-- & --- & .010 \\
\hline Uganda & 240 & 11.2 & 7.1 & 55 & 33 & 15.9 & ---- & $5 c .0$ & 6.2 & 20.0 & --- & 22.6 & 4.9 \\
\hline Upper Vclta & 90 & 5.9 & 11.0 & 20 & 17 & 25.8 & $-\cdots$ & $3 \varepsilon . G$ & -- & --- & --- & 5.5 & 9.7 \\
\hline Yemen A. Rep. & 180 & 6.5 & 5.4 & $\angle 9$ & 27 & 20.6 & $-\cdots$ & $37 . c$ & -- & -- & 2.9 & $-\cdots$ & ----- \\
\hline
\end{tabular}

* Value adted in factcr values.

** No exports listeć. 
GNP Per Capita ${ }^{a}$

KEY TO DATA

1974 U.S. dollars.

Population

1974 estimated

Percent Urbanization

Urban population as percentage of total population. (Different

definitions of urban areas may affect comparability of data.)

Commercial Energy Consumption d

Per Capita, 1975. Kilograms: of coal equivalent per capita.

PQLI (Physical Quality of Life Index ${ }^{h}$

Scaled from 1 to 100 , see Chapter $\mathrm{C}$

Crude Death Rate

Per thousand of mid-year population; an estimated 5-year average ending in 1975.

Infant Mortality ${ }^{e}$

Rate per 1000 live births; 1970 figure.

Life Expectancyc

Average number of years of life remaining at birth (usually 5-year average, ending in 1975).

Income Received by Lowest $20 \%$ of Households ${ }^{c}$

Percent of private income (both in cash and kind); 1975 figures.

Income Received by Highest $5 \%$ of Households ${ }^{c}$

Percent of private income (both in cash and kind); 1975 figures.

Manufacturing Value Added $f$

Producers Values Except Where Otherwise Noted as Percent of GDP

Figures pulled from industrial statistics for year in 1970-1974

range and GDP corresponds to that year; there are country to

country variations.

Exports as percent of GNP

Latest figures available from oxford Economic Atlas.

Arable Iand (Square Kilometers) Per Capita ${ }^{9}$

Latest figures available from Oxford Economic Atlas.

a World Bank Atlas, 3.976.

b U.N. Statistical Yeárbook 1975

Table 18 .

c World Bank, World Economic \& Social Indicators, May-June 1977.

d U.N. World Energy Supplies, 19711795 , Seriés J, 1977. e World Bank, World Tables 1976.

f U:N. Yearbook of Industrial Statistics 1975, 1977.

$g$ Oxford Economic Atlas.

h Overseas Development Council The United States and World Development, Agenda 1977, Praeger, N.Y., 1977 . 


\begin{tabular}{|c|c|c|c|}
\hline Industrialized & $\mathrm{R}$ & $\mathbf{P}$ & $R_{R / P^{(c}}$ \\
\hline Argentina & 2.50 & 440 & 16 \\
\hline Brazil & .88 & 162 & 15 \\
\hline Child & .44 & 22 & 35 \\
\hline
\end{tabular}

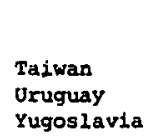

TOTAL

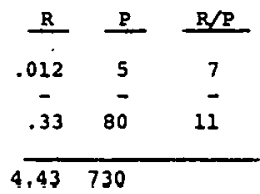

Oil Exporters

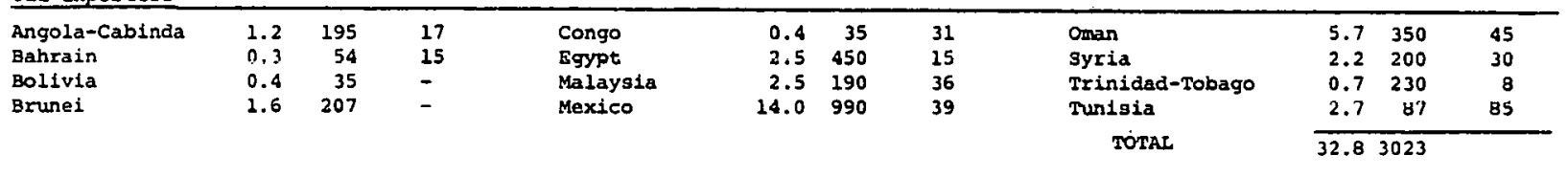

Balanced Economies

\begin{tabular}{|c|c|c|c|c|c|c|c|c|c|c|c|}
\hline Colombia & .96 & 140 & 19 & Pakistan & .28 & 10 & 77 & Peru & .73 & 90 & 22 \\
\hline \multirow[t]{2}{*}{ Greece } & .63 & - & - & Panama & - & $=$ & - & $\begin{array}{l}\text { Philippines } \\
\text { Turkey }\end{array}$ & $\begin{array}{l}.1 \\
.37\end{array}$ & 65 & 16 \\
\hline & & & & & & & & TOTAL & 5.47 & $\overline{505}$ & \\
\hline
\end{tabular}

Primary Exporters

Botswana

Guinea

Guyana

$\begin{array}{ll}- & - \\ - & -\end{array}$

Liberia

Mausitania

Moroceo

$\begin{array}{ccc}- & - & - \\ -00015 & 0.4\end{array}$

$\begin{array}{ll}- & \text { Togo } \\ \text { - } & \text { Zaire } \\ & \text { Zambia }\end{array}$

slerra Leone

Zambia

TOTAL

\begin{tabular}{rrr}
- & - & - \\
.15 & 24 & 17 \\
- & - & - \\
\hline 15 & 24
\end{tabular}

Aqricultural

Afghanistan

Bangladesh

Benin

Burma

Burundi

Cameroon

Central Afr.emp.

Chad

Camoros

Costa Rica

Gyprus

Dominican Republic

El Salvador

Eq. Guinea

Ethiopia

Eiji

$\begin{array}{lrr}.084 & 0.2 & 1150 \\ - & - & - \\ -055 & 23 & - \\ - & - & - \\ .06 & - & - \\ - & - & - \\ - & - & - \\ = & - & - \\ - & - & - \\ - & - & - \\ - & - & - \\ - & - & - \\ - & - & - \\ - & - & - \\ - & - & -\end{array}$

$\begin{array}{lcl}\text { Gambia } & - \\ \text { Guatemala } & .016 \\ \text { Ghana } & - \\ \text { Haiti } & - \\ \text { Honduras } & - \\ \text { Ivory Coast } & - \\ \text { Jordan } & - & - \\ \text { Lebanon } & - \\ \text { Lesotho } & - \\ \text { Madagascar } & - \\ \text { Malawi } & - \\ \text { Mali } & - & - \\ \text { Mausitius } & - & - \\ \text { Mozambique } & - & - \\ \text { Nepal } & - & - \\ \text { Nicaragua } & - & -\end{array}$

$\begin{array}{ll}- & - \\ - & - \\ - & - \\ - & = \\ - & - \\ - & - \\ - & - \\ - & - \\ - & - \\ - & - \\ - & - \\ - & -\end{array}$

Source: Gordian Associates, Inc., based on 011 and Gas Journal and World Oil.

Niger
Papua New Guinea
Paraguay
Rwanda
Sonoral
Somalia
Gri Ianka ,
Sudan
Susinam
Swaziland
Tanzania
Thailand
Uganda
Upper Volta
Yamen Arab Rop.

TOTAL

ALL COUNTRIES

\begin{tabular}{ccc}
- & - & - \\
- & - & - \\
- & - & - \\
- & - & - \\
- & - & - \\
- & - & - \\
- & - & - \\
- & - & - \\
- & - & - \\
- & - & - \\
- & - & - \\
.00027 & 0.2 & 4 \\
- & - & - \\
- & - & - \\
- & - & - \\
\hline 22 & 23 & \\
\hline 4.1 & 4305
\end{tabular}

(a) Estimated proved crude oil reserveg as of Jan. 1, 1978 (billions of barrels).

(b) 1977 Production (thousands of barreis per day).

(c) Ratio of reserves to annual production (barrels/barrels per year). 


\section{APPENDIX B}

\section{WORKSHOPS}

As part of this study three workshops were held to discuss energy problems in developing countries as they relate to 1) the food system, 2) rural/domestic issues, 3) resource management. The purpose of the workshops was to clarify the major issues and to make recommendations on programmatic areas for U.S. assistance in these sectors. A brief discussion of the conclusions of these three workshops are outlined below and a list of the participants follows.

\section{A. Food System}

The Workshop on "Energy Needs, Uses and Resources in the Food Systems of Developing Countries" was held at Cornell University on December 23, 1977. The participants found that specific energy technologies that are environmentally sound and would significantly aid the economic development of the rural poor include reforestation, simple cooking stoves, food storage facilities, and soil and water conservation. In addition, appropriate use of power technology could reduce the time spent plowing, planting and harvesting crops, thereby raising ágricultural production and increasing employment: The report by this group stresses the importance of a sound program of planned resource management for each country since the available energy and environmental resources for each country are unique. The report recommends that these resources. then be managed as a total system, since the factors that make up the food system are closely interrelated. 


\section{Energy Needs, Uses and Resources}

in the Food Systems of Developing Countries

Workshop

List of Participants

\author{
Dr. Edward S. Ayensu, Director \\ Endangered Species Program \\ Smithsonian Institution \\ Dr. Edward Beardsworth \\ Brookhaven National Laboratory \\ Dr. Norman Brown \\ Country Program Specialist \\ office of International R\&D Programs \\ ERDA \\ Dr. Vashek Cervinka \\ California Department of Food \& \\ Agriculture \\ Dr. Otto Doering \\ Agricultural Economics Dept. \\ Purdue University \\ Dr. James Keiser \\ Brookhaven National Laboratory \\ Mr. W1111am Knowland \\ Overseas Development Council \\ Mr. Stephen Klein \\ Deputy Director of Development \\ Resources \\ Bureau of Africa \\ AID \\ Dr. Walter Lynn \\ Civil Environmental Engineering \\ Cornell University
}

Technical assistance provided by:

Ephraim Back

Marion Harris
Dr. Joseph Metz

International Agriculture

Cornell University

Dr. David Pimentel*

College of Agriculture and Life Geionaea

Cornell University

Dr. Victor Rabinowitch

Board on Science and Technology

for International Development

National Academy of Science

Dr. Peter Rogers

Meta systems, Inc.

Dr. Elinor Terhune

National science Foundation

Dr. David Thurston

Plant Pathology

Cornell University

Mr. Walter Vergera

Agricultural Eng Ineering

Cornell University

Dr. Madison Wright

Agronomy

Cornell University

Dr. Regina Ziegler

Fletcher School of Law and

Diplomacy

Tuftos Iniversity 
B. Rural Issues

The Workshop on "Rural/Domestic Energy Issues" was held at Meta Systems Inc. in Cambridge, Massachusetts on January 5-6, 1978. Recommendations for assistance programs were made in the areas of technology, planning, and training. Technologies to be developed include photovoltaics, small scale hydropower, solar thermal applications, biomass, and biogas. The cooking and transportation sectors of the rural economy were thought to merit individual attention because of their significance in rural development and their contribution to rural energy use.

Planning activity should cover examination of rural energy problems, identification of nonconventional resource supplies, demand and supply analysis integrating rural analysis with urban industrial analysis into the overall national energy picture, and rural economic/resource studies to define the dynamics of energy supply and demand in rural areas.

Recommended programs in training include training of village development workers and village women, training of artisans and small businesspersons in appropriate technologies, special courses for teachers and other opinion leaders, and formal education programs for trained technical personnel (including economists). 
Rural/Domestic Energy Issues Workshop

\section{List of Participants}

Mr. James Austin

Planning officer

Ministry of Finance

Botswana

Dr. Edward Beardsworth

Brookhaven National Laboratory

Mr. Binayak Bhadra

University of Oregon

Center for Economic Development

and Administration; Tribhuvun

University, Katmandu, Nepal

Dr. Douglas Braithwaite

Meta Systems Inc.

Dr. John Briscoe

Dacca 2, Bangladesh

Dr. Norman Brown

Office of International R\&D Programs

ERDA

Mr. Benjamin Carr

Harvard University

Division of Applied Sciences

(Planning Commission, Gambia)

Ms. M. Virginia Davis, consultant to Brookhaven National Laboratory

Dr. Russell J. delucia

Meta Systems Inc.
Mr. Namet Ilahi

Harvard University

Kennedy School of Government

(Planning Commission, Pakistan)

Mr. William Knowland

Overseas Development Council

Mr. Michael Lesser

Meta Systems Inc.

Mr. V. Mubayi

Brookhaven National Laboratory

Mr. Alan Poole

Institute for Energy Analysis

Dr. Peter P. Rogers

Harvard University

India Project; and

Meta Systems Inc.

Dr. Douglas V. Smith

Meta Systems Inc.

Dr. D. K. Subramanian

ASTRA, India Institute of

Science

Bangalore, India

Dr. Richard Tabors

Massachusetts Institute of

Technology

Energy Laboratory

Chairman 


\section{Resource Management}

The Workshop on "Energy Related Resource Management in LDCs" was held at the Belmont Conference Center in Elkridge, Maryland on January 8-10, 1978. The group focused its discussion on three subject areas: the development of conventional resources, the development of large scale renewable resources and their urban applications (rural and domestic applications of small scale technologies having been covered at the Rural/Domestic Workshop), and government management of energy related activities.

The development of conventional resources should begin with the identification of resources including oil, all types of natural gas:and geopressured gas, nuclear fuel, coal and other solid hydrocarbons (oil shale, tar sands) and. geothermal resources. Exploration should follow to determine the existence of deposits sufficiently large to:justify commercial production. Assistance should be given in bringing small deposits to commercial use and in other facets of production and use of the resources. Finally, adequate procedures for the regulation and management of resources must be established.

Renewable resources are both overexploited and underutilized in LDCs. Urban waste management, wind, electrical generation and larger scale industrial energy supply from biomass, cogeneration, storage, hydroelectricity were each examined and recommendations were made covering research and development, information transfer, and implementation of these resources and related technologies.

Recommended government management of energy related activities include the formulation of a national energy plan, coordination among institutions, and provision of public financing and promotion of private sector involvement. 
Energy Related Resource Management in LDCs Workshop

List of Participants

Dr. Shem Arungu Olende

Centre for Natural Resources,

Energy and Transportation

United Nations

Mr. James Austin

Planning Officer

Ministry of Finance

Botswana

Dr. Jọseph Barnea

Senior Fellow, Project on the Future

United Nations Institute for Training and Research

Dr. Jerome Bosken

Project Manager for Energy

Agency for International Development

Mx. B. K. W. W. Copeland

Board on Science and Technology for

International Development

Commission on International Relations

National Academy of Sciences

Ms. M. Virginia Davis, ** consultant to

Brookhaven National Laboratory

Dr. Russel1 J. delucia

Presjient

Meta Systems T.no.

Dr. D.L. a'ombrain

Director of Research

Brace Research Institute

McGill University

Dr. Jose Goldemberg

University of Sao Paulo

Brazil

M3. Karla King

LDC Energy Program

Office of International Affairs

Department of Energy
Mr. William E. Knowland

Overseas Development Council

Dr. Philip F. Palmedo*

Head, Policy Analysis Division

National Center for the

Analysis of Energy Systems

Brookhaven National Laboratory

Mr. William Parham

Consultant

Gordian Associates

Dr. Harry Perry

Consultant

Resources for the Future, Inc.

Mr. Alan Poole

Institute for Energy Analysis

Dr. J. Thomas Ratchford

Associate Executive officer

American Association for the

Advancement of Science

Dr. John A. Reinemund

Chief, office of International Geology

U.S. Geological Survey

Profeagnr. Vaclav Smil

Department of Geography

University of Manitoba

Dr. D. K. Subramanian

ASTRA, India Institute of

Science

Bangalore, India

Mr. J. D. Whitelaw

Senior Advisor

office of public Affairs

EXXON

Chairman

**

organizer 
II. ISSUE PAPERS

A. LDC Energy Supply/Demand Balances and Financing Requirements, Gordian Associates, Inc.

B. Rural and Domestic Energy use in Developing Countries, The Overseas Development Council.

C. Review of Literature, Conferences and Programs Concerning Energy Assistance to Less Developed Countries, Donovan, Hamester and Rattien, Inc.

D. Urbanism and Energy in Developing Regions, Richard L. Meier, Center for Planning and Development Research, University of California, Berkeley.

E. Energy Production and Distribution in Developing Countries, Robert R. Nathan Associates Inc.

F. Perspectives of Transportation and Liquid Fuels in the Less Developed countries, Thomas Vietorisz. 